\title{
Cartas del general Francisco Retz a la Provincia del Paraguay
}

Carlos A. Page

\section{Recibido: 12 de noviembre de 2013}

Evaluado: 21 de diciembre de 2013

\section{Francisco Retz $1^{\circ}$ Prepósito General 1730-1750}

Siguiendo con la publicación de las cartas de los generales González y Tamburini (Page, 2013: 248-320) vamos a continuación a transcribir las 48 que conocemos del $\mathrm{P}$. Francisco Retz que escribe para la Provincia del Paraguay entre 1731 y 1739. Es decir una serie incompleta pues todavía le quedaba una década de mandato.

Quien fue decimoquinto general, nació en Praga en 1673 donde se doctoró en Teología (1709) cuando ya era doctor en filosofía en Olomouc (1703). Comenzó a ocupar cargos importantes en Roma en 1711, cuando se lo designó secretario para los asuntos de la asistencia de Alemania. Fue luego dos veces provincial de Bohemia, rector del colegio de San Clemente de Praga y Asistente de Alemania durante el mandato del general Tamburini. Lo sucedió a su muerte, luego de ser elegido en la Congregación General de 1730. Era tiempo de Voltaire que arremetía contra la Iglesia, incluso los jesuitas debieron abandonar varias casas en Polonia, aunque en la Provincia del Paraguay, si bien los jesuitas ganaron la simpatía de Felipe $\mathrm{V}$ por la intervención de los guaraníes en restablecer el orden en Asunción, luego el P. Retz debió ceder a la evacuación de los siete pueblos guaraníes (1750), en tiempos en que operaban en Iberoamérica 2.171 misioneros (Mellinato, 2001: 1653-1654).

Las cartas están dirigidas a los provinciales Jerónimo Herrán Jaime de Aguilar y Antonio Machoni y la primera al superior de las misiones. Abarcan un sinnúmero de temas. Desde la enhorabuena de haber descubierto un paso por el Pilcomayo para llegar a los zamucos, hasta la condena estricta hacia el P. Antonio Ligotti por las consecuencias que derivaron en poner en la cñarcel a varios indios, lo que provocó su perpetua reclusión.

El P. Retz determinó el nombramiento de jueces para los ya crecidos pleitos de tierras que se venían dando en las reducciones, además de tres cartas con los nombramientos de todos los cargos para la provincia. 
Así como es severo en algunas cuestiones no deja de ser considerado con el trabajo que venía haciendo por ejemplo, el P. Martín López en la estancia de Calamuchita que estaría destinada a los gastos de los Ejercicios Espirituales de toda la provincia. Pues comenzaba a afianzarse la práctica entre los laicos y así sabemos por una de sus cartas que para 1734 hubo 526 ejercitantes.

Lo del P. López debía ser una excepción pues recrimina la mala administración del resto de las estancias por pleitos, compras de tierras innecesarias sin licencia del provincial y para peor vuelve a insistir un tema recurrente como el de las tan prohibidas "negociaciones". Por aquellos años también se terminaba de construir el Hospicio de Misiones en el Puerto de Santa María que fue costeado por las provincias ultramarinas como la del Paraguay.

Entre otros detalles veremos cómo de las 17 cartas que escribe, o al menos se enumeran para el 13 de diciembre de 1732, falta la quinta. Pero hay otra carta sin numerar de la misma fecha que se encuentra en un libro manuscrito donde se compilan cartas de generales y provinciales dirigidas a la provincia o a las doctrinas en general. Posiblemente haya pertenecido a un colegio o con mayor seguridad a alguna reducción. Interesante pieza documental que se encuentra en la Biblioteca Nacional de España, donde se transcribieron como "Tomo Primero", cartas desde el P. Aquaviva hasta el P. Retz y casi todos los provinciales de igual periodo ${ }^{1}$.

Evidentemente estas valiosas cartas difieren bastante de las conocidas Cartas Anuas en cuanto a que nos brindan una información mucho más realista de la situación de la Provincia Jesuítica del Paraguay, pues no se muestran como en aquellas los importantes logros, sino que también se vislumbran por igual aciertos y errores.

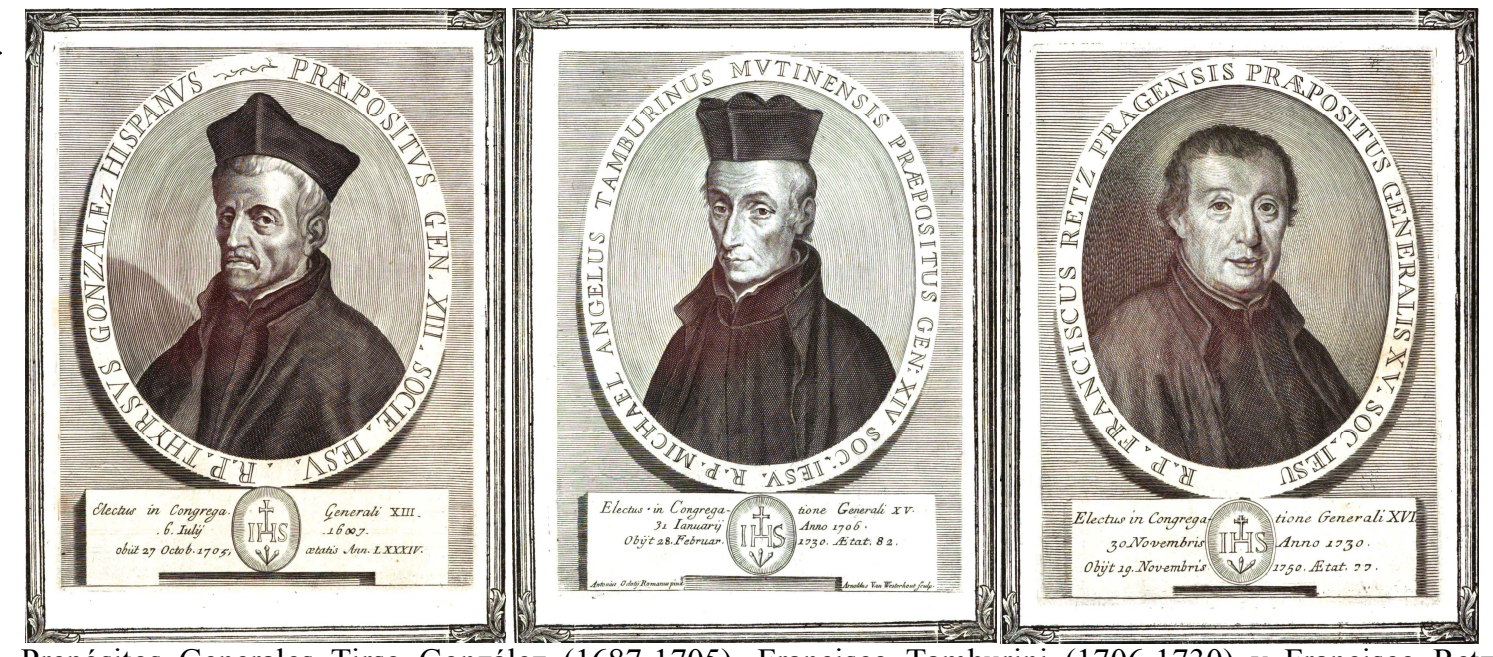

Prepósitos Generales Tirso González (1687-1705), Francisco Tamburini (1706-1730) y Francisco Retz (1730-1750) (Westerhout, 1756)

\footnotetext{
${ }^{1}$ Biblioteca Nacional de España. Ms. 6976.

http://bibliotecadigitalhispanica.bne.es/view/action/singleViewer.do?dvs=1387289566363 52\&locale=es_ES \&VIEWER_URL=/view/action/singleViewer.do?\&DELIVERY_RULE_ID=10\&frameId=1\&usePid $1=$ true\& usePid2=true
} 


\section{Francisco Retz \\ cartas de 1731 a 1739}

$2^{\circ}$ via $14-I V-1731$.

de Francisco Retz al P. Sup ${ }^{o}$ de las Missiones

P.C.

Consta por las relaciones de essa Mission Apostolica la facilidad grande, que huviera descubierto el Rio Pilcomayo de introducir la fé â muchas Naciones Gentiles: y pra. aquel descubrimiento se â solicitado fundar una Reduczion en los Zamucos. Deseo con anxia se perfecione esta empresa, y â V.R. le ruego por la maior Gloria de Dios, que la acalore, y encienda los pechos de los P.P. Missionos. para ganar tantas Almas â Christo, de cuia buena disposicion para ello me han dado noticias favorables en los Sant. Sacrificios y Orac. de V.R. me encomdo. Roma, Abril 14 de 1731.

De V.R.

Siervo en Chrô

Francisco Retz

$2^{a}$ carta - $1^{o}$ via $14-I V-1731$.

de Francisco Retz al P. Gerónimo Herrán

P.C.

Años há, llegó a este Oficio la escandalosa Causa del Pe. Antonio Ligoti: mas é aquí al mismo tiempo las escusas de Persona, ó Personas dignas de entero credito á cuia causa, y porque despus, ni por Superiores, ni por Particulares se me ha hablado sobre esta materia, ni aun la palabra mas leve, estaba enteramte. persuadido, que esta Causa ia se avia visto, decidido, y sentenciado allá: ni como podía yo ni aun levemente sospechar en una Prov ${ }^{\mathrm{a}}$ tan religiosa, observante, y zelosa del servicio de e; Sr. como essa del Paraguay, omission, descuido, y silencio tan pernicioso, y de tan malas consequencias? A la verdad hiziera escrupulo en sospechar tanta falta, si no la viera por la experiencia. Supuesto pues, que esta se esta semejante Causa indecisa, paso á pronunciar mi sentencia.

Aviendo visto la Causa del Pe. Ant ${ }^{\circ}$ Ligoti de las Prov ${ }^{\mathrm{a}}$ del Paraguay, que se principio por el Pe. Joan Bapt ${ }^{\mathrm{a}}$ Zea, y se terminó por el Pe. Joseph Aguirre, Provinles. de dicha Prov de que se me imbió por este Copia Authentica en $1^{\circ}$ de Noviembre de 721, y hecho sobre ella repetidas vezes particular reflexion delante de N.V. Fallo, que los Capitulos, que en ella contra dho. Pe. Se expressan estan suficientemente, y en bastante forma probados; y por tales los declaro, y que en ninguna cosa satisface el Pe. Antonio Ligoti, ni en una, ni en otra de sus dos Juradas Declaraciones; assi tambien lo declaro: y en consequencia, que de dichos Capitulos es reo, y porque los crueles, y inhumanos castigos,

261 Carlos A. Page. Las cartas de los generales... a la provincia del Paraguay... 259-322. 
que dio á las pobres Indias en las Carceles, ó Calabozos, que hizo, para este fin, como tambien fuera de ellos, fueron sin duda causa suficientissima de los abortos, y muertes, que se siguieron despues, le declaro por Yrregular.

Por tanto, le condeno á perpetua reclusion; á perpetua privacion de celebrar el Sto. Sacrificio de la Missa; á perpetua privacion de poder administrar el Sto. Sacranto. de la Peniten $^{\mathrm{a}}$ á toda suerte, y condicion de Persona, de qualquier estado, sexo, calidad, y condicion, que sean; á perpetua privacion de voz activa, y passiva, y finalmte. á todas las demás Penas, que contra tales delitos estan por Derecho puestos. Y quiero, y ordeno, y en caso necessario mando, que luego sin suplica, ni apelacion, esta mi Sentencia, y todas, y cada una de las cosas, que n ella se expressan, se guarde, cumpla, y execute enteramente, á la letra, y sin ninguna diminucion.

Y porque temo, que el Pe. Sin embargo de la Yrregularidad há celebradol y de ay, que ha incurrido en las Censuras y Penas, que contra los tales, sabe V.R ${ }^{\mathrm{a}}$. estan por Derecho y estas; por tanto, para sacarlede tan infeliz estado, dispenselo luego V.R ${ }^{\mathrm{a}}$. en la Irregularidad, y absuelvale de las Escomuniones, Censuras, y demas penas, en que huviere incurrido, por aver celebrado, ó exercido Acto de Orden Sacro, estando impedido con el impedimt ${ }^{\circ}$ de Yrregularidad: para lo qual le doi á V.R. toda mi potestad, y veces plenariamte. con facultad de subdelegarlas en la Persona, ó Personas, que sean de maior satisfaccion Y paraque esta mi determinacion sirva á otros de escarmiento quiero, que se imbie Copia expressa de ella á los P.P. que estan en los Pueblos de la Mission; y que se publique, y haga saber por la Prov a para maior bien de todos. Más, encargo mui seriamente, se execute esto con todo secreto, y sin que llegue á los Externos ni la especie, ó noticia mas ligera: sobre lo qual dará V.R . las ordenes mas extrechas; poniendo, si assi lo juzga, Precepto, paraque ninguno de los Nuestros, ni de palabra, ni por Escrito trate, ó hable cosa alguna sobre esta determinacion con ningun Externo, sea en si, el que se fuere.

En mi Despacho de dies y siete de Henero, de mil setecientos, y veinte y dos, di algunas providencias, $\mathrm{p}^{\mathrm{a}}$ que no huviesse excessos en los castigos de los Indios. Vealas V.R ${ }^{\mathrm{a}}$ y Yo las confirmo, y ratifico en este Despacho presente. En los santos Sacrificios de V.R ${ }^{a}$. me encomiendo. Roma, y

De V.R

\section{Siervo en Chrõ}

Esta determinacion fue dada por mi Antecessor de B.M. en esta gravisma. causa del Pe. Ant ${ }^{\circ}$ Ligoti: no la firmó su Patend. por averle sobrevenido la muerte. Y sin embargo de ser todas las penas establecidas, condignamte. debidas á los meritos del Processo; más porque no tengo presentes las diversas circunstancias, que pueden aver ocurrido aî en tan dilatado tiempo; y por razones justas, que me mueven, quiero usar de alguna benignidad, y moderar la Sent ${ }^{\mathrm{a}}$ dada por mi Antecesor: condenando, como condeno á dhó Pe. Ligoti á solas las penas siguientes: á perpetua privacion de Voz Activa, y Pasiva; á perpetua privacion de poder administrar el Sacramto. de la Confesion, assi á Hombre, como á Mugeres de qualquier edad, estado, calidad, y condicion, que sean; á que por espacio de un año entero por ningun titulo, ó pretexto, ni por mucho, ni por poco tiempo salga de nrã. Casa, sino que guarde en ella, por todo esse tiempo, un recogimiento inviolable; y en este dicho año todos los Viernes saldrá al Refitorio con disciplina, y hará los Exercicios por espacio de un mes, además de los que ha de hazer con la Comunidad. Estas penas se

262 Carlos A. Page. Las cartas de los generales... a la provincia del Paraguay... 259-322. 
executarán sin replica, ni apelacion; como tambien las demás prevenciones hechas por mi Antecessor: las quales yo confirmo enteramente.

\section{Prevencion particular}

Más, porque esta benignidad me ocasiona algunos remordimtos. Por tanto, para entero descargo de mi conciencia, ordeno extrectamte. á V.R ${ }^{a}$. que con sus C.Ces. ordin ${ }^{a}$. Y as graviera, vean delante de Vs. ete punto; y como quien de ello ha de dar extrecha quenta á su Magd. y si juzgan á dhõ. Pe. Ligoti por esta Causa merecedor de maiores penas, que las, que yo dexo señaladas, se las impondrán, y se executará sin falta lo que el maior numero de Votos fallare: y quiero se atienda no solamente al bien espit. del Pe. sino al bien publico, y satisfaccion de todos: y de todo se dará puntual noticia á las Missiones, como á toda la Prova . y á mi de aver executado enteramte. esta mi resuelta, y determinada voluntad. En los Stos. Sacrifs. de V.R ${ }^{\mathrm{a}}$. me encomdo. Roma, y Abril 14, de 1731.

De V.R.

Siervo en Chrô

Francisco Retz

\section{5-VIII-1731.}

de Francisco Retz al P. Provincial

P.C.

Rvd $^{\circ}$. In Chrô. Pr.

Communico $\mathrm{Rev}^{\mathrm{o}}$. Vrg. et per toti isti Provinciæ Decreta Congregationis Generales XVI. Et quamvis ad observanda ea, que tantâ maturitate, zelo, et animoru consensione fuerunt statuta, omnes incitatura sit interni amoris lex, et studiu communis Boni; nibilominus ad Rev $^{\mathrm{a}}$ Vrg. et alios Superiores preciqué pertinebit, corum executionem, atque exactam observantiam pro viribus procurare, et ubi necesse erit, etia urgere. Rua in re, si meâ etig operâ, et authoritate opus fuerit, easemper in prompta, ae presto erit: neque aliquid, quod mearum partiu erit, desiderari unqua patiar. Sed duo præ sunt, quæ ex Congregationis Voluntate. Reva . Vre, omnibusque Superioribus summoperé commendare debeo: id que eó etig libentius facio, quod ea per se quoque maximé mibi cordi sint. Jn primis postulatum fuerat a Congreg ${ }^{\circ}$. remedium efficax adversus nonnullorum nimia sané libertate, ac licentiam, qua seú privatis semonibus, seu scriptis ad alia Cillegia, imóetiam ad Externos epistolis, defectus nostroru propalare non verentur, haud modicâ Religiose Charitatis, et pacis iacturâ, ac detrimento famæ etiam Societatis. Exarsit pro rei gravitate Patrum zelus; et quamvis hac in re novo, ac peculiari Decreto opus non videretur, utpote quo ipsa mali magnitudo, ac fraterne Charitatis lex per se satis comendat; moneri tamen a me voluit gravissime Superiores omnes, tu gliscenti huic malo, omni studio, ae solicitudine occurrant: et si quos in hoc deliquisse compererint, meritis pænis afficiant; Literas etiam ultró, citróque missas (prout Rega 35 Rectis. prescribitur) diligenter legant, et si qua furtivas deprebenderint, non patiantur impuné abire eum, qui illas scripserit: noverintque omnes, si 
quid incommodi, ae damni ex nostrorum Literis, incauté scriptis acciderit, me non solum ab earum Authoribus, sed etia a Superioribus, qui esa legere neglexerint, velectar non suppressenint, rationem, ac ubi videbitur, poenas etia exactum.

Alterum, quod Patrum anima vehementissimé commovit, et in quo meam, et alioru Superioris cura, et solicitudine Congregatio precipué imploravit, est frigescens alicubi Orationis, et rerum Spirituales studium. Hoc malum, si culpâ nostrâ (quod Deus avertat) invalesceret, certam Societati nostre perniciem afferret. Vnde oro, obestorque Superiores omnes, tu pro ea, quo in Societate, eiusque conservatione feruntar amore, non desint in re omnium gravissimâ muneri, ac conscientis sue; sed qerruptis quibusvis obstaculis, diligentis et authoritate sua omne adbibeant, tu in eis, quoru cura ipsis commissa est, et de quibus Deo ratione reddore debent, Exercitationum Spiritualis fervens studium foveatur, ac promoveatur, et si foris intepuerit, accendatur. Et quoniam quidquid in hane rem confere poiest, abundé continetur in Literis, quas R.P. Michael Angelus Tamburinus P.M. ad Provincias misit, et que annis singulis publicé in mensa prelegi debent, ea omnia exactissimé servari, et executioni mandari curent, e quibus duo plurimum profutura, peculiari ratione ex Congregationis mente Superioribus commendo: in primis tu laudatissimam illa consuetudine visitandi mané anté solitum Meditationis signum, atque adorandi S.S. Sacramenti omni ope conservare, ac fovere studeant. Deinde, tu tempore Orationis, et utriusque Examinis nostros diligenter visitari curent, relipsi quoque quandoque visitent: hecque prestent eâ assiduitate, et constantiá tu Subditi omnes intelligant, Superiorem nom destituru, donec optatu finem obtineat. De me sané persuasum, atque certy omnibus esse volo, non solum promptum, ae paratum me fore, ad remedia omnia, que opportuna indicavero adhibenda; sed fixum mihi omnino esse, etiam interposito, si opus fuerit, obedientic Precepto, Superiore ad tam pracipuam officij partem implendam advtringere. Verum spero eam omnium fore virtute, et obsequendi studiu, tu ad tam dura, mihique nôn minus, qua ipsis molesta remedia pervenire, opus nunquam habeam. Va veró hec ad omnium notitia veniant, Rev ${ }^{\mathrm{a}}$ Vrâ huius Epistole exenpla ad singulos Superiores mittat, et publicé ad mensam prelegi iubeat. Demum rem hanc, nunqua satis commendata, Rev $^{a}$ Vra curæ, ac vigilantia, me veró S.S eius Sacrificijs interum iterúque enixissimé commendo. Roma, 25 Augusti, 1731.

$\mathrm{Rev}^{\mathrm{a}}$

Servus in Chrô

Franciscus Retz

$1^{\circ}$ via 26-VII-1732.

de Francisco Retz al P. Provincial

P.C.

$\mathrm{Rd}^{\mathrm{o}}$. In Chrô Pr.

264 Carlos A. Page. Las cartas de los generales... a la provincia del Paraguay... 259-322. 
Inter alia, que ab Vltima Congreg ${ }^{\circ}$ Genli. Sapienter sancita fuerunt, illud insignem Societati nostre utilitatem allaturum videtur, quod Decreto 38 mihi perficiendum commendavit, tu scilicet precigna Congregationum Generalium Decreta seligerentur, que annis singulis vna cum Monitis generalibus publicé prelegi debeant. Ego voluntati Congregationis, vt paerat, obsecutus, adhibito otiam P.P. A.A. concilio, illa preciqué Decreta seligi curasi, que et maioris momenti visasunt, et quorum notitiam, ac memoriam nostris renovari ad religiosam diseiplinam conservandam, ac promovendam magis necessarium in Dnô indicari. Ea nunc typis impressa $R^{a}$.V.E. transmitto, toti Prov ${ }^{a}$ communicanda, et statis temporibus publicé legenda.

Sicuti vero defectus, qui contra tam salutaria Decreta alicubi forté irrepserano, magnam partem tribui facilé possunt, non satis exacte eorum notitie: ita de religiosa Nostrorum virtute omnino confido, fore vt omni studio observare conentur ea, qua a Societate Vniversa pro communi suo bono statuta fuisse, deinceps ignorare non poterunt.

Superiorum in primis munus exigit, vt non solum exemplo suo, vigilantia, monitionibus, et erbi opus erit, poenis exacté omnia observari procurent, sed etiam paterna charitate, et discretione Subditis observationom facilem, ac suavem roddere conentur, in ijs preciqué, que ad Paupertatis puritatem conservandam directa sunt.

Hunc cerré in finem Superioribus omnibus gravissimé commendatum cupio, tu quam vigiles, intentique esse debent ad vitam communem inter nostros conservandam, tam soliciti sintin providendis, et liberales in suppeditandis ijs omnibus, que ad illam pertinent: tu in auscultandis Suorum necessitatibus sese benignos, et in dandis facultatibus, que salva discipline, ac S. Paupertatis integritate concedi possunt, faciles potius, quam duros exhibeant. In tarctandis deinde Nostrorum Depositis, ac Pensionibus (si que Collegio suo adcripte sint) atque eleemosynis, que non numquam occasione Ministeriorum Nostri offeruntar, itase gerant, vt nullam Subditis occasionem relinguano suspicandi, ac conquerendi Paupertatis zelum a Superiore obtendi, re ipsa autem eupiditati indulgent, maioremque vtilitatis Collegij, qua paterne charitatis ratione haberi.

Verum hec non ita accipi vellem, vt propterea isti licitum sibi existiment, Subditis indulgere, ac permittere edque Legionus nostris, ac religiose discipline adversa, aut parum conformia sunt. Huiusmodi enim nimia indulgentia, ac facilitas e queé vel magis improbanda foret, vt poté que non verá charitas, sed defectus potius est ordinate charitatis, que verum Societatis, ac Subditorum bonum, quod in Legum notrarum custodia preciqué consistit, spectare in primis debet. Multo etiam minus vellene, vt ex his, que Superioribus commendata sunt, alij occasionem arripiant, velea postulandi, que sine religiose discipline detrimento concedi vixo possunt, velde Superioribus conquerendi, si eso minus, quam vellent, sibi indulgente experiantur.

Id potius vnicé desidero, ac Deum precor, vn omnes proprio in primio perfectionis studio, deinde Superiorum paterna, ac prudenti charitate ad Legum nostrarum custodiam efficaciter simul, ac suaviter incitentutur. $\mathrm{R}^{\mathrm{a}}$. $\mathrm{V}^{\mathrm{a}}$. curet, vt hec in omnium notitiam veniant, meque in S.S. suis Sacrifs. Deo Commendet. Rome, 26 July 1732.

$\mathrm{R}^{\mathrm{a}} \mathrm{V}^{\mathrm{a}}$. 
Franciscus Retz

$1^{\circ}$ via 26-VII-1732.

de Francisco Retz al P. Provincial

P.C.

Cum in postrema Sessione Ppbus ad Comitia Generalia Congregatis inter cetera exponerem, me iam inde á quo Curam Vniverse Societatis demendatam accepi, mihi, et illi pro avertendis preciqué deterrmis, nec vllá sepé industriâ satis dispellendis calumnijs, et obtrectationibus, quibus adversarij famam, atque existimationem nostram, que ad Dei Gloriam promovendam adeó necessaria nobis est, impetere vndique conantar, Patronum, et Advocatum delegisse mirabilem plané boni nominis Protectorem D. Martyrem Joannem Nepomucenum, at que ad obtinendum certius Sti. Ejusdem patrocinium Ipsorum quoque piam opem implorarem: in tantum plerisque omnibus consilium isthoc meum placere, probarique visum fuit; vt illud non landarent modó, sed liberaliter etiam non minus quam pié addicerent, quad postulabam. Observata una nimi adeó omnium confensione, approbatione que facilé in eamfiduciam veni, quód tam pium religiosissimorum PP. exemplus cetori quoque socij prompté secuturi essent, atque ad promerendum ordini nrô ejusdem Sti. patrocinium tantó libertius opera collaturi, quanto magis singulis cordi est, et fame sue, et communis Ordinis nrî illibatus decor; si precigné aliud aliquod pietatis huius illicium, atque fomentum accederet. Curavi proinde á $\mathrm{Ssm}^{\circ}$. Dnõ Nrõ obtinere, vt Sacerdotibus nris officium, ae Missam die 16 Maij (qua scilicer die gloriosum Martyrium subijt) de odem dicore, ac celebrare licoat; et tam elli, quam certeri, qui aodem die $\mathrm{St}^{\mathrm{a}}$ Communione refecti, consuetas preces effuderint, et Deum etiam pro impetranda Ordini Nro Ejusdem Sti. protectione, atque patrocinio oraverint, plenariam omnium peccatorum consequi valoant. Superest nune, vt, quod presentibus enixissimé postulo, sollicitudini mea pro communi bono, ac honore societatis nrê. suam singuli conjungant, et qua benignum ac facilom in preces meas expertus fui Pontificem Maximum, tam seduló concessis favoribus ad conciliandy nobis Sti. Martyris patrocinium vtantur. Suvat enim sperare, quod sicut

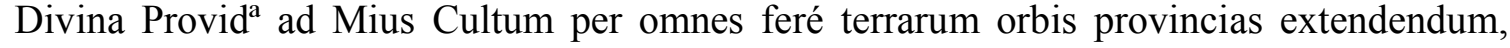
operam P.P. Nostrorum adhibere dignata fuit; ita quoque Intercessore eo uti decreverit, ad conferendas singularos in Societatem nrâm gratias: quas inter vtinam et illa vit, quam obtentu difficilis, tam necessaria nrîs omnibus in obsequio Proximorum semper occupatis: vt sciliceo preclaro Sti. Martyris exemplo illa silentio premere, et tacere condiscamus, que dicendanon sunt, et preciqué que pro Societatis bono, atque honore teceri convenit. Ceterum vt omnes magnâ erga hune Sanctu fiduciâ, ac pietati, ferri, magnopere desidere; nolo tamen per hoc quidquam derogari fiducie, ac venerationi, quam Sanctis Nostri, ac preprimis $\mathrm{Ssm}^{\circ}$ Fundatori, Parentique Nostro precipnam debemus: quin potius hac occasione ad accumulandalis difficillimis temporibus erga eundem religiosi Cultus officianihilo inferiori studio omnes exhortos Curet $\mathrm{R}^{\mathrm{a}} \mathrm{V}^{\mathrm{a}} \mathrm{vt}$ hec epistola nrã ad omnium notitiam perveniat, et mei in Ssmis. suio Sacrifs. diligenter meminerit. Rome, 26 Julij 1732.

$\mathrm{R}^{\mathrm{a}} \mathrm{V}^{\mathrm{a}}$

266 Carlos A. Page. Las cartas de los generales... a la provincia del Paraguay... 259-322. 
$1^{\circ}$ via $26-V I I-1732$.

de Francisco Retz al P. Provincial

P.C.

Aviendo visto, que en la Constitucion Romanus Pontifex, con la qual su Sand. Ha moderado, y reducido al Derecho Comun algunas Bulas de la S.F. de su Predecesor, está tambien comprehendida la Bula Pretiosus á favor del Orden de PPs. Predicadores; he juzgado ser de mi obligacion encomendar á V.R ${ }^{\mathrm{a}}$. zele con todos los medios, que su prud ${ }^{\mathrm{a}}$. Sabrá sugerirle, al fin que los Nros. en una tal coiuntura hablen con toda aquella moderacion necess ${ }^{\mathrm{a}} \mathrm{p}^{\mathrm{a}}$, que los P.Ps. Dominicana no tengan ni aun leve motivo de quexarse de Nosotros: pues qualquiera defecto en esta parte, ademas de ser contraria á aquella caridad, que á todos debemos, podria ocasionar no ligeros perjuicios á la Compañía. Y no siendo esta á otro fin, me encomd ${ }^{\circ}$ en los Stos. Sacrifs. de V.R ${ }^{\mathrm{a}}$. Roma, Julio 26 de 1732.

De V.R.

Siervo en Chrô

Francisco Retz

$1^{\circ}$ via $8-X I-1732$.

de Francisco Retz al P. Provincial

P.C.

$\mathrm{Rd}^{\mathrm{o}}$ in Chrõ Pr.

Cum in postrema Congreg ${ }^{\circ}$ Genli. a pluribus Provincijs proposíte fuduset querele, ac postulaty efficax remedium adversus nonnulloreum e nrîs nimiam in rebus Philosophiscis opinandi libertate, eory precipié qui in ea Philosophia parte, vbi de Corporis Naturalis Principijs, et constitutione agitur, relicta Aristotelis. Doctrinâ, Atomistarum potius Sententias sectantur. Congregatia huia malo, quod soliditati, ac vniformitati Doctrine in Constitutionibus tantoperé nobis commendate non parum officere posset, occurrendum omnio censuit. Vnde De creto 31 non solum statuit Philosophie Aristotelis inherendum esse, vt porte quam, esu Theologie magis vtilem, et a $\mathrm{St}^{\circ}$ Pe. Nro p. $4^{\mathrm{a}}$. cap. 14 tam diserté preseriptam, Societas dudam anplexa estsed insuper mihi impensé commendaría, vt Propositiones, que ab hac Societatis Doctrina magis aberrant, in elenechum redigi curarem, et a nrîs Professoribus tradí, aut doseri prohiberem. 
Vt igitar tam inste Congregationis Voluntati morem geram, omnibus in Ano maturé perpensis, ex P.P. in ipsa Congrege. ad id deputatorum sententia, adhibito etiq. PP. AA, alioramque Virorum doctorum consilio sequentes Prepositiones Nrîs prohibendas censui.

$1^{\text {a }}$ Non alister corpus concipi, aut explicari potest, quan vt substantia actua extensa.

$2^{\mathrm{a}}$ Idea Materie prime Aristoteliec convenit etiam atomis Epicuri, aut Materia Cartesiane.

$3^{a}$ Materia prima non est entitas substantialis incompleta, et ordinata ad aliam compartem, tanquam potentía ad Actum, seu tanqua Subjertum ad Forma, cum qua totum substantiale componat.

$4^{\text {a }}$ Tripleo est elementum, scilicet subtilis quedam materia, deinde globosa, denique cuassior, et ramosa.

$5^{a}$ Ex omnia corpora sensibilia constant, que vel mixta sunt, vel elementa secundaria, et sensui obvia.

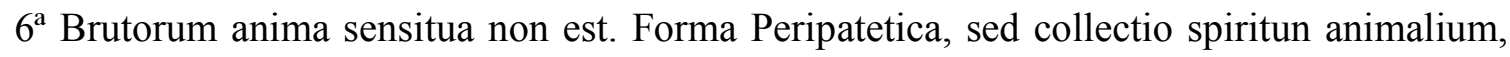
aut aliorum corpuscalorum.

$7^{\text {a }}$ Similiter anima vegetativa Plantarum non est Forma Peripatetica, sed colletio corpusculory calidery, aut frigidory, aut aliorum.

$8^{\mathrm{a}}$ In Composito naturali Materia, et Forma nec por entitates, nec per distinctum nexum vniuntur phisicé intrinsecé.

$9^{a}$ Actas Potentiary anime vationalis ita distingutar ab anima, tanquam modi a remodificata, vt tamen ipsi actus quando. Phisicé existunt, stricté, et phisicé identificentur cum anima, atque aded tunc non distinguntur phisicé ab anima.

$10^{\mathrm{a}}$ Cuod existit, et in vno instanti non est eum alio stricté phisicé identificatum, potest in alio instanti cum illa stricté, et phisicé identificari. Et vice versa: quod existit, et in eo infranti est cum alio stricté phisicé identificatum, potest in alio instanti existere, quin stricté, et phisicé cum illo alio identificetur.

Has itaque Propositiones omnes, et singular a nostris vllo modo deceri, aut propugnari severé prohibeo: simulque omnibus Provincialibus, Recorribus Studiorum Prefectis, et Librorum Revisoribus injungo, vt diligenter invigilent, en aliqua ex predictis Propositionibus sivé in Libris typo imprimendis, sive in manscriptus, aut voce etiam a nrîs tradatur, ac doceatur. Si quis vero huius nrê Prohibitiones violate reus deprehensus fuerit, gravibus penis afficiendus, et nominatim a docendi muxere amovendus erit.

Hac etiam occasione Superioribus omnibus gravissimé commendo, vt pro munere suo ab omnibus accuraté observari curent id, quod in Constitutionibus prescribitar, vt sulicet Nrî sequantur in gravis Facultate securiorem, et magis approbata Doctrina. p. $2^{\mathrm{a}}$ e 5. Heque permittant introduci Optiones novas, aut Sententias a Nrîs. Predecessoribus alias prohibitar, esa preciqué, quas R.P. Michael Angelus Tamburini p. m. in literis encyclicis 15 Junio 1706 datis, doceri, aut defendí vetuit. 
$\mathrm{R}^{\mathrm{a}} \mathrm{V}^{\mathrm{a}}$ presentes literas cum omnibus, ad quos pertinent, quamprimum communicet, atque earum exempla apud Prefectos Studiory asservari curet, meique in Ss. suis Sacrificijs diligenter meminerit. Roma, $8^{\text {a }}$ Novembris, 1732.

$\mathrm{R}^{\mathrm{a}} \mathrm{V}^{\mathrm{a}}$

Svus. in Chrô

Franciscus Retz

$15-X I-1732$.

de Francisco Retz al P. Provincial

P.C.

$\mathrm{Rd}^{\circ}$ in Chrô Pr.

Transmissis nuper Decretis Congregationum Generalium, que auctoritate postreme Congregationis soligi inssi, adiungo nunc ex PP. RR. consilio peculiarem elenchum coru, que maioris momenti visa sunt, et de quorum executione inxta ejusdem Congregationis decretum in posterum Provincie, Consultores singulis annis as Prepositum Generalem scribere debebunt. Sunt antg sega

1. An aliquis exemptus fuerit a tertio Probationis anno integré peragendo, aut ante finem biennij Novitiatus missus as stadia abique commissione, et facultare. Prepositi Generalis, contra Dec 34 Cong 16, et Dec 14 Cong 2.

2. Vtrum ab omnibus facta Exercitia spiritualia: item Votorum Venovatio, et triduana collectio ab ijo, qui Vota renovare debent inxta De 29. Cong 6.

3. Vtrum alicuit prorogata fuerit Bonorum possessio vtra quadriennium ab ingressu in Societatem abique disponsatione. Prepositi Generalis, aut permissa corum administratio, etiam quo tempore dominium retinet. Dec 15 Cong. 5.

4. An alicubi admissa obligatio ex institia ad Ministeria Spiritualia, aut stipendium, sive eleemosyna in esmpensationem errum, contra Dec 14 Cong 1. et

Dec 39, et 40 Cong 12 .

5. An vita communis illibata vbique servetur inxta Dec 43 Cong 12. et Dec. 27 Cong 16.

6. Ruani accuraté observetur Preceptum de non procurandis Externorum in tercessionibus. Dec 18 Cong 10.

7. An vigeat studium Missionum, et Doct $^{\circ}$ Christ. Dec 46 Cong 5 et Canlo Cong 2.

8. An observentur ea, que circa Confessiones, collocutiones, et visitationes feminarum ordinata sunt De 43 Cong 6: item de non habenda cura feminarum certis Legibus vná viventium. Dec 56. Cong 5.

269 Carlos A. Page. Las cartas de los generales... a la provincia del Paraguay... 259-322. 
9. Vtrum concessa aliquibus, presertim juvenibus, facultas vnsticandi apud externos, aut excurrendi extra Domos Nostras: contra Dec 25 Cong 16.

10. Vtrum quidpiam types vulgatum absque revisione, et facultate Prepositi Generalis Dec 18 Cong 11: item an introducantur Doctrine nove, laxe, aut in Societate prohibite; et speciatim ano in Philosophia teneatur Doctrina Aristotelis. Dec 28 Cong 12. et Dec 36 Cong 16.

11. De administratrione rerum temporalis, an gravius aliquid peccatum sit contra Instructionen ea de re editam, et probatam a Cong 14 Dec 12: preciqué in edificis non necessarijs, contraherdis debitis $\mathrm{A}^{\mathrm{a}}$.

12. Euomodo observentur ea, que de Litibus forensibus fugiendis, et negotijs secularibus externorum vitandis statuta innt Dec 55 Cong 2. et Dec 13Cong 5.

13. An quot annis legantur publicé Precepta nostris imposita, monita generalia, et Decreta Congregationy Generalium inxta Dec 23. Cong 8. Et Dec 38 Cong 16.

De predictorum igitur Decretorum executione omnes Prov $^{\mathbf{0}}$ Consultores, literis separatis, et nihil alind continentibus, sub finem cuiuslibet anni scholastica non generaliter, et obiter, sed aceurate, et singillatim Prepositum Generalem edoceant: quas deinde literas Socius Provinlis. prout in Reg 15 ipsi prescribitur, colligere, et Romam mittere debebit.

Provinciales veró post visitatam Provincia Consultatione instituant, inqua de istorum preciqué Decretorum observatione agendum: tum vt hac ratione consultores melirrene de aory excutione notitia acquirant: tum vt de corrigendis efficaeiter contrarijs defectibus deliberetur.

$\mathrm{R}^{\mathrm{a}} . \mathrm{V}^{\mathrm{a}}$ presentes literas inter reliquas Generalium Ordinationes assevari, et cuem singulis pro tempore Provincie Consultoribus eary exemply communicari curet. Ae Ss. $\mathrm{R}^{\mathrm{a}} \mathrm{V}^{\mathrm{a}}$ Sacrifs. me perimpensé commendo. Roma, 15 Novembris 1732.

$\mathrm{R}^{\mathrm{a}} \mathrm{V}^{\mathrm{a}}$

Servus in Chrõ.

Franciscus Retz

$1^{a}$ carta $-2^{\circ}$ via $13-X I I-1732$.

de Francisco Retz al P. Gerónimo Herrán

P.C.

Recibo diez y ocho cartas de V.R ${ }^{\mathrm{a}}$. de $1^{\mathrm{o}}$ y 30 de Dicieme. de 1730 , y de 6 de Julio de 1731, con las Informaciones as Gradum, y demas Papeles, que refiere. Comienzo mi respuesta por los Grados. Vistas, y consultadas con los P.P.A.A. las Informaciones ad gradum, coon su parecer he determinado hagan la Profession de Quatro Votos los P.P. Antonio Almoguera; Juan Delgado, avisado antes por V.R ${ }^{\mathrm{a}}$. de las faltas, q. constan de sus Informaes. Francisco Baptista; Luis Chartes; Joseph Angulo; Joseph Martin; Estevan 
Palozi; Thomás Yzedo, avisado antes seriamte. Por V.R ${ }^{\mathrm{a}}$. de las faltas, que constan de sus Ynformes. Manl. Palacio; Francisco Valdiviesso; Juan Zervantes; Baltasar Villafañe; Thomas Figueroa; Jacobo Zenenti; Pedro Lizrain; y Pedro Zegu avisado antes por V.R ${ }^{\mathrm{a}}$. de las faltas, que constan de sus Infrormes. No ai en este officio censuras in literis de los P.P. Joseph Paez, Roque Rivas, Luis Santos, Lorenzo Ovando, Andres Parodi, Juan de Molina, y Pedro de Castro. Si las ai en este oficio, y tienen en su favor tres votos minimé dubios, harán la Profession de Quatro Votos, y se imbiarán acá las Censuras si no los tienen, se formarán coadjutores espirituales $=\mathrm{Al}$ Pe. Joseph Cardiel le faltan siete años para cumplir la edad, y tiempo de Religion establecido para el Grado. Y porque en tanto tiempo puede aver mutacion; por tanto á su tiempo vuelvaseme á proponer con nuevas informes. Al Pe. Francisco Collado doi lizencia para segundo examen; y si tuviere en su favor, por lo menos, tres votos mínimo dubios, hará la Profession de Quatro Votos; si no, se formará Coadjutor Espiritual. Formaránse Coadjutores Espirituales los P.P. Thomás Araoz, y Joseph Guinet; y Coadjes. temples. Los H.Hs. Domingo Ugarte, y Juan Baptista Veracierto= todos estos Grados recevirá V.R ${ }^{\mathrm{a}}$. ó señalará quien los reciva en mi nombre. Esto se entiende con tal que los Interesados, aian cumplido la edad, y tiempo de Religion establecido y que de nuevo no aiase incurrido en faltas, á cuia can[roto]deba dilatarseles el Grado á maior numero de Votos de V.R ${ }^{\mathrm{a}}$. y sus consultes. ordin ${ }^{\circ} \mathrm{s}$. y ad graviora.

Cosa mui fuera es assi aver dilatado la Profesion al Pe. Joseph Vgedo, que se imbió en 22 de Junio de 1726, como averle ya despedido de la Compa según me informan los unos, y lo otro debio executarse assi: y yo agradezco, y confirmo la execucion. Más si acaso no es cierto el informe que me dan, de que ya está despedido, déle V.R ${ }^{\mathrm{a}}$. la Dimisoria luego, y sin clausura alguna, que pueda retardar su mas prompta execucion: y embíese á este Oficio en la forma, que se acostumbra, el tratado ad Dimissione, para que siempre de ella conste $=$ Al Pe. Baptista Spet corresponde graduarse, cumplidos diez añosde Religion desde el dia de su seguridad recien: en esta inteligencia se me propondrá á el tiempo, que le corresponde, y que sea bastante, para que quando le toca haga el Grado: y doi mi lizencia para que se examine de Lengua Yndica: y con las Informaciones se imbiarán acá las Censuras, para señalarle en vista de todo el Grado, que le corresponde. En los Stos. Sacrifs. de V.R . me encomdo. Roma, Dicieme. 13, de 1732.

De V.R.

Siervo en Chrô

Francisco Retz

$2^{a}$ carta - $2^{\circ}$ via $13-X I I-1732$

de Francisco Retz al P. Gerónimo Herrán

P.C.

Vista la incapacidad del Herm. Domingo de Funes, estudiante $\mathrm{p}^{\mathrm{a}}$. aprender Latinidad, y que á esta causa el mismo Herm. pide el estado de Coaj ${ }^{\circ} \mathrm{r}$ templ. Tengo á bien sea agregado á este estado. Siendo tanta la rudeza del Herm. Joseph Aguirre $\mathrm{p}^{\mathrm{a}}$ el mismo fin 
de aprender Latinidad, que á juicio de su Maestro, despues de mucho tiempo, y trabajo, arrivará quando mas á entender el Latin del Misal, no es capaz por falta de ciencia deves promobida á el Sacerdocio. Por tanto persuadasele con movidad se aplique al estado de [roto] suponiendo que en algo podrá servir la Compa . y quedará con la debida religiosidad. Y si el Herm. no abrazase este estado, V.R ${ }^{\mathrm{a}}$. con sus C.Ces. Ordin ${ }^{\circ}$ s. y ad [roto] examine este punto, y la determinacion, que puede tomarse según nrãs Leyes $\mathrm{p}^{\mathrm{a}}$ reducirlo á dhõ estado: y quanto nada bastare, me avisará de todo para que yo determine.

Es cierto como dice V.R ${ }^{\mathrm{a}}$. que la causa de estos males, y otros no menores, que essa Prova llora, es la poca, ó ninguna selección que en los Recivos ai han puesto los Superes. atendiendo á particulares motivos, y no unicamte. como debian, y era su oblig ${ }^{0}$. á la Gloria de Dios, y bien de la Religion. Y aunque $\mathrm{p}^{\mathrm{a}}$ el escarmiento era cosa mui proporcionada, que por algun tiempo determinado yo les quitara la potestad de recevir, pues usan de ella siniestramte., mas porque este medio tiene tambien no pequeños inconvenientes, no tomo por aora esta determinacion: me contento con repetir, y confirmar la que dio mi Antecessor de B.M. en 14 de Abril de 1731, en su Despacho, firmado por mi, por no averlo podidio executar su Paternd. á causa de averle sobrevenido la muerte: en el qual, confirmadas las providencias dadas en su Despacho de 22 de Junio de 1726, sobre el assmpto de los Recibos, determina, y ordena; que el Provincial ni aun quando sale á Visita, dase la facultad de recibir ni al Pe. Rr. del $\mathrm{Col}^{\circ}$. de Cordova, ni á otro alguno, sea el que fuere, sino que los Recivos corran unicamte. por mano de su [roto] el qual no recevirá á alguno, sino procediendo la aprobacion de los PP.CC. del Colegio, á que toca el Pretendte. y la de el maior numero de votos de los PP.CC. de Provincia, y no en otra forma. Esa es la determin $^{\circ} \mathrm{n}$ de mi Antecessor, que yo confirmo enteramte. y ordeno extrechisimamte. Su cabal cumplimiento previniendo,que con la noticia de su transgrecion, pondré á quitar immediatamte. Los PP. Provinles. la facultad de recevir, ô daré por nulas, y invalidas los Recibos, que en otra forma se hizieren. En los Stos. Sacrif. de V.R . me encomdo. Roma, Dicieme. 13 de 1732.

De V.R.

Siervo en Chrô

Francisco Retz

$3^{a}$ carta $-2^{\circ}$ via $13-X I I-1732$.

de Francisco Retz al P. Gerónimo Herrán

P.C.

Veo con mucho consuelo mio el buen estado, en que en su Visita encontró V.R ${ }^{\mathrm{a}}$. las treinta Reducciones del Paraná, y Uruguay, y agradezco el consuelo, que dio á los Yndios con sus exhortaciones, el averseles proveido de curas, que los asistan, el aver removido á los que reconoció $\mathrm{p}^{\mathrm{a}}$ estos oficios menos aptos; finalmte. el aver dado la providencia de que se hiziesen las diez y seis canoas ligeras, y bien arenadas, que anden siempre á corso para defender aquellos Pueblos de los Ynfieles Payaguas. Yo deseo mui intensamte. el bien de 
las Missiones, y queriendo cumplir en esta parte mi obligacion, confiando lo dispuesto en este assunpto por mis Antec. de B.M. ordeno estrechissimamte. y doi las provida ${ }^{a}$. siguientes.

Es indubitable, como dice V.R . que todo bien, ó mal de essas Missiones, y Pueblos de los PP. Curas depende: si estos fueron los que deben, buenos estarán los Pueblos, si no, no. A esta causa es mui grave obligacion nuestra señalar curas idoneos, y remover, y quitar los que no lo fueren: y si (quod Deus avertat) á esta obligacion faltaremos, no solo seremos reos de esta gravissima falta, sino tambien de todas aquellas, que de ella se siguieren. Por tanto encargo á V.R . lo mas estrecha, y encarecidamte. que puedo, que solamte. señalen $\mathrm{p}^{\mathrm{a}}$ Curas aquellos Sugetos, en quienes aya las buenas partes de virtud, literatura, prudencia, paz, caridad, zelo de las almas, intelig ${ }^{a}$ y cuidado de lo templ. que se requieren $\mathrm{p}^{\mathrm{a}}$ hazer aquel oficio con buena satisfaccion y los que con esta no lo hizieren, sea culpable, ó sea inculpable la causa, sea la que fuese, sean al punto recividas del curso, y retirados á los Colegios; ni por motivos ningunos se execute lo opuesto.

No se cargue contribucion alguna á los Yndios $\mathrm{p}^{\mathrm{a}}$. sustento de los PP. Curas, y sus compañeros en aquellos Pueblos, en que sea bastante $\mathrm{p}^{\mathrm{a}}$ su sustento la limosna, que les toca del Synodo,ó que da su Magd. y en los que no fuere suficiente, solamte. se les cargará lo que sea necessario $\mathrm{p}^{\mathrm{a}}$ su congrua, y religiosa sustentacion, y nada mas. Y para la debida justificacion tomese razon de aquella limosna; y la tassacion de alimentos no se haga por los PPs. Curas, sino solamte. ó por el Pe. Sup ${ }^{\circ}$. de las Missiones, ó por V.R ${ }^{\mathrm{a}}$. y los PPs. Curas, que contravinieren á esse orden sean immediatamte. removidos de los Curatos, retirados á $\mathrm{Col}^{\circ} \mathrm{y}$ castigados con las penas correspondientes, á juicio de V.R ${ }^{\mathrm{a}}$. dandome aviso de lo executado $\mathrm{p}^{\mathrm{a}}$ consuelo, y sosiego de mi conciencia: y si esse no fuere bastante, me veré precisado dar el ultimo remedio del Precepto.

Nada se saque de los Pueblos de Yndios, ni $\mathrm{p}^{\mathrm{a}}$ el socorro de la Provincia, ni para el Colegio de Cordova, ni $\mathrm{p}^{\mathrm{a}}$ ningun otro Colegio, Residencia, ó Casa nuestra, ni $\mathrm{p}^{\mathrm{a}}$ ningun otro fin exceptuados aquel, ó aquellos solamte, $\mathrm{p}^{\mathrm{a}}$ que esté dada expresa, y formal lizencia por mis Anteces. de B.M. y con las condiciones, y limitaciones, que estuviese dada, y no en otra forma. Esto está ya repetidas vezes ordenado; más no se vé el cumplimiento, que se desea: ante se me dice, que no pequeña parte del cuidado de alguno de los PPs. Superiores, aun maiores, Rectores, Procuradores, Administradores, especialmte. del Colegio de Cordova, está en sacar de los Curas grandes limosnas, conservandose á vezes á causa de estar el oficio de cura, quien no es idoneo para el, y aun quien da escandalo, y nota creeré algun excesso en el informe; más no puedo negarlo todo; maiormte. quando son tan antiguas, y repetidas las que veo sobre este particular.

V.R . en virtud del zelo,que le asiste de la Gloria de Dios, y bien de la Religion de las mas extrechas providencias para el efectivo remedio de todo esto, no dexe á los transgressores sin la pena correspondiente, y que sirva á otros de escarmiento, y exemplar. En los Stos. Sacrifs. de V.R ${ }^{\mathrm{a}}$. me encomd ${ }^{\circ}$. Roma, Dicieme. 13, de 1732.

De V.R. 
$4^{a}$ carta - $2^{\circ}$ via $13-X I I-1732$.

de Francisco Retz al P. Gerónimo Herrán

P.C.

Por todos los medios posibles se deben solicitar entre los Pueblos la union, paz, y christiana caridad, y quitar de raiz los Pleytos, entre ellos pues regularmte. son el origen de las discordias, con otras no pequeñas faltas y queriendo yo en cumplimto. de mi oficio concurrir en quanto pueda á este fin, conformandome con lo dispuesto por mi Antessesor de B.M. el Rdo. Pe. Tyrso Gonzalez en sus Despachos de 25 de Sete. de 1691; de 12 de Abril de 1699; y 4 de Marzo de 1702, y añadiendo una ú otra cosa, que me ha parecido necessaria; para que los Pleytos ha presente pendientes entre algunos de los Pueblos, y los que en adelante se suscitaren ó en ellos, ó entre otros qualesquiera que sean en puntos de terminos, tierras, ó Haziendose quanto antes se terminen, y no se hagan eternos, y doi las cosas siguientes, y que á la letra se observen.

$1^{\circ}$ Cada Provinl. con su Consulta al principio de suss oficios nombra tres Sugetos de los mas antiguos, y inteligentes en las Doctrinas del Paraná, y otros tres en los del Paraguay, para que conozcan essos Pleytos, y sean juezes en ellos. $2^{\circ}$ Los Juezes señalados en el Paraná conozcan, y juzguen todos, y solos los Pleytos de la espacie ya referida, que huviere ó de presente, ó en lo venidero en las Doctrinas del Uruguay, y alcanssaria los Juezes señalados en las Doctrinas del Uruguay en la misma forma conozcan, y juzgen todos y solos los Pleytos, que huviere en las del Paraná. Y si sucediera que algun Pleyto entre dos Pueblos, uno de las Doctrinas del Paraná, y otro de las del Uruguay; entonzes sean los Jueces unos de aquellas Doctrinas, otro de estas, y el terzero el Pe. Superior, que como Pe. de las unas, y las otras, á todas las [roto], como supongo, con igual paternal amos y si algun justo motivo se juzgare conveniente, que su $\mathrm{R}^{\mathrm{a}}$. no lo sea, sealo el que por maior numero de votos del Provl. Y sus Cces. Se juzgare mas indiferente, y aproposito.

$3^{\circ}$ La sentencia dada por los Juezes immediatemte. se notificará á las Partes; á las quales se les concede dos meses de termino peremptorio, y que en manera alguna da lugar á otro termino maior, contados desde el dia de la notificacion, paraque si tuvieron en prueba de su Derecho otros nuevos fundamentos, ó documentos, que presentar, todo en escrito lo entreguen al Pe. Superior para el fin que inmediatamte. se explicará. $4^{\circ}$ El Pe. Superior, pasado que sea aquel termino, con Persona segura, original cerrado, y sellado remitira al Pe. Provinl. y si no otro su $\mathrm{R}^{\mathrm{a}}$ en Cordova, á quien ha señalado en su lugar, la Sentencia, que los Juezes dieron; los fundamentos, los movimientos, y pruebas, que las Partes alegaron, y los que en el termino concedido huvieren nuevamte. alegado. $5^{\circ}$ El Pe. Provl. ó si no está en Cordova, quien allá está en su lugar, con los PP. CCes. de Provincia ordinarios, y ad graviora, todos assi vean decisivo en este punto, sean y juzquen segunda vez esta causa: y la Sentencia, que diere el maior numero de votos esta sea definitiva, y irrevocable; ni se pueda por los PPs. Provinles. ni por los Visitadores, ni por alguno otro revocar, mudar, ni alterar, etiam perviam concordie; exceptuando solamte. el caso de que ciertamte. Conste,

274 Carlos A. Page. Las cartas de los generales... a la provincia del Paraguay... 259-322. 
que es injusta: y esto avisandome primero las razones, y fundamtos. que hazen cierto el agravio de la Parte, contra quien se dio sentencia, y esperando mi respuesta.

Y a dicho ciertamte. para concluir puras probabilidades, antiguo sean mui fundados, á las quales si se da lugar, seran los Pleytos interminables. Añado, que quando no esten en Cordova todos los Consultores señalados, ó quando por Legitimo impedimto. no pudiere alguno ver, y juzgar la causa, quiero que entonzes entren con Voto decissivo hasta llenar el numero de los siete los PPs. Procurador de Prov ${ }^{\mathrm{a}}$. y Maestros de Teol ${ }^{\mathrm{a}}$. del $\mathrm{Col}^{\mathrm{o}}$ Maximo.

$6^{\circ}$ Dada la Sentencia, original, cerrada, y sellada la remitirá el Pe. Provinl. ó quien está en su lugar con la primera Sentencia de los tres Juezes, y demas Papeles, que se le imbiaron, á el Pe. Superior de las Doctrinas, y este al Pe. Cura del Pueblo, en cuio favor definitivamte. se ha juzgado: y todo se conservará en su Archivo paraque siempre conste, y no vuelva mas semejante Pleyto á sucitarse. V.R ${ }^{\mathrm{a}}$. avisará esta mi determinacion á todos los PP. Curas, y que la noten entre los demas ordenes de los PP. Generales, paraque siempre tengo el cumplimiento, que con intension deseo: ni dexará á los transgresores sin las penas correspondientes. En los Stos. Sacrifs. de V.R ${ }^{\mathrm{a}}$. me encomdo. Roma, Diciembre 13, de 1732.

De V.R.

Siervo en Chrô

Francisco Retz

$6^{a}$ carta - $2^{\circ}$ via $13-X I I-1732$.

de Francisco Retz al P. Gerónimo Herrán

P.C.

Disenme, uncede algunas vezes en tiempos de Congreg ${ }^{\text {on }}$ Provinl. que ordenan los PPs. Provinles. á algunos de los PP. Curas,que tiene jus suffragij, baxe á Cordova con Yndios, Musicos, y Danzantes $\mathrm{p}^{\mathrm{a}}$. festejar assi á los PP Congregados, como á los Procures. electos, de que se siguen gravissimos inconvenientes, quales son los crecidissimos gastos assi en el viage de los Yndios, como en los ricos vestidos, que se les hazen $\mathrm{p}^{\mathrm{a}}$. la funcion; desuerte que el gasto hecho $\mathrm{p}^{\mathrm{a}}$. esta Ultima Congrego ${ }^{\mathrm{o}}$, en esto, importó mucha plata; muertes de no pocoas Yndios, pues de los 145 que salieron del Pueblo de Loreto $\mathrm{p}^{\mathrm{a}}$. dhá Congregacion me dicen murieron 62. Muchos de los Musicos, y Danzantes ya casados no vuelven á sus casas, ó porque se huien, ó porque se guardan entre los Españoles: y asi quedan sus Mugeres ni casadas, ni viudas, y sus hijos huerfanos. Ademas de estos gravissimos inconvenientes, este modo de celebrar las Congreges. es proprio unicamte. de seculares, y en la Comp ${ }^{a}$ tenido por mui pueril, con aiunos, y oraciones se reciba de Dios el acierto. Ordeno, que jamas se use este festejo, ni aun en canonizacion de Santos.

Ha [roto] inconventes. que con sola la liz de los PPs. Provinl. y sin el consentimto. y registro del Pe. Superior de las Doctrinas, se introduzcan en estas generos de Castilla, oro, 
plata, telas, galas V $\mathrm{V}^{\mathrm{a}}$ avisando al Pe. Superor. quando ya estan los Generos en los Pueblos, y no puede negarse la lizencia; como algunas vezes convendrá hazer, de que se me refieren casos particulares de generos en esta forma introducida por los PPs. Procures. de essa Prov ${ }^{\mathrm{a}}$. y del $\mathrm{Col}^{\mathrm{o}}$. de Cordova en los Pueblos de Loreto, y los Martyres: y concluien, que sin embargo de los estrechas ordenes, y aun preseptos en contra, para la introduccion de aquellos generos; nunca mas abiertas las puertas, que aora. Ordeno pues á VR ${ }^{\mathrm{a}}$. y á sus Successores (y lo mismo se entienda con los PP Visitadores) que nunca den esta lizencia, sin que preceda in scriptis la del Pe. Superior, ni sin el previo registro de este se introduzcan los generos en los Pueblos, y quando en alguno aya necessidad de algun genero, el Pe. Cura avisará de ello al Pe. Superior, paraque reconocida por este, dé, ó no de su lizencia, como mas conveniente le pareciere en el Señor.

Provease á los PPs. Missioneros de las Campañas de aquellas alajas, que necessitan $\mathrm{p}^{\mathrm{a}}$ hazer con decencia religiosa su viaje: ni es convente. se les añada la molestia de que ellos las aian de buscar. Mucho maior cuidado se ponga en que las alajas, y sacros ornamentos, que llevan $\mathrm{p}^{\mathrm{a}}$ celebrar, tengan la limpieza y desencia, que $\mathrm{p}^{\mathrm{a}}$ aquel fin son necessarias; y no este, quales me dicen, rotos, y llenos de manchas: y si esto es assi, que aprecio ni respeto han de concebir los Yndios, y personas rudas del cargo á las cosas de nrã Sagrada Religion, si ven que nosotros mismos tratamos con menos reverencia á la Suprema de todas? Finalmente quando los PPs. Missioneros se retiran á algun Colegio á descanzar, cuidense en lugar decente, y seguro. Y si no fuesse otra la voluntad de los Donadores, aquellas limosnas, que se dan $\mathrm{p}^{\mathrm{a}}$ estas Missiones, expendanse en primer lugar en conservar, reparar, y hazer de nuevo, quando sea necessario, estas alajas, y en aquellos donecillos, que suelen darse á los Misioneros $\mathrm{p}^{\mathrm{a}}$ [roto] las almas.

El Pe. Antonio Almoguera me dice, se dedicará de por vida á estas Missiones, dandole Compañero de satisfaccion y que convendria, que se hiziese no solamte. en las campañas, y cortas Poblaciones, sino en las Ciudades tambien. Yo por mi no tengo dificultad, antes mui intensamte. deseo, aia en todas partes el frequente exercicio de las Missiones, por Sugetos, que $\mathrm{p}^{\mathrm{a}}$ ello sean: mas yo no tengo presentes todas las circunstancias, por tanto dexo la determinacion á V.R. en cuios Stos. Sacrifs. me encomdo. Roma, Dicieme. 13 de 1732.

De V.R.

Siervo en Chrô

Francisco Retz

$7^{a}$ carta $-13-X I I-1732$

de Francisco Retz al P. Gerónimo Herrán

P.C.

Me dizen, que quando el Pueblo de los SS Martyres Cosme y Damian se dividio del de la Candelaria, este dio á aquel en emprestido unas tierras de dos leguas de distrito; las 
quales eran, y son del de la Candelaria, y no de Sn. Cosme, y Damian, como todo expressamte. Constaba de un Papel, que siempre se avia guardado en el Archivo de la Candelaria, escrito mas ha de cinquenta y seis años, y firmado de los PP. Francisco Ricardo, Superior entonzes de las Missiones, ó Doctrinas, Jul. Romeo, y Joseph Serrano Curas que fueron de ambos Pueblos; y Manuel Bertol, y Phelippe Bazan. Y sin embargo VR . adjudicó, y dio dichas tierras al Pueblo de Sn. Cosme, y Sn Damian, y se los quitó al de la Candelaria con gravissimo sentimiento, y perjuicio de este ya por averlo injustamte. despejado de lo que le pertenecia, y era suio, como constaba del ia citado Ynstrumento ya porque teniendo antes de la determinacion de V.R ${ }^{\mathrm{a}}$. cada una de los dos Pueblos siete leguas de termino, y estancia; oi el de Sn. Cosme tiene nueve, y el de la Candelaria solo cinco: á cuia causa no tiene el termino, y tierra que necessita $\mathrm{p}^{\mathrm{a}}$. apacentar sus Bacas. Concluien diciendo (lo que yo mui dificilmte. creeré) que V.R ${ }^{\mathrm{a}}$. $\mathrm{p}^{\mathrm{a}}$ que â los de la Candelaria nunca se restituiessen aquellas tierras, sino siempre se poseyessen por los de Sn. Cosme, quemó, ó deshizo el ya citado Ynstrumento, que por el tiempo ya dho se guasdara, y conservaba, en el Archivo de la Candelaria.

No dado, que V.R . con algun motivo (que echo menos) daría esta determinacion: más sin embargo yo la anulo, y declaro por de ningun valor, ni efecto: y en consequencia determino, y es mi expresa voluntad, que luego, y sin dilacion [roto] dos Leguas de tierra sean restituidas efectivamte. á el Pueblo de la Candelaria, desuerte que ambos Pueblos queden como de antes estaban, cada uno en el goze, y posession de siete leguas de tierra, y estancia. Puestos en esta igualdad los dos Pueblos, es mi voluntad, se vea, y determine este Punto por los Juezes, y en la forma, que ya dexo expressada, y que en él se observen sin falta las cosas siguientes.

$1^{\mathrm{a}}$. Averiguese por personas fidedignas, y noticieras, si es cierto avia en el Archivo de la Candelaria el Ynstrumento, que se me diere, y qual era su contenido: y si es como se me dice, estese enteramente á el: sean dhãs tierras perpetuamte. de la Candelaria, y no se pase á otra cosa, ni se de oidos á ningunos argumentos en contrario, por mas fundadas que sean; pues aquel Ynstrumento quita toda duda, y tiene mas fuerza que todos. $3^{\mathrm{a}}$. Quando un Pueblo se divide en dos, se parten, ó deben partirse entre ambos todos los muebles, Ganados $\mathrm{Es}^{\mathrm{a}}$ y mucho mas las estancias y territorios, todo por partes iguales. Por tanto averiguase, si quando se dividieron los dos Pueblos, de que hablamos, se guardó, ó no esta igualdad en la adjudicacion de terminos. Si se quardó entre a ella, y no se pase á otra cosa, y queden perpetuamte. las tierras que es de la Candelaria. Si no se guardó; si constan ciertamte. que por esta desigualdad se dio por el Pueblo de Sn. Cosme al de la Candelaria la justa, y debida compensacion; en este caso sean las tierras del de Sn. Cosme: mas si ciertamte. no constare aquella Compensacion, son de la Candelaria. Y assi yo se las adjudico ia perpetuo, $\mathrm{p}^{\mathrm{a}}$ que assi se guarde á los Pueblos la justicia, y igualdad, que se les debe, y aia entre ellos la paz, caridad, y correspnd ${ }^{a}$ que mui intensamte. deseo. Y assi se lo avisará V.R ${ }^{\mathrm{a}}$ á los Juezes, $\mathrm{p}^{\mathrm{a}}$ quesabida mi voluntad, le den el debido cumplimto. Finalmnte. ordeno estrechissimamente, que no por los PPs. Provles. ni Visitades. ni por alguno otro en ningun caso se deshaga, ni se saque Papel alguno de los Archivos de los Pueblos: conservense en cada uno los que les tocan, y quando aia necessidad de alguno, saquese una Copia autorizada, y guardese siempre en el Archivo el Original. En los Stos. Sacrifs. de V.R ${ }^{\mathrm{a}}$. me encomdo. Roma, Dicieme. 13, de 1732. 
De V.R.

Siervo en Chrô

Francisco Retz

$7^{a}$ carta - $2^{a}$ via - 13-XII-1732.

de Francisco Retz al P. Gerónimo Herrán

P.C.

Mucho me consuela el buen estado, en que se halla la Posession del Valle de calamuchita, que se compró con los caudales, que $\mathrm{p}^{\mathrm{a}}$ ello dieron los Ses. Dn Alonso Alfaro difto. Y Dn Pedro de Echezarraga ya de nrã Comp ${ }^{a} p^{a}$ los fines, que en la fundacion se expressan, y yo luego diré N.S. lo conserve, y aumente á Gloria mia. Déle V.R ${ }^{\mathrm{a}}$. en nombre mio mus. gras. al Pe. Martin Lopez, á cuio zelo, y buena conducta se debe esta obra en tanta parte: y quien no será removido de su administracion hasta que esté esta obra enteramente acabada.

Dichos Fundadores dieron estas cantidades: Dn Alonso Alfaro 120 Pesos, y fue su voluntad, que los 60 expendiessen en fabricar, y adornar con las alajas necessarias una Casa en Santiago del Estero, $\mathrm{p}^{\mathrm{a}}$ que en ella todos los años hagan los Exercicios las Personas Seglares, que quisieren. El Antecessor de V.R . avisó se trabajaba con calor en la fabrica de esta Casa; V.Ra. no toca en sus Cartas este punto, y yo le deseo saber, y si está ya perficionada 1 Fabrica: V.R ${ }^{\mathrm{a}}$. déme de todo aviso puntual. Los otros 60 Pesos quiso se expendiesen en el mismo fin, que quiso tambien Dn Pedro Echezarraga: es á saber, en comprar una Posesion, cuios frutos se expendan en los siguientes fines: en costear los gastos, que cada $\mathrm{Col}^{\circ}$ de essa Prov ${ }^{\mathrm{a}}$ hiziere, dando cada año los Exercicios á los Seglares, que los quisieren hazer; y paraque los Colegios imbien todos los años Sugetos, que hagan Missiones por sus Partidos: y al $\mathrm{Col}^{\circ}$. que en lo uno, ó en los otro algun año faltare, no se le dé en él la porcion correspondiente á la falta. Las Cantidades, que $\mathrm{p}^{\mathrm{a}}$. esto dio Dn. Pedro, son las que refiere la Escriotura de Donacion inter vivos, que supongo tiene V.R ${ }^{\mathrm{a}}$. presentes, y por esso digo yo. De estas cantidades no se han entregado aun al Pe. Administ ${ }^{\circ} \mathrm{r}$. de á 8 reas. de Plata, que tenia en Cadiz en poder de D. Pedro Vztariz, y V.R ${ }^{\mathrm{a}}$ cobró, llevó en generos quando volvio con la Mission de Europa. Tte. Doce Mayas, ó Ramos grandes, de plata, que me dicen valen setecientos Pesos. Ordeno mui estrechamte. que los 100791 Pesos sean luego entregados al Pe. Admis ${ }^{o} \mathrm{p}^{\mathrm{a}}$ que dho Pe Administror los expenda en bien de la Possession ni por motivo alguno á otros fines se apliquen, aunque $\mathrm{p}^{\mathrm{a}}$ ello dé su consentimto. el $\mathrm{Herm}^{\circ}$ Echezarraga, quien por la Donacion inter vivos, y estado Religioso que tiene, no tiene accion $\mathrm{p}^{\mathrm{a}}$ la mudanza. En quanto á las 12 Mayas ya aplicadas á la Sacristia del $\mathrm{Col}^{\circ}$ de Cordova, es mi voluntad, que se entregue al Pe. Administrador el precio moderado de ellas á juicio de dos Personas de inteligencia, que señalarán la una el Pe. $\mathrm{R}^{\mathrm{o}} \mathrm{r}$ del $\mathrm{Col}^{\mathrm{o}}$. y la otra el Pe. Administ ${ }^{\circ} \mathrm{r}$. y en caso de discordia señalará tercero V.R ${ }^{\mathrm{a}}$. Y $\mathrm{p}^{\mathrm{a}}$ que el $\mathrm{Col}^{\circ}$ no tenga que desembolzar, podra hazer reencuentro con el Pe. Admin ${ }^{\circ}$. no perciviendo de su [roto] por los gastos de Seglares Exercitantes, y avio de Missioneros otra 
tanta cantidad, como en la que se avaluen las doze Mayas. Finalmente si alguna otra cosa de las expresadas en la Donacion no se huviere entregado ya al Pe. Administrador, entreguesse sin dilacion. En los Stos. Sacrifs. de V.R ${ }^{\mathrm{a}}$ me encomiendo, Roma, y Dicieme. 13, de 1732.

De V.R.

Siervo en Chrô

Francisco Retz

$8^{a}$ carta - $2^{a}$ via - 13-XII-1732.

de Francisco Retz al P. Gerónimo Herrán

P.C.

Veo con gozo mui especial las fundadas esperanzas de la Converssion de los Yndios de la Nacion Guañana, y como V.R. ha señalado $\mathrm{p}^{\mathrm{a}}$ ella al Pe. Joseph Pons con su Comp ${ }^{\circ}$ quiera N.S. sea con igual fruto, que todos á Gloria suia, y bien de aquellas almas deseamos. Me consuelan assimismo notablemente las noticias, que me dá V.R ${ }^{\mathrm{a}}$. de las Missiones de los Chiquitos, y lo mucho, que se van extendiendo las Conquistas espirituales entre los Indios Guaraños, de los quales el año pasado de 1729 se avian convertido hasta quatrocientas Familias. V.R . en nome. mio á todos los Missioneros, que trabajan en estas gloriosas Conquistas, y especialmte. á los PPs. Joseph Pons, y Agustin de Castañares les dará mus. agradecimtos. Y de todas estas Conquistas, y Missiones me dará V.R a noticia mui individual.

Muchos años há, que juzga essa Prov ${ }^{\mathrm{a}}$ necessaria summamte. tener una Finca Nusa., y suficiente $\mathrm{p}^{\mathrm{a}}$ que con sus redditos se costeen los gastos en conducir las Misiones de Europa. Para este fin por el año de 1711 tenia ya juntos, y efectivamte. Existentes y Cien mil Pesos: los sesenta mil dados graciosamte. por los Pueblos de las Missiones, y los quarenta mil por la Provincia. Y la Congregacion, que en dho año de 1717 celebró, en el quarto de sus Postulados pidió á mi Ant ${ }^{\circ}$. de B.M. tuviesse á bien assi aquella limosna, de los Indios, como el que todos aquellos Cien mil Pesos se empleassen en la compra de la Finca, y siuviesse Capital $\mathrm{p}^{\mathrm{a}}$. el fin ya mencionado de conducir las Missiones de Europa. Su Ante ${ }^{\circ} \mathrm{r}$ en su respuesta de 31 de Marzo de 1723 no solamte. condesdendio con lo uno, y con lo otro; sino que con precepto mandó, que ni por los PP. Provles. ni por alguno otro de los Nuestros dhos Cien mil Pesos ni en todo, ni en parte se aplicasen, y distrayessen á otros fines: ite que si alhuna parte se avia ya distraydo, se repussiesse, y reintegrasse, y toda la Cantidad enteramte. se guardasse, y conservasse hasta la efectiva compra de la Finca, ó Imposicion del Capital. Y sin embargo de todo esto me dice V.R ${ }^{\mathrm{a}}$. que quando tomó el Gobierno de essa Prov ${ }^{\mathrm{a}}$. que fue en 2 de Junio de 1729, de todos aquellos Cien mil Pesos solamte. hallo existentes, y en ser 10000 , y que toda la restante cantidad se avia ya gastado en urgencias, y necessidades de la Provincia. 
Confirmo á V.R . no alcanzo á explicar quanto me disuena este hecho; ya por ver frustrado lo que con tanta ansia, y razon essa Prov ${ }^{\text {a }}$ ha deseado, y le tiene tanta quenta; ya por ser la facilidad en alterar, y dilatar las voluntades de los piadosos Donadores, con no pequeño motivo á las quexas, y murmuraciones, y á que seamos notados de poca fidelidad; ya porque las mismas urgencias, que oi, há padecido essa Prov ${ }^{\mathrm{a}}$. comunmte. y la prud ${ }^{\mathrm{a}}$ religiosa de los PPs. Provles. ha hallado otros medios de socorrerlos; ya finalmte. porque en el tiempo de aquella distraccion no veo en essa Prov ${ }^{a}$ otra urgencia extraordinaria, que el avio de V.R . á Europa: en el qual no puede averse gastado ni la tercia parte de la Cantidad, que dice V.R ${ }^{\mathrm{a}}$. falta: además que $\mathrm{p}^{\mathrm{a}}$ este avio dieron los Yndios 140 Pesos, y claro está, que la Provincia daria á lo menos otra tanta cantidad. No hago memoria del Precepto, que puso mi Antecessor, porque creere que quando llego allá, estaba ya distraida toda aquella Cantidad V.R ${ }^{a}$. me imbiará puntual razon con cargo, y data explicandome con claridad por orden de quien, y en que se ha gastado la cantidad, que de los Cien mil Pesos se me dicen falta, $\mathrm{p}^{\mathrm{a}}$ que visto por mi, proceda, y determine. Y queriendo dar alguna provid $\mathrm{p}^{\mathrm{a}}$ que dichos Cien mil Pesos enteramte. se reintegren, y repongan; y teniendo preferentes los cortos medios de essa Prov a sus urgencias, y necessidades; mando con Precepto en virtud de Sta. Obediencia á V.R . y á sus Sucessores, que de los Bienes, frutos, y reditos de essa Prov $^{a}$ depositen cada año en Arca de tres llaves tres mil Pesos, hasta la efectiva, y total reintegracion de aquellos Cien mil Pesos de Capital. Assimismo con el mismo Precepto mando, que mi V.R ${ }^{\mathrm{a}}$. ni alguno de sus sucessores, aunque sea Visitador por motivo, ni caso alguno de la cantidad, que se huviere depositado, distrayga, ni preste algo; sino que toda ella se guarde en dicha Arca hasta la entera reintegracion de dichos cien mil Pesos. Y para este caso confirmo, y repito el Precepto ya citado, puesto por mi Antecessor, el qual quiero tenga entonces toda su fuerza, y vigor, y yo nuevamte. le impongo. Assimismo junta que sea aquella Cantidad, toda ella se emplee, quando aya ocasión, en el fin ya referido de la Finca. Finalmte. siempre que V.R ${ }^{\mathrm{a}}$ ó sus Sucessores me escrivan, denme puntual aviso, y razon del entero cumplimiento de esta mi determinacion. En los Stos. Sacrificios de V.R ${ }^{\mathrm{a}}$. me encomdo. Roma, Dicieme. 13, de 1732.

De V.R.

Siervo en Chrô

Francisco Retz

$9^{a}$ carta - $2^{a}$ via - 13-XII-1732.

de Francisco Retz al P. Gerónimo Herrán

P.C.

En el quarto año de theologia deben nrõs estudiantes theologos assistir á las clases, escribir todas las materias, que dictaren, y tener todas las Funciones literarias acostumbradas: todo del mismo modo,que en los tres años anteriores: assi se practica inconcussamente en las Provincias; y assi en essa indefectiblemte. se observará. Por tanto no hizo bien V.R ${ }^{\mathrm{a}}$. en conceder la dispensacion, que me dice, á los dos Hs. theologos, que

280 Carlos A. Page. Las cartas de los generales... a la provincia del Paraguay... 259-322. 
avian de defender los Actos Generales; de que solamte. escriviessen las materias de Prima, y Visperas. Mas me disuena lo que assimismo se me avisa, que otros cinco, ó seis Sugetos, con los PP Pedro Logu, y Ign ${ }^{\circ}$ Oyarzabal, solo de ceremonia, y cumplimto. hizieron el quarto año, assistiendo á las clases por mui poco tiempo, y sin tener las funciones literarias acostumbradas: todo esto si es assi, gravemte. Reprehendo: y ordeno estrechissimamte. que por motivo ninguno semejantes dispensaciones en adelante se concedan; sino que se observe enteramte. lo dispuesto por el Ratio Stadiorum, y practica inconcusa, que ya dexo insinuada.

La tercera Probacion debe con todo rigor cumplirse, según lo establecido en el Instituto, y de nuevo encomendado, y ordenado en la Vltima Congregacion Genl. Por tanto extraño, que por solo aver cuidado el Pe. Diego Orbegozo de los Novicios en la Navegacion por solos tres meses, se le aya dispensado de tercera Probacion: y no menos sensible me es, que en el Informe ad Gradum deste Pe. me diga V.R. ha tenido la tercera Probacion, quando esta ha sido, según me informan, en el modo ia dicho. V.R ${ }^{\mathrm{a}}$. que carece la importancia, y necessidad de ser los informes, quales los necessita el Genl. $\mathrm{p}^{\mathrm{a}}$ su gobierno; concederá tambien, que el suio en este punto no me ha sido qual debio esperar. Ordeno pues, que para compensar dicho tiempo de $3^{\text {a }}$ Probacion, ademas del referido ya en el cuidado de los Novicios; por espacio de ocho dias haga dicho Pe. los Exercicios Espirituales distintos de aquellos, que deben preceder al Grado ocho dias antes. El Pe. Diego Palacios estudió en la Comp ${ }^{a}$ hasta el primer año de theologia y assi debe tener $3^{\mathrm{a}}$ Probacion, no del año entero, sino de la parte, que corresponde á sus estudios en la Compa . En los Stos. Sacrifs. de V.R ${ }^{\mathrm{a}}$. me encomdo. Roma, Dicieme. 13, de 1732.

De V.R.

Siervo en Chrô

Francisco Retz

$10^{a}$ carta $-2^{a}$ via $-13-X I I-1732$.

\section{de Francisco Retz al P. Gerónimo Herrán}

P.C.

Los usos, y costumbres legitimte. introducidas en las Provincias deben enteremte. Observarse, y lo contrario de seio es causa suficiente de malissimas conse quencias: y acaso lo es de las no pocas, que con gravissimo dolor en essa Provincia miramos: ello es cierto, que era otro su estado, quando era mas exacta su observancia. V.R ${ }^{\mathrm{a}}$. que no ignora la importancia del asumpto, zele su mas entero cumplimto. ni dexe á los transgressores sin la penitencia, que merecen. Entre las costumbres legitimas de essa Prov ${ }^{\mathrm{a}}$. tienen el primer lugar las de no usar la Yerba de Paraguay, y no tomar tabaco en polvo: y sobre la una, y la otra se han dado repetidos ordenes assi por los Superiores de essa Prova . como por mis Antecessores de B.M. Y aun sobre la segunda el Pe. Lauro Nuñez, Provl. que fue de essa Prov $^{\mathrm{a}}$ mandó con Precepto, que ninguno de los Nuestros tomasse tabaco en polvo ni delante de Seculares, ni de caxas de mugeres. No obstante tan importantes, y repetidos ordenes, se 
me dice, que en una, y otra cosa ai una summa facilidad, tomando tabaco en publico, y usando de la Yerba aun sin algun recato algunos PPs. del $\mathrm{Col}^{\circ}$. de Cordova (que no me dicen quales son) con nota de aquella juventud: y la que con este exemplo usa de dha Yerba; como y tambien mus. de los Herms. Coadjutores, y aun (lo que yo no creyera) Hers. Novicios. Si semejante falta me disuena tanto aun en quienes aparece pudiera tener menos inconvente., como en los antiguos de Religion; quanto mas en los que comienzan á vinir en ella me hará disonancia? Viendo que un tan uso, aun omitiendo otros inconvenientes, y daños á la juventud; trae consigo la perdida del tiempo tan precioso á un Estude. y mas á un Novicio, y no poco detrimento á la regular observancia, y virtud de la Pobreza.V.R ${ }^{\mathrm{a}}$. no dexe medio alguno $\mathrm{p}^{\mathrm{a}}$ desterrar de essa Prov ${ }^{\mathrm{a}}$ un tal uso, castigando á los culpados, como se merecen. Y por lo que mira al Precepto del Pe. Lauro Nuñez yo lo revoco, y anulo con un todo, y le dexo otra fuerza, que la de un orden estrechissimo $\mathrm{p}^{\mathrm{a}}$ usar del tabaco en polvo, ni delante de Seglares, ni de sus Caxas. A esto me mueve la confianza, que tengo, de tan religiosa Provincia, que sin tan rigoroso medio, como es el del Precepto, sabrá no dar lugar ó que yo renueve, y confirme el que ahora anulo, y revoco. En los Stos. Sacrificios de V.R . me encomdo. Roma, y Dicieme 13, de 1732.

De V.R.

Siervo en Chrô

Francisco Retz

$11^{a}$ carta $-2^{a}$ via - 13-XII-1732.

de Francisco Retz al P. Gerónimo Herrán

P.C.

Algunas no pequeñas faltas se me avisan del $\mathrm{Col}^{\circ}$. de Cordova, como son conversaciones, murmuraciones, y poco fervor en los estudios: y que á nrõs estudiantes, y aun á algunos Novicios se conceden en la comida y bebida algunas liciencias, que tienen inconvente. y directamte. se oponen á la practica siempre observada en la Provincia. Creeré algun excesso en el Ynforme: mas sin embargo encargo á V.R ${ }^{a}$. mui encarecidamte. vea lo que en otro ai, y corrija aquello,que juzgare debe remediarse.

No estraño esté este $\mathrm{Col}^{\circ}$. empeñado en los 70 Pesos, que V.R ${ }^{\mathrm{a}}$. me dice; sino que no lo esté en mucha maior cantidad: porque si se señalan por Procures., y Administradores de sus Haziendas Sugetos, que no tienen ni aplicación, ni inteliga. si estos á pasar de la razon, $\mathrm{y}$ con conocimientos de que no son $\mathrm{p}^{\mathrm{a}}$ ello, se les conserva en los oficios por años, y años; si no se cuida no solamente de que sus Haziendas se adelanten, pero ni aun de que se conserven, labrando, y cultivandolas: si todo el cuidado assi de aquellas, como de los PP Rectes. está en recoger limosnas de los Pueblos de las Missiones; de todos estos principios, que V.R . expresamte. Confiessa; que otra cosa se puede prudentemte. esperar, que la decadencia, y ruina total de esse $\mathrm{Col}^{\circ}$.? Los Superes. que son reos de estas faltas, y causa de ellas con su omission, ô con otros respetos, debieran ser advertidos, y corregidos $\mathrm{p}^{\mathrm{a}}$ el escarmiento de otros, $\mathrm{y}^{\mathrm{a}}$ que conociessen assi su obligacion en no poner, ni conservar 
tales Supes. Admines. ó Procures. sacrificando â su poca, ó ninguna inteligencia, ó á su reprehensible omission la Hazienda de los Colegios.= Veo el mal estado en lo templ. y espiritual del $\mathrm{Col}^{\circ}$. de Buenos Ayres, á causa de la mala conducta del Pe. Ju de Alzoa su $\mathrm{R}^{\mathrm{o}} \mathrm{r}$ añadiendose su inobed ${ }^{\mathrm{a}}$. â las ordenes, que en la Visita V.R ${ }^{\mathrm{a}}$. le dexó. A este Pe. no se me proponga mas $\mathrm{p}^{\mathrm{a}}$ gobernar: ni allá aun en suplemento sera para ello señalado; como ni $\mathrm{p}^{\mathrm{a}}$ algun manejo, ó administ ${ }^{\circ} n$ de Haziendas.

Los demas Colegios de essa Prova ${ }^{\mathrm{a}}$ estan tambien atrasados: la causa es por la mala administracion, ó por la poca inteliga , ó por el menor zelo, y aplicación al cultivo de las Haziendas de los PPs. Re. de los Procres. y Estancieros: ó por lo que con gravissimo daño de los Colegios sucede no pocas vezes, deshazer, ó alterar los unos lo que hizieron, y dispusieron otros, no siendo otro el fruto de estas mudanzas, que la perdicion de los Colegios. Yo deseo mui intensamte. el remedio de todo esto, y á esta causa encargo á V.R . lo mas estrechamte. que puedo, que ni se propongan $\mathrm{p}^{\mathrm{a}}$ Res. y mucho menos se señalen para Procures. ni Estancieros aquellos, en quienes aya alguna de las referidas nulidades; y sean quanto antes removidos de los oficios aquellos, en quienes los huviere, sino ai otro medio con que se repare este daño: pues no siendo Señores, sino puros administradores de los bienes de la Religion; es grave obligacion nrã hazer quanto en nosotros esté, $\mathrm{p}^{\mathrm{a}}$. que se administren con debida satisfaccion. En los Stos. Sacrifs. de V.R ${ }^{\mathrm{a}}$ me encomdo. Roma, Dicieme 13 de 1732.

De V.R.

Siervo en Chrô

Francisco Retz

$12^{a}$ carta - $2^{a}$ via - 13-XII-1732.

de Francisco Retz al P. Gerónimo Herrán

P.C.

Ademas de las faltas en lo espiritual ya referidas, me notician de otras dos, que por su gravedad, y consequencia me dexan con no poco cuidado, y desconsuelo. La una es sobre cierta especie de negociacion, que se practica, aun despues de los referidos ordes. de mis Antecessores, y contra lo que por nras Leyes esta prohibido, y mandado; ocasionando assi, y fomentando las murmuraciones, con que nrõs emulos infaman nrõ buen nombre. Y como quiera que estos lamentos son tan repetidos, como antiguos en este oficio, me hazen sospechar, que á ellos da fundamto. y que este ni lo han procurado quitar los Superes. ni poner en execucion las ordenes dadas de los Generales. Los que yo por aora doi no son otros, que los ya dados en los otros Despachos. A V.R ${ }^{\mathrm{a}}$. pues encargo, que assi por la obligon. de sus oficios, como por la de nrõ estado, y Ynstituto zele con la maior vigilancia un tan reprehensible defecto, sin perdonar medio alguno $\mathrm{p}^{\mathrm{a}}$ extirparlo de essa Prov $\mathrm{v}^{\mathrm{a}}$. castigando severissimamte. á los que hallare culpados en adelante; y removiendolos (su fuere necessario) de aquellos oficios, donde aya peligro de falta tan destestable: la que si aun con estos medios no se verá del todo enmendada, usaré de aquellos, á que aora me 
reservo $\mathrm{p}^{\mathrm{a}}$ los primeros lamentos, que de essa Prov ${ }^{\mathrm{a}}$. me vengan en este punto. $=$ La segunda no menos sensible, y sobre manera dañosa á la union, y caridad fraterna, y al aumento de essa Christiandad es el demasiado afecto de Nacionalidad, y de este los perniciosos efectos, que diré por las noticias, que me escriven. Estas son: que no está en los Armarios de los Pueblos de las Missiones (no se me dice en quales) de poco tiempo á esta parte el Retrato de su Magestad Cat ${ }^{\mathrm{a}}$ aviendo estado, y debiendo conservarse siempre en ellas; que algunos de los PPs. Missioneros llevados del afecto á su Nacion ya en lo politico, ya en lo sagrado ha introducido, y introducen ciertos modos, y usos, que se practican en su Mission, mas no en la española: por el contrario otros, que en esta se estilan, los han quitado, y abrogado, queriendo, según parece, que vaian todas las cosas al modo, que en su Nacion, y propria Patria. Que cierto Pe. Missionero salio á V.R ${ }^{\mathrm{a}}$. quando iba visitando, con comitiva de Yndios, que llevaban Vandera de cierto Soberano, distinto de su Magd. Cath ${ }^{\mathrm{a}}$ proclamando á aquel los Yndiezuelos pequeños en el idioma, que tambien los avia enseñado el Pe. que acaso no avria hecho otro tanto de la Doctrina Xpna.

Confiesso, que no tengo palabras para explicar el dolor, y desagrado, que estas cosas me causan. Considere V.R ${ }^{\mathrm{a}}$. la gravedad del delito de levantar vandera, y proclamar Soberano en Dominios distintos, y territorio extraño; de retraher con estas especies (y de suio commover, y sublevar) á los Yndios del amor, y sujecion, que deben á su Soberano legitimo, que es su Magd. Cath ${ }^{\mathrm{a}}$. con la circunstancia de ser executado todo esto por aquellos mismos, á quienes su Rl. Beneficencia dá los necessarios alimentos á fin que en cumplimto. De su Vocacion en essos vastos Payses hagan el oficio de Apostoles. Y si como es tan natural todas estas cosas llegan á los oydos del Rl. Supremo de Ynds. y de ai á los de su Magd. que resolucion tomaran? De temer es, sea esta con gravissimo daño, y quizá ruina total de essas Doctrinas, y Prov a de Paraguay: y como quiera que sea siempre será con gravissimo daño, deshonra, y descredito de toda la Religion.

V.R . saque luego de las Doctrinas á los Sugetos, que huvieren influido en alguna cosa de estas, y deles aquellos penitencias, que juzgare merece su delito. Pongase inmediatamte. en todas las Armeria el retrtato de su Magd. Cath ${ }^{\mathrm{a}}$. y en ellas se mantenga, y confirme. Mui en lo politico, como en lo sagrado guardense inviolablemte. solos aquellos modos, estilos, usos, y costumbres, que se practican por la Nacion Española; todos los demas, sean los que fueren, immediatamte. se quiten, y abroguen in totum.

Y por lo que mira al Pe. que hizo á V.R ${ }^{a}$. el referido recevimiento, si bien ni me contento con la reprehension, que allí le dio V.R . ni con averle sacado (como indubitablemente supongo) de las Doctrinas, y retirado á un Colegio; pues su atentado merecia maior, y exemplar castigo: mas porque el darlo aora pudiera con renovar la memoria de la culpa suscitar aquellas especies, que quiza estaran ya dormidas, y hazer con el remedio mas sensible la llaga; ordeno solamte. que si acaso ai prudente temor de que al Sr. ViRey de Lima, ó á los Ministros Reales de essas Partes llegue la noticia de este sucesso, ó que ya aya llegado; V.R $\mathrm{R}^{\mathrm{a}}$. juntando sus Consultores $\operatorname{Ord}^{\mathrm{o}} \mathrm{s}$. y ad graviora, y examinando si quedarán aquellos satisfechos del castigo executado, ó si se pueden tener graves inconventes. de no darle otro maior al Pe., se executará, y se le dará aquel castigo, que el maior numero de votos juzgare debido á su delito, ó á la satisfaccion del Rey en sus Ministros, y á apagar el fuego, que un tal hecho puede emprender. En los Stos. Sacrif. de V.R ${ }^{\mathrm{a}}$. me encomdo. Roma, Dicieme. 13, de 1732. 
De V.R.

Siervo en Chrô

Francisco Retz

$13^{a}$ carta $-2^{a}$ via $-13-X I I-1732$.

de Francisco Retz al P. Gerónimo Herrán

P.C.

Sobre las graves faltas, que de algunos particulares me refiere assi V.R. como otros Sugetos de essa Prova . no puedo explicar bastantemte. mi sentimiento, y aflixion: assi por su gravedad en los que las cometen, como por la omision, y descuido de quienes las disimulan.No puedo ocular á V.R ${ }^{\mathrm{a}}$. mi desconsuelo en esta parte, y dexar de decirle, que el zelo, y entrega en algunos Superiores ha sido menos de lo que yo me esperaba, y pediam con su obligaon. los delitos de algunos Sugetos; y en que ve V.R ${ }^{\mathrm{a}}$. que ni sus Antecessores han zelado sobre estos con aquel cuidado debido á remediar sus faltas, y impedir que se propaguen en otros con el mal exemplo de los que las cometen, sin otro temor que el de vna reprehension dulce, y ligero castigo: y contentandose los Supes. con avisar al Genl. distante tanto Mundo, las faltas $\mathrm{p}^{\mathrm{a}}$ la correccion ó castigo, que siempre llegará tres, ó quatro años despues de cometida la culpa, quando esta merecia castigarse promptamte. A que sirve su autoridad, el consejo de sus Consultores, y su estrecha obligacion, sino á remediar promptamte. aquellas faltas, que en la dilacion de ir, y volver de Roma crecen no castigadas? Y quando el Genl. sobre ellas determina, se executa promptamte. lo determinado? Quisiera Ds. Fuesse assi, y que con su perniciosa omision, con su reprehendible disimulo, y que sé yo si por otros respectos, no fomentassen los Supes. los delitos, ó no castigando, ó no poniendo en execucion los castigos determinados de los Genles. No pretendo tengan los Provinles. en esta distancia vna tal potestad, como sus Subdito Juezes en lugar de Padres: digo solamte. que no $\mathrm{p}^{\mathrm{a}}$ todo se ha de esperar determinacion de Roma; digo que quando las faltas no sufren tan crecida dilacion, el Superor. aconsejado de sus Consultes. y según su dictamen, debe allá corregirlas, y no contentarse con solo avisarlas; y digo finalmte. que nada deseo mas en los Superes, que lo que es espiritu de la Comp ${ }^{\mathrm{a}}$ amor y compasion Padres respecto de sus Subditos: pero no descuido, y omission que nazca de falta de entereza $\mathrm{p}^{\mathrm{a}}$ castigar los delitos, que el amor, y correccion, y los avisos no pueden enmendar.

Paso ya á determinar sobre las causas que se me han avisado Vista la poca, ó ninguna enmienda del Pe. Ant ${ }^{\mathrm{o}}$ Ligoti, su reincidencia en faltas de honestidad, y su inobed ${ }^{\mathrm{a}}$. al Precepto de que no admitiesse Muchachos en su Aposento; ordené en mi Despacho de 14 de Abril de 1731: y que se executen assimismo en dho Pe. todas aquellas mas penas, que V.R . y sus $C$ Ces $\operatorname{Ord}^{\mathrm{o}} \mathrm{s}$, y ad graviora le ayan impuesto, y de que le ayan juzgado merecedor, según en dho Despacho determino, y atendiendo los fines, que en el prevengo: finalmte que sea puesto immediatamte. en reclusion, en la que estará el tiempo, que el maior numero de Votos de V.R . y sus CCes. ya dhos juzgue necessario $\mathrm{p}^{\mathrm{a}}$ la enmienda del 
Pe. y $\mathrm{p}^{\mathrm{a}}$ la publica satisfaccion: desuerte que si $\mathrm{p}^{\mathrm{a}}$ estos fines se juzgare necessario, que el Pe. esté perpetuamte. recluso, assi sin falta se executará.

Mi Antecessor inmediato conformandose con lo dispuesto por el $\mathrm{Rd}^{\mathrm{o}}$. Pe. Mucio Viteleschi, en Carta á esse Oficio de 1 de Mayo de 1716, á la duda, que de allá le propusieron, sobre que se avia de hazer con vn Professo incorregible, respondió; si no ay otro remedio, tenerlo recluso mientras no se enmienda: desuerte que si $\mathrm{p}^{\mathrm{a}}$ la constante enmienda no ay otro medio, que la perpetua reclusion, debe ser puesto en execucion este medio. Y ordenó assimismo su Paterd. que se executasse este medio con los PP Diego Lezana, y Joseph Gomez: yo me conformo con esta determinacion; en cuia consecuencia ordeno, que V.R . y los mismos CCes. vean, si $\mathrm{p}^{\mathrm{a}}$ la consecucion de aquel fin en dicho Pe. Joseph Gomez, y en el Pe. Bernardo de Villanueva, professor ai, ó no, otro medio, que recluirlos: si le ai, executese este medio; si no le ai sean luego recluidos, ó perpetuamte. ó tempus; todo según lo juzgare el maior numero de Votos. Y advierto, que no levanto, antes confirmo, y dexo en toda su fuerza, y vigor las demas penas ya impuestas á dhos. PPs. Ó por este oficio, ó por esse.

Embieseme el Tratado ad dimissionem del Pe. Joseph Benavides Coadj ${ }^{\circ}$ E Espirl. segun determiné en mi ya citado Despacho de 14 de Abril, y lo confirmo de nuevo.= No se señale jamás al $\operatorname{Herm}^{\circ}$ Guillermo Catalani $\mathrm{p}^{\mathrm{a}}$ alguna Administ ${ }^{\mathrm{o}} \mathrm{n}$ ó Procuracion: $\mathrm{y}$ apliquense todos los medios, que se pudieren, á fin que haga, y cumpla su deber, poniendolo en reclusion, si las reprehensiones ya publicas, ya secretas, y penitencias, que se le daran, no produxeren aquel fin: pero si nada bastare, embieseme el tratado ad Dimissionem. En los Stos. Sacrifs. de V.R . me encomdo. Roma, y Dicieme 13, de 1732.

De V.R.

Siervo en Chrô

Francisco Retz

$14^{a}$ carta $-2^{a}$ via $-13-X I I-1732$.

\section{de Francisco Retz al P. Gerónimo Herrán}

P.C.

El Segundo Recibo del pe. Jul de la Barrera en la Com ${ }^{a}$ fue no solamte. contra esta por nrãs Leyes establecido, y contra lo que en su Despacho de 28 de Abril de 1725 expresamte. determinó mi Antecessor de B.M.; sino aun contra lo que la misma razon natural propone: la qual aun en negocios de mucha menor importancia, como lo es el recevir en Religion, pide, que no se proceda á ciegas, sino con la previa luz de los suficientes, y necessarios informes: y estos se huvieran (como se debian) tomado de los PPs. del $\mathrm{Col}^{\circ}$ de la Rioja, donde vivio el Pe. Barrera lo mas, ó todo el tiempo, despues que fue de la Religion despedido, no dudo no lehuvieran recevido segunda vez: pues ni su mutabilidad, y inconstancia, ni el abandono de las Almas, que estaban á su cuidado, ni la irregularidad, y poco ajuste de costumbres, ni el no averle á esta causa querido recibir en las 
Religes. de Sto. Domingo, y Sn Franco. daban á ello lugar. No menos me desagradan las muchas consescendencias, que se vsan con este Pe. y los pocos medios, que se aplican, $\mathrm{p}^{\mathrm{a}}$ que sea el que debe, y quiere la Religion. Por todos estos motivos es mi voluntad, que nunca sea señalado este Pe. a enseñar Teologia, ni Filosofia, ni á los Nrõs. ni á los Externos: y si acaso ya estuviere señalado $\mathrm{p}^{\mathrm{a}}$ alguna de estas Catedra, immediatamte. será removido de ella: pues no ai en el Pe. las dotes, que se requieren, $\mathrm{p}^{\mathrm{a}}$ hazerlo con edificacion de los Discipulos, y credito nuestro. Por los mismos motivos nunca sea señalado ni $\mathrm{p}^{\mathrm{a}}$ algun Pueblo de las Doctrinas, ni $\mathrm{p}^{\mathrm{a}}$ las Missiones Circulares: mantengase siempre en Colegio, en que le sugete el peso de la Distribucion Religiosa, y zelo de los Superiores.

No han venido á este oficio las causas de los PP. Juan Ignacio Astudillo, y Segismundo Aperger Professos: Del $1^{\circ}$ se me dixo en el Despacho antecedte. que eran contra el varias delaciones de esse oficio, mas que el Pe. lo negaba todo, y de todo echaba la culpa á su Comp ${ }^{\circ}$ el Pe. $\operatorname{Ign}^{\circ}$ Ximenez: por el contrario este se justificaba, y culpaba, y decia horrores de aquel. En vista de estas noticias en mi ya citado Desp ${ }^{\circ}$ de 14 de Abril dixe á V.R ${ }^{\mathrm{a}}$. averiguase esta Causa, y hiziesse justicia. $=$ En las Cartas $3^{\mathrm{a}}$, y $7^{\mathrm{a}}$ deste presente Despacho me dice V.R . que este Pe. vivio mui a con escandalo en los Pueblos de Ytapua, y Sn Joseph: á cuia causa, y por su descuido, y omission en lo temporal, y por las limosnas, que imbiaba al $\mathrm{Col}^{\circ}$ de Cordova, y á varios particulares avia dexado en mucha pobreza á ambos Pueblos. No me dice V.R ${ }^{\mathrm{a}}$. si esto consta en virtud de las delaciones solas, ó en virtud de la justificacion, que de todo ello se ha hecho.

Contra el Pe. Aperger se escrivio de esse oficio a via varias delaciones en punto de honestidad: mas que aun no estaba esta Causa justificada. En virtud de estas noticias determiné sobre esta Causa lo mismo, que sobre la del Pe. Astudillo. En las Cartas de este presente Despacho se me dice, que el Pe. Jul de Anaya en virtud de orden de el Pe. Provl. hizo la debida averiguacion de esta Causa, y tambien el pe. Joseph Ynsaurralde Sup ${ }^{\circ}$. de las Missiones; y de la vna, y de la otra resultó el pe. Aperger Reo de mui graves, y escandalosos delitos: y concluien. En mui poco se distinguen esta Causa, y la del Pe. Ligoti?= Que el Pe. Ign ${ }^{\circ}$ de Arteaga removio por esta causa á este Pe. de las Misiones; y que sin embargo V.R ${ }^{\mathrm{a}}$. le avia restituido á ellas, y hecho Cura del Pueblo de Sn Lorenzo, con grave dolor, y aun escandalo de no pocos, viendo premiados los delitos, y sin el castigo, que se merecen: finalmte. que los motivos de V.R ${ }^{\mathrm{a}}$. parece fueron que el Pe. Rillo en los ultimos dias de su vida dixo, que era calumnia quanto se decia contra el Pe. Aperger, y que los dichos de los Yndios no prueban.

El primer motivo me avisan es increible, y que no puede nacer de otro principio, que de aver sido informado siniestramte. V.R . pues el Pe. Rillo siempre estuvo en el juizio contradictorio. $=\mathrm{El}$ segundo no subsiste ciertamte, pues conque otros testigos, que los Yndios, quiere V.R ${ }^{\mathrm{a}}$. se averiguen las faltas, que se hazen en las Missiones. Cosa debida es, que en las averiguaciones (y lo mismo en las declaraciones) se proceda con prudencia, y con cautela: mas puestos estos medios, es preciso estar á lo que los Yndios deponen; pues ni ai otros, de quien valernos, ni otro medio $\mathrm{p}^{\mathrm{a}}$ averiguar la verdad: $\mathrm{y}$ es menor inconveniente que en algun caso particular el inocente parezca, que dar lizencia con la falta del castigo á que en las Doctrinas viva cada uno como fuere su voluntad. En vista de todo esto sin otra dilacion saque V.R . de las Doctrinas á dhos PP. Astudillo, y Aperger, y nunca los vuelva á ellas: y lo mismo se executará con toda aquella, que en materia de honestidad,

287 Carlos A. Page. Las cartas de los generales... a la provincia del Paraguay... 259-322. 
estuvieren notados, y indiciados con bastante fundamto. Assimismo V.R. y sus CCes. en las Causas anteriores juzguen las de estos dos PPs. si tienen, ó no alguna cosa en su favor, que deshaga, ó disminuya la Causa ó todo, ó en parte: y executese sin dilacion lo que en vista de todo sentenciare el maior numero de votos, y de ello se me dará aviso. En los santos Sacrifs. de V.R. me encomd ${ }^{\circ}$. Roma, Dicieme. 13, 1732.

De V. R .

Svo.en Chrô

Francisco Retz

$15^{a}$ carta $-2^{a}$ via - 13-XII-1732.

de Francisco Retz al P. Gerónimo Herrán

P.C.

En la $3^{\text {a }}$ Carta de mi ya citado Despacho de 14 de Abril dixe á V.R ${ }^{a}$. las faltas que se me avisaban de los PPs. Rodrigo Perez. Ignacio Ximenez, Anselmo Mata, y Jacobo Vancutsen: las que se me decia, que á pocas diligencias se probarian con muchos oculares testigos en los Pueblos de las Doctrinas, en que avian dichos PP. residido: en vista de lo qual dixe á V.R ${ }^{\mathrm{a}}$. averiguasse lo que avia en esto, y procediesse según razon, y justicia: si por no estuviere hecho executelo V.R ${ }^{\text {a }}$ luego assi, paraque no se queden sin castigo. Del Pe. Jul de casas se avisaron estas faltas: mucha libertad en la lengua aun contra los Superiores; sobrada especulacion de quanto sucede en Casa con grave ofensa de todos, y que por estas causas no cabia el Pe. en ninguna Parte; finalmte. menor observan ${ }^{\mathrm{a}}$. No me dice V.R . nada sobre este particular: por tanto yo le encargo averigue lo que en esto ai: y execute lo que delante de N.S. juzgare correspondte. á los meritos de la causa, atendiendo assi al bien publico, como al particular del Pe. Casas.

Por el motivo, que me dice V.R ${ }^{\mathrm{a}}$. me parece bien se removiesse al Pe. Joseph de Matos del $\mathrm{Col}^{\circ}$ de Salta al de Santiago del Estero: y supongo, que no se le dio al Pe. el Grado, que le corresponde, y yo le imbie en mi ya citado Despacho, siendo necessario, que dé primero el Pe. una mui cumplida satisfaccion á Ds. y á la Religion; desuerte que esta pueda prudente. juzgar, que su Rev ${ }^{\mathrm{a}}$. está ia reconocido, y enmendado, y que en adelante procederá con la debida religiosidad. $\mathrm{VR}^{\mathrm{a}}$. y sus CCes. ya dichos vean, y juzguen esta Causa, y señalen á el Pe. las penitencias correspondientes; desuerte que quede corregido, y satisfecha la Religion. Y si el Pe. las rehusare, sea puesto inmediatamte. en reclusion, y embieseme el Tratado ad Dimissionel; pues los inobedtes. no pueden tolerarse en la Religion.

Tengo noticia de que tiene sus exenciones, y nulidades el Sugeto, que informó á V.R ${ }^{\text {a }}$ lo que me avisa del Pe. Thomas Gonzalez, Rr. que fue de Tatija; y que á su dicho no se debe dar entero credito V.R ${ }^{\mathrm{a}}$. averiguelo bien, y si hallare, que es cierto, en nombre mio de al Pe. Gonzalez una mui grave reprehension, significandole el gran dolor, que me causa, que vn Jesuita use del Pulpito no $\mathrm{p}^{\mathrm{a}}$ los fines, que debe, y quiere N.S. sino para lastimar 
Familias, vengar, y satisfacer sus pasiones previniendoleal mismo tiempo, que se (lo que no espere en semejante falta reincidiere, haré en el vn castigo exemplar.

Sin embargo de la enmienda, que se reconoce en el Pe. Xptovl. de Cordova; $\mathrm{p}^{\mathrm{a}}$ que no reincida, $\mathrm{y} \mathrm{p}^{\mathrm{a}}$ que proceda con maior edificacion deben velar sobre el los Superiores, vsando $\mathrm{p}^{\mathrm{a}}$ aquellos fines de los medios, que quiere, y practica la Religion: y lo mismo se executará con el Herm. Rivarola. Finalmte. me parece bien, que á los PPs. Alexandro de Villavieja, y Francisco Vzedo, removidos por inutiles de las Missiones, se les aya señalado en los $\mathrm{Col}^{\circ} \mathrm{s}$ ocupacion.

El Hmo. Sr. Dn Jul de Sarricolea, y Olea Obpõ de Tucumán me pide liz ${ }^{a} p^{a}$ ser recevido en la Comp ${ }^{\mathrm{a}}$ y hazer los Votos Religiosos en la hora de la muerte, precediendo, como supongo, el beneplacito de la Sta. Sede, cuia solicitacion me dice su Yma. encargó á los PP. Procures. de essa Prov ${ }^{a}$. Esta misma liz de ser recevido en la Comp ${ }^{a}$. y hazer los Votos Religiosos en la hora de la muerte me pide $\mathrm{p}^{\mathrm{a}}$ si mismo el Sr. Dor. Dn Ju Gonzalez Melganejo, Dign ${ }^{\circ}$ Chantre, y $\mathrm{Can}^{\circ}$ de Paraguay. Concedo estas dos lizanzias: en esta inteliga ${ }^{a}$ V.R ${ }^{\mathrm{a}}$. dará las provid ${ }^{\mathrm{a}} \mathrm{s}$ necessarias, para que llegado aquel caso una, y otra voluntad se ponga en execucion. En los Stos. Sacrifs. de V.R ${ }^{a}$. me encomdo. Roma, Dicieme. 13, 1732.

De V. R ${ }^{\mathrm{a}}$.

Svo.en Chrô

Francisco Retz

16 carta - $2^{a}$ via - 13-XII-1732.

de Francisco Retz al P. Gerónimo Herrán

P.C.

Los PP. Procures. no han traido ni las Ynformaes. ad gubernandum, ni los Catalogos todos, ni las Annuas de esta Prov ${ }^{\mathrm{a}}$. solamte. han traido las Propuestas de V.R ${ }^{\mathrm{a}}$. y sus CCes. $\mathrm{p}^{\mathrm{a}}$ el Gobierno: y algunas de estas con tan poca formalidad, que solamte. me proponen Sugetos $\mathrm{p}^{\mathrm{a}}$ el Gobierno de la Provin ${ }^{\mathrm{a}}, \mathrm{Col}^{\mathrm{o}}$. y el Noviciado de Cordova, $\mathrm{p}^{\mathrm{a}}$ las demas á ninguno determinadamte. me proponen: solamte. me dicen en general, y me hazen un Catalogo de los aptos $\mathrm{p}^{\mathrm{a}}$ gobernar. A esta falta acompaño otra de no menor consideracion, porque se me avisa, que el Antecessor de V.R ${ }^{\mathrm{a}}$. Pe. Lorenzo Rillo tenia ya dispuestos todos estos Papeles, ó en el todo, ó en la maior parte: pero muerto su Reva , el Pe. Ministro del $\mathrm{Col}^{\circ}$ de Cordova los quemó todos. Yo estraño notablemte. estas faltas: la primera, porque yo no tengo otra luz $\mathrm{p}^{\mathrm{a}}$ el Gobierno de las Provin ${ }^{\mathrm{a}} \mathrm{s}$. que los informes, instrumentos, y papeles, que me imbian de estas; y si estas faltan, nada puedo yo hazer. La segunda, porque los Papeles tocantes, al oficio, y Gobierno de Provincia no pueden ser registrados por otro, que por el Provl. ó su Compañero. Este como se le ordena en la ultima de sus Reglas, debe cerrar, y sellar quantos escritos tocan al Provl. y á su oficio, $\mathrm{p}^{\mathrm{a}}$ entregarlos despues al Sucessor: y no hallandose este su Comp ${ }^{\circ}$ en la Casa, que el Pe. Rillo murio, sino en otro 
$\mathrm{Col}^{\circ}$. debieron sin duda guardarse todos, y entregarse al nuevo Provl. Creeré no procedido el Pe. Ministro de malicia, sino con sana intencion: mas digasele lo que se debe en caso semejante hazer; y pongase todo cuidado, que no se cometa mas ni una, ni otra falta. $=$ Con esta ocasión encargo á V.R ${ }^{\mathrm{a}}$. recoja, y ponga en su Archivo varios Papeles, que me escriven andan esparcidos por algunos aposentos, como son Cartas de los PP.GG. y otras pertenecientes á el Gobierno. Y á la verdad, si esto es assi es un descuido mui pernicioso, y como tal digno de una reprehension mui severa. Finalmte. el Pe. Provl. quando dexa su oficio, debe entregar á su Sucessor inmediatamente todos los Papeles, que el oficio pertenecen, sin reservar ninguno en si. Nada de esto era necessario advertir; pero ai quexas, y por esso lo advierto.

La diversidad de pareceres en las Propuestas $\mathrm{p}^{\mathrm{a}}$ el Gobierno aun respeto de cada Casa, no pocas vezes es tanta, quantas son los Sugetos, que me escriven, y dicen su parecer: y mal podré yo con essa confussion de informes señalar el Sugeto, que conviene, aun despues del no pequeño trabajo de revolver Cartas, Registros, Ynformaciones y Catalogos anteriores. Y deseando, que se pongan los medios mas proporcionados $\mathrm{p}^{\mathrm{a}}$ el muerto en cosa tan del todo grave; es mi voluntad que las Propuestas $\mathrm{p}^{\mathrm{a}}$ el Gobierno de la Prov ${ }^{\mathrm{a}}$. y de las Casas principales, se me hagan como hasta aora, literis separatis: mas en orden á los $\mathrm{Col}^{\circ}$. pequeños V.R ${ }^{\mathrm{a}}$., y sus CCes. $\mathrm{Ord}^{\mathrm{o}} \mathrm{s}$. y ad graviora, leidas ante todas cosas las Informaciones de los Sugetos, que se discurre proponerme; y conferidos los fundamtos. que á cada uno se le ofrecieren por una, y por otra parte, y satisfechas las dificultades, y convenidos V.R . $^{\mathrm{a}}$ proponganme en la terna que á maior numero juzgaren á proposito. Si V.R ${ }^{a}$. que tienen ai presentes los Sugetos, y las circunstancias necessarias, no se convienen, como lo haré yo con tan diversos informes, y sin fundamtos. de preferir un dictamen á otro?

Concedo á los Sacerdotes de essa Prova a assi á los que de presente lo son, como á los que en adelante lo fueren, los privilegios siguientes: de poder rezar del Ssmo. de Concep ${ }^{\circ} n$. de N.S. Pe. de Sn. Xavr. segun nrõs privilegs. y en la forma, que nos está concedido por la Sta. Sede; el de la Indulga del Crucifixo por los Moribundos; y sacar una Anima de Purgatorio por cada una de las Misas, que celebraren. Se me dice, que el Herm ${ }^{\circ}$ Andres Astina es Mayorazgo: si esto es assi, sea luego promovido á la Profession solemne de tres Votos, reciviendo antes V.R ${ }^{\mathrm{a}}$. las Informes. acostumbradas, y confiriendolas con sus CCes. y no resultando cosa en contra. Este Grado recevirá V.R ${ }^{a}$. ó señalará quien lo reciva en mi nome. $=$ Me dicen , que el $\mathrm{Col}^{\circ}$ de Buenos Ayres ai quatro Negros, que se llaman Christoval; Domingo, que fue Capataz en Areco; Bartolome, que es Sastre; y Luis: todos los quales ademas de gravissimos daños á nrãs Haziendas en mui crecidas Cantidades, son de tan malas costumbres, que son el escandalo de la Ciudad, con no pequeño descoro nuestro: sin dilacion sean vendidos todos quatro por el precio, que se pudiere: y si no se encontrare Comprador, deshagase de todos quatro el Colegio, dandoles Carta de Libertad, siendo el informe verdadero.

La Sra. Da. Josepha Rosa de Alvarado hija, y heredera de los Fundadores de la Novena de Sn Xavier en el $\mathrm{Col}^{\circ}$. de Buenos Ayres, se quexa de que aviendo su Pe. dispuesto en su testamto., que mientras ella viviesse, continuasse haziendo dha Novena; y aviendo executado assi hasta aora con el esmero, y devocion, que ha podido; sin embargo parece se le quiere privar deste consuelo: por quanto en la Escriptura de imposicion á Censo de los 30 Pesos de Capital se dire, que el Censualista sea obligado á pagar cada año

290 Carlos A. Page. Las cartas de los generales... a la provincia del Paraguay... 259-322. 
al $\mathrm{R}^{\circ} \mathrm{r}$ de aquel Colegio los redditod correspondientes $\mathrm{p}^{\mathrm{a}}$ hazer la Novena. Executese á la letra la voluntad de los Fundadores, y no se dé á esta Sra. justo motivo de sentimto.

Las singulares, y continuadas finezas, que el Ilmo. y Revmº. Sr. Dn. F. Joseph Palos se sirve hazernos, nos precissan al mas sincero reconocimto. y aunque le supongo en todos los Sugetos de essa Prova; todavia significo á V.R ${ }^{\mathrm{a}}$. mis intensos deseos de que en quanto sea posible se procure á su Ilma. complacer. Yo quedo con el cuidado de escribir al Pe. Confor. de su Magd. Cath' ${ }^{\mathrm{a}}$. Haga presentes assi á su Magd. como á los Sres. Minrõs los meritos de esse Ilmo. Prelado, $\mathrm{p}^{\mathrm{a}}$ que sea promovido á otra Sup ${ }^{\circ}$. Silla: y lo mismo esciviré al Pe. Proc ${ }^{0}$ r. de Yndias en Madrid. En los Stos. Sacrifs. de V.R ${ }^{\mathrm{a}}$. me encomdo. Roma, Dice. 13 de 1732.

De V.R

Svo.en Chrô

Francisco Retz

$17^{a}$ carta $-2^{a}$ via $-13-X I I-1732$.

de Francisco Retz al P. Gerónimo Herrán

P.C.

En esta, dripnes de dar á V.R ${ }^{\mathrm{a}}$. ms. gras. por el zelo, y aplica ${ }^{\circ}$. con que ha gobernado essa Prov ${ }^{\mathrm{a}}$. paso, porque ya es tiempo, á señalar nuevo Gobierno. Y ante todas cosas renuevo, y confirmo las ordenes, y preceptos puestos en los Despachos antecedentes, de no alterar, ni immutar, estas disposiciones, sino en los casos, y circunstancias de muerte de alguno de los nombrados, ó de legitimas razones, que á juizio de el maior numero de Votos de V.R ${ }^{\mathrm{a}}$. y sus CCes. odin ${ }^{\mathrm{o}} \mathrm{s}$. y ad graviora sean tenidos por suficientes $\mathrm{p}^{\mathrm{a}}$ no entregar la Patente al Sugeto, que se trata: y en este caso ordeno,y declaro debe proseguir el Antecessor nombrado por este oficio, si por mi no es promovido á otro nuevo Gobierno; ó que no aya en el antecedente satisfecho á maior numero de Votos de V.R . y sus CCes. $\mathrm{Ord}^{\circ} \mathrm{s}$. y ad graviora. Assimismo renuevo, y confirmo las Ordes. y Preceptos puestos acerca de la solemnidad, con que deben guardarse los Casus mortis, y quemarse cerrados, y sellados los antiguos. $=$ Vistas las Ynformaciones ad Gubernandum del año 1723, que son las mas recientes, que aquí ai; los informes, y noticias, que de essa Provincia han venido á este oficio, y consultado todo con los PPs. AA. será

Provincial de essa Prova ${ }^{\mathrm{a}}$ de Paraguay, Pe. Jaime Aguilar.

Rr. del $\mathrm{Col}^{\circ} \mathrm{Max}^{\mathrm{o}}$ de Cordova, Pe. Miguel Lopez.

Rr. del Noviciado, Pe. Ant ${ }^{\circ}$ Machoni: y si se excusare; el Pe. Ant ${ }^{\circ}$ Alonso.

Rr. del $\mathrm{Col}^{\circ}$ de la Asumpcion, Pe. Jul Joseph Rico.

Rr. del Colo de Buenos Ayres, Pe. Geronimo Herrán.

Rr. del $\mathrm{Col}^{\circ}$ de santiago del Estero, Pe. Ignacio Joseph de Ledesma.

291 Carlos A. Page. Las cartas de los generales... a la provincia del Paraguay... 259-322. 
Rr. del $\mathrm{Col}^{\mathrm{o}}$ de Santa Fé, Pe. Miguel Benavides.

Rr. del $\mathrm{Col}^{\circ}$ de Salta, Pe. Geronimo Zeballos: avisandole primero corrija las faltas de maior aficion á sus Parientes, y menor amor á los de Europa, como se dice en sus Ynformaciones.

Rr. del Col ${ }^{\circ}$ de Tucumán, Pe. Raphael Cavallero.

Rr. del Col${ }^{\circ}$ de la Rioja, Pe. Joseph Astorga.

Rr. del $\mathrm{Col}^{\circ}$ de Tarija, Pe. Lucas Zavala.

Rr. del $\mathrm{Col}^{\circ}$ de Corrientes, Pe. Ignacio Perez.= Para todos imbio Patentes, que les encargará V.R ${ }^{\mathrm{a}}=$ Superior de las Misiones de el Paraná, y Uruguay, Pe. Bernardo Nusdorfer: y en su defecto, el Pe. Francisco Garsia.= Superior de las Misiones de los Chiquitos, Pe. Sebastian de Sn Martin: y en su defecto ó el Pe Bartolome Mora, ó el Pe. Agustin de Castañares, ó el Pe. Francisco Lardin. Compañero del Provinl. Pe. Pedro Arroyo, Pe. Gabriel Novat.= Consultores Ordinarios, PP. Rr. del Col ${ }^{\circ} \mathrm{Max}^{\circ}$. ${ }^{\circ}{ }^{\circ}$. del Noviciado, Pe. Ygnacio Arteaga, y el Compañero del Provl.= Ad graviora Pe. Lusi de la Roca, Geronimo Herran, y Antonio Machoni, si no acepta el Gobierno del Noviciado: pero si lo acepta, lo será el Pe. Antonio Alonso.= Deses toda felicidad á essa Provincia, y que N.S. eche su Bendicion sobre este nuevo Gobierno. En los Stos. Sacrifs. de V.R ${ }^{\mathrm{a}}$. me encomd ${ }^{\mathrm{o}}$ Roma, Dicieme. 13, de 1732.

De V.R ${ }^{\mathrm{a}}$.

Svo.en Chrô

Francisco Retz

$1^{a}$ carta $-1^{a}$ via $-1^{o}-I V-1734$.

de Francisco Retz al Pe. Provincial

P.C.

Suponiendo estará ya VR en posse ${ }^{0} \mathrm{n}$ de su oficio $\mathrm{p}^{\mathrm{a}} \mathrm{q}$ con tanto gusto mio le señale, como confianza tengo de que desempeñará su zelo, y prudente entereza la que VR he echo, porndré en su noticia mi respuesta á cinco cartas de su Antecessor, que con fecha 15 de $\mathrm{Agt}^{\circ}$ de 1732 recibo. Vienen con ellas el Cathalogo anuo, y suplemento de el Publico de dho año; algunas Censuras ad Professionem; Informaciones ad Gradum; de que hablaré despues; y las causas de Dimision de $\mathrm{Ju}^{\circ} \mathrm{Franc}^{\circ}$ Sanchez estudiante, y de Dn. Joseph Vsedo Presbytero, despedidos ya dela Compa $p^{\mathrm{a}}$ lo que doi por bien echo, y ordenaba se hiziere con el segundo en mi Despacho de 13 de Dize. de 1732. He leido assi en las Cartas de el Pe. Herran, y de otros sujetos de essa Prova, como en las de el Ilmo. Señor Obispo dela Assumcion la segda. Rebellion de essa Prov $^{\mathrm{a}}$, y expulsion de los nrõs el dia 19 de Febro de 1732 dela Ciudad y $\mathrm{Col}^{\circ}$ dela Assumcion: con una extensa relacion de quanto executó aquel Commun contra nosotros, y de quanto hemos debido en este lanze al Ilmo. Sr. Obispo. Y si bien los sucedidos males, y los que se temian en las Corrientes y demas lugares de esse $\mathrm{Rn}^{\circ}$ me dexan bien aflixido, y mas cuidadoso asta saber con certez 
a, se hansossegado essos animos; el dezirme todos que de nuestra parte ninga ${ }^{\mathrm{a}}$. causa se ha dado y que antes se han portado los Nrõs con la tolerancia y humildad correspondiente á hijos dela Comp ${ }^{a}$ me ha servido deespacialissimo consuelo, y de augmentar mi confianza en Nrõ $S^{o}$ r., para esperar de su piedad el remedio de estos males. Las providencias que en estos dió el Pe. Ger Herrán, y especialmente las que fueron tan oportunas á impedir la invasion, que en nrãs Missiones se intentaba; parecen (quanto en esta distancia puede juzgarse) muy prudentes, y acertadas. Yo espero hazer el mismo juizio delas que para el mismo fin avrá dado VR, por las que dará para todas las ocurrencias, de continuar la rebellion, ó de restituirse los Nuestros ala Ciudad, y $\mathrm{Col}^{\circ}$, quedando persuadido dela Religiosidad de todos, y dela Vigilancia de VR en este punto, que no permitirá abusen de su misma innocencia, $\mathrm{p}^{\mathrm{a}}$ triunfar vanamente de quienes ahora los persiguen, ni darán el mas minimo motivo de quexa á nrõs emulos: y cuio empeño en hazernos mal ha de vencerse con el recurso de Dios, y con maior empeño en hazerlos bien, y servirles con maior amor, que antes. Lo contrario sobre ser muy ajeno de las Leyes de la Charidad, y delas que observa la Compañía, volveria á encender el fuego y á renovar en mi la presente afliccion, obligandome, como lo executaré promptamte. á el merecido castigo. Mas espero que á este no me dará lugar el zelo de $\mathrm{VR}^{\mathrm{a}}$.

La conversion de los Chiriguanos, que a instancia delos mismos, y por suplica dela Ciudad de Tarija, encomendo á la Compa el Sr Vi-Rey, y Rl Audiencia delas Charcas, y de que tengo en mi poder Copias; assi como deseo se logre, y que se funde esta Mission con mejor successo, que el q asta ahora ha tenido, assi deseo no la malogre el contrario genio, que á ella han mostrado algunos. No duda seran tan bravos como alguno los pinta, describiendo la muerte que dieron a tres Religiosos y amenazaban dar á los dos sujetos nrõs; que han repugnado siempre a la $\operatorname{predica}^{\circ} \mathrm{n}$ de el Evangelio; y que solamente el desecho de esta Nacion era lo que estaba á nrõ Cargo, quedandose en la infidelidad lo mas florido de ella. Mas supuesto que nuevamente claman por Predicadores de el Evangelio, y que vnicamente á la Compañía se encomienda esta Conversion (a que no debio negarse el Pe. Herran) con exclusion de otros Religiosos, aun que sea con la sola esperanza de volver á ganar aquel derecho, y ovejas, que una vez fueron de la Iglesia, se debe emprender esta Mission con empeño. No oiga yo lo que a mi Antecessor escrivio alguno, con mas ardor en este punto que estima de essa Prova; diciendo, que ella miraba como reprobos a los Chiriguanos, y de el todo los abandonaba. Aunque nose sacasse mas fruto, que el que me consta se sacaba, de que los niños que morian, iban bautizados, bastaba esto solo para volver ahora con esperanza de el mismo y mayor fruto. A la ferocidad de sus Naturales sobre las Providencias, que daria el Pe. Herran, y que avrá dado VR para seguridad delos Nrõs; y delos que se convirtieren a la feé; no poco cuidará para domesticarla, el ser solos los Jesuitas quienes los traten y enseñen: lo que si se ahze con el amor, y Charidad debida y con alguna mas espera de su emmienda, que en los tiempos passados; puede esperarse no se huian á los montes, y Gentilidad, como han echo otras vezes. La embriaguez vicio tan connatural de los Indios, quanto mas dificil de vencerse en los Chiriguanos, tanto pide maior espera en la emmienda y medios á conseguir esta, que obliguen, no que irriten sus animos: y bien se sabe quantos años duraron incorregibles los Chiquitos en este vicio, aun con ser de mas docil indole, que los Chiriguanos: ni la de estos me persuado, sea tan incorregible como se dize; pues si es cierto lo que se informa, de que todos ó muchos de los que teniamos avian dexado la multiplicidad de sus mugeres, quienes enfrenaron su 
impureza, corregirán la embriaguez. No quisiera tampoco pudiera impedir á los buenos successos de esta Mission el amor á la de los Chiquitos, y el deseo de consensuar, y conservar las possessiones de estos, acaso con lo que nos suio. Digo esto, porque mi Antecessor de B.M. en su Despacho de 14 de Mayo de 1721 al Pe. Joseph Aguirre Provl. de essa Provincia ordenó, que se restituiessen a esta Mission ciertas Casas en Potosi, y en la Estancia de las Salinas, si era assi lo que le informaban, de aver la Rl Audiencia dado para dicha Mission las tierras Realengas, que para la misma se pideiron, y de que estuvo en possession asta la sublevacion delos Chiriguanos, en que se aplicó á los Chiquitos dha estancia con todos sus Ganados; mas que aviendo vuelto los Chiriguanos segunda vez á pedir Ppes., y formarse de echo reduccion, el Pe. Cea Provl. por el amor, que tenia á los Chiquitos, no quiso se restituiesse la estancia, que tanto necessitaban los PPes. é Indios de esta nueva Mission, como de justicia se les debi, y avia ordenado el Pe. Roca Provl. se restituiessen. Ordenó su Pat ${ }^{a}$ demas de esto, que fuesse restituida con todas sus Vacas Mulas, y Aperos, como la entregó el Pe. Castañeda, y que si en algo se avia defraudado, se compensase enteremte. el daño. En 28 de Abril de 1725 volvió su Paterna á tocar este punto, y lo repitio en 22 de Junio de 1726, mostrando su deseo de que se huviessen ya adjudicado dhas tierras, y estancia á los Chiriguanos. Siendo todo esto assi, y que la justicia parece que está á favor de estos, ordenó á VR, que siendo verdad el informe, se restituian á los Chiriguanos las Casas en Potosi, y la dicha estancia con todos sus aperos, vacas, etc, como ordenó mi Antecessor; pues basta ya lo que la han desfrutado los Chiquitos, y por quienes ninguna razon me proponen para gozar lo que por muchos informes se me dize, es proprio de los Chiriguanos. En los Stos Sacrificios de VR me encomiendo Roma y Abril $\underline{1}^{\mathrm{o}}$ de $\underline{1734}$.

De VR

Siervo en Xpto

Francisco Retz

$2^{a}$ carta $-1^{a}$ via $-1^{o}-I V-1734$.

de Francisco Retz al Pe. Provincial

P.C.

De el comun de essa Prov a y sus Missiones me informa bien su Antecessor de VR, pero con mas concisio de la que yo esperaba, especialmente en punto de Missiones, sobre que tengo pedidas individuales noticias. No obstante en vno, y otro se me participan algunas cosas, que necessitan de prompto, y eficaz remedio. No creiera llagara el Caso tantas vezes amenazado de este oficio de obligar con Precepto á los Nrôs á no dar pareceres á los Seglares sobre sus Pleytos: pues sobre lo ofensivo, que esto es de suio, lo reparable, qye ya se ha hecho aun en los Tribunales y Audiencias, lo que fomenta, y presentemente ha fomentado discordias y dissensiones en Casa, según las diversas Partes, á que cada vno favorece; el ser una cosa tantas vezes, y tan seriamente encomendada de mis Antecessores, se merecia otra atencion, y respeto, que el que asta aquí se ha tenido: mas no viendose este, 
y continuado la misma falta, ordeno á VR, que en todas las Casas, Residencias, ô Reducciones de essa Prov a ponga á todos los Nrôs Preceptos de Sta Obediencia, pena de pecado mortal, para que ninguno en adelane de su parecer, ô dictamen en los Pleytos delos Seculares, ô sea in scriptis de mano propia, ô agena; ô sea in voce, y de palabra instruiendo, y dirigiendoles en sus pleytos, sino es precediendo la aprobacion de la $\mathrm{m}^{\circ} \mathrm{r}$ parte de los Consultores de la casa, que en su Consulta examinarán delante de Dios, si conviene a su Gloria, y al bien de la Compañía dar el dictamen, que se pretende en todas circunstancias, y si no se temen ô todos, ô alguno de los inconvenientes dichos: entendiendose con el nombre de Pleytos de Seglares quantos no son de essa Prova ${ }^{a}$, de sus Casas, e intereses. Y quito á todos los Provinciales, y Visitadores la facultad de dispensar, ô abrogar este precepto, que á mi yá mis Successores reservo. Con esta ocasión prohibo con Precepto de Santa obediencia en essa Provincia quanto sobre las Lites forenses prohibió sin precepto la $S^{\mathrm{a}}$ Congrega $^{\mathrm{o}} \mathrm{n}$ General decr ${ }^{\circ}$ 13: cuia Observancia en este punto nuevamente encomendada en la 16. Congreg ${ }^{\mathrm{o}} \mathrm{n}$. Genl. decr ${ }^{\mathrm{o}} 31$ dexo comprehendida debaxo de el mismo Precepto en quanto sobre ingerirse en pleytos seculares supone ya prohibido, y virtualmte. prohibe dho Decreto31. mas no obligo con Precepto a los Superiores á castigar a los delincuentes, como alli se les ordena y establece. Assi se obviará á tantas quexas, y se atenderá al justo zelo de tantos como me piden esta determina ${ }^{\circ} n$.

Estraño no menos lo que se ha executado en el $\mathrm{Col}^{\circ}$ de Cordova, haziendo ubo de los Nrôs el testamento devna Señora, que dexó en el algunos esclavos a dho $\mathrm{Col}^{\circ}$, y que escrito de mano devno Nrô (bien conocida en la Ciudad su letra) se presentó despues authorizado de escrivano publico ante el Juez para entrar en la herencia de el legado. Y mucho mas estraño que Reprehendiendo el Pe. Provl. este hecho, como contrario á nrô Instituto, y á la Regla 28 de los Sacerdotes; huviesse Consultor de Prova que le respondiesse, no estaba prohibido un tal modo de hazer testamentos, ni ser esta la inteligencia de dha. Regla: la que con esta ocasión me pide dho Pe. Herran declare yo en este punto. VR significando á esse Consultor mi sentimto, y la dissonancia, que me ha hecho dictamen, dira al mismo, y lo hara saber á todos, que el hazer en este modo los testamentos lo declaro por contrario al espiritu, ê inteligencia de el Instituto, y de dha Regla 28 de los Sacerdotes, a que de hecho se ha contravenido en este caso. Ni necessitaba de explica $^{\circ}$ el Instituto y Regla dicha, si en ella se atendiesse, solo no solo alo que intenta prohibir según el espiritu dela Comp ${ }^{\mathrm{a}}$, y no precisamte. alo que dize en su corteza: no pudiendo dudarse prudentemte, que á quienes se prohibe assistir á los testamentos de los Seglares moribundos, se entienda prohibido, aun con maior razon el hazer y formar dhos testamentos, escrivirlos de mano propria, y para el fin de disponer assi el testamento ô legado á nrô favor, como en este caso se ha hecho: lo que siendo tan detestable al desinteres, que desea la Compañía, yá quitar toda sospecha de codicioso proceder; es aun mas visible este fin en el caso dicho, y no tan temeraria la sospecha, que debiera prudentemente huirse. Espero, no se repita tan feo caso en essa Prov ${ }^{\mathrm{a}}$, y que no me veré precisado á prohibirlo con Precepto, como executaré al primer aviso, castigando con severissimas penas á los delinquentes.

Muy creible se me haze entre causas que puede aver para fomentar essa aversion tan comun ala Comp ${ }^{\mathrm{a}}$ en toda essa Prov ${ }^{\mathrm{a}}$ no solo la que ya he dicho sobre pareceres en Pleytos seculares; sino tambien la que se me dize de costosas ê inutiles compras de Haziendas ô possessiones, que se hazen, sin necessitarlas los Colegios, ni tener mas fin en ellas, que ô el 
de hazer vanissima ostentacion de riqueza, ô el de impedir la compren otros, cuia vezindad no se quiere: sacrificando á estos bienes las vantas de los Colegios en compras, ô poco fructuosas, ô deel todo inutiles. A esta causa si que puede el $\mathrm{Col}^{\circ}$ de Cordova atribuir el detrimento y atrassos, que tantos años ha padece, y que como effecto de continuados malos años se escrive a Roma con menor sinceridad. A sus compras de tierras pocos años ha contiguas ala estancia de Jhs Maria poco utiles, y de que nada necessitaba; ala compra de una estancia de Sta Cathalina con terco empeño, y oposicion á un Cavallero, que queria comprarla, asta hacernos el objeto de satyras, y papelones por este caso, con escandalo no poco de la Ciudad. La experimentada sinceridad de quien en esto me informa no me da lugar á dudar de la verdad, y á conozer necessita de remedio vn tal desorden. $V^{a}$ en nombre mio intimará por escrito en todos los Colegios y casas de essa Prov a el siguiente orden, que inviolablemente se observará, y sobre que $\mathrm{VR}^{\mathrm{a}}$ y sus successores deberán zelar. Ordeno pues, que desde oi en adelante qualquiera $\mathrm{Col}^{\circ}$, Residencia, ô Casa nrâ que según su obligacion y cargas tuviere bastante $\mathrm{p}^{\mathrm{a}}$ cumplir con ellas, y mantenerse con religiosa decencia los nuestros, haziendose el computo por el espacio y tiempo de diez años, no pueda comprar hazienda, Possession, ô bienes algunos raizes sin consulta de los Consultores Ordinarios y ad graviora, y expressa licencia in scriptis de el Provl, para qual quiera de estas compras. Si en dha Consulta á $\mathrm{m}^{\circ} \mathrm{r}$ num ${ }^{\circ}$ de votos se juzgare que el $\mathrm{Col}^{\circ}$, ô Casa tiene bastante para vivir con decencia por espacio de diez años los nrôs, y cumplirse con la fundacion; y que no le son necessarios (aunque le sean utiles) nuevos bienes; en este caso ordeno estrechissimamente a los Provinciales ô Visitadores, que por tiempo fueren, no den licencia $\mathrm{p}^{\mathrm{a}}$ la compra, que pretende. Si no tuviere lo bastante para el tiempo dicho de diez años, entonces precediendo la Consulta, y aprobacion en el modo referido, podrá el Provincial dar la lizencia, que deberá ser in scriptis, y sin la qual no se comprarán Possession, ô Estancia alguna; para hazer Compra de los Bienes, que verdaderamte. se necessitan, y áque obliga la necessidad de vivir con decencia según nrô estilo, y q no pueda tener visos de que se compra por puro enriquezer, como si huvieramos hecho Profession de atesorar.

Los excesivos gastos, que en las entradas de Obispos, Governadores $\mathrm{V}^{\mathrm{a}}$, con no poco detrimento delos Colegios se han hecho hasta aquí, medizen los ha moderado su Antecessor de VR. Sé muy bien lo importante que es conservar buena correspondencia con tales personajes, tenerles gratos, y bien affectos á la Compañía, especialmte. donde está, como le sucede en essa Prov ${ }^{\mathrm{a}}$ tantos emulos tiene, y tanto necessita dela authoridad y brazo de estos sugetos para no ser impedida en sus ministerios, y gloriosas conquistas. Por tan justo y tan importante fin apruebo aquellas demostraciones: pero deseo, y ordeno, que sean proprias, y conformes á nrô estado, y como de pobres Religiosos: pues el excesso en esto no solo es contra el bien de los Colegios, y moderacion dela Compañía; sino ocasión a invidias, y aun á murmuraciones, de que intentamos por este medio prevenir y ganar las voluntades, y atraherlas ala nuestra, y disponer de ellas á nrô gusto ê intereses. Creo que ni VR permitirá en su tiempo lo que en esto huviere de excesso, ni dexarán de seguir su exemplo los successores en su oficio= Mucha facilidad se me dize di en descubrir lo que se trata en las Consultas, aun de $\operatorname{Prov}^{\mathrm{a}}$, siguiendose de esto los inconvenientes, que se dexan entender: no quienes sean los transgressores, que deseara saber $\mathrm{p}^{\mathrm{a}}$ remedio de falta tan perniciosa. Deseo no solo que VR zele sobre este punto, y castigue tan nociva facilidad; sino que me de prompto aviso delos sugetos, que en esto faltaren, para primarles 
perpetuamente deun oficio, en que tanto importa el secreto, y fidelidad de esta. $=$ De el Col ${ }^{\circ}$ de Buenos Ayres, y de otros de essa Provincia se me dize no se tienen en ellos con la regularidad debida las Consultas de mes y que vniversalmente se falta mucho en escribir los Consultores al Provl. en los tiempos, que deben hazerlo. Vna y otra falta es muy grave por las consequencias: pues mal podrá el Provl. zelar la observancia en la $\operatorname{Prov}^{\mathrm{a}}$, y el $\mathrm{R}^{\mathrm{o}} \mathrm{r}$ en su $\mathrm{Col}^{\circ}$, si uno y otro carecen delas noticias, que por este medio debian tener. No dudo que $V^{a}$ remediará estas faltas, y quantas para la $\mathrm{m}^{\circ} \mathrm{r}$ observancia deessa Prov ${ }^{\mathrm{a}}$ tengo avisadas en mis Antecedentes Despachos. Si el Pe. Marcos Avendaño avisáre á VR las faltas, que de tres sugetos á mi me escribe, oigale VR, y examinada la verdad ponga el debido remedio. En los Stos Sacrifs. de VR me encomiendo. Roma y Abril $1^{\circ}$ de 1734.

De $V^{\mathrm{a}}$

Siervo en Xpto.

Francisco Retz

$3^{a}$ carta $-1^{a}$ via $-1^{o}-1 V-1734$

de Francisco Retz al Pe. Provincial

P.C.

En las Informes. ad Gradum, que se me embian no hazen los PPes. Roca, y Arteaga mencion de todos los Sugetos, que se proponen: lo mismo le sucede al Pe. Miguel Lopez, quien embia su Carta en Castellano debiendo ser en latin. VR les avise estos defectos, tanto mas reprensibles, quanto mas faciles de obviarse, y que solo piden no hazer con descuido lo que tanto importa. Antes de señalar los Grados para los sugetos, que se proponen, diré los que tengo expedidos, y los que expido aora para varios sugetos, que partieron en esta ultima Mission: pues lo mucho, que tardaran oportunas ocasiones de escrivirá Indias me haze anticipar estas providencias, por no diferir el Grado á los Interessados. En 10 de octubre de 1733 embié al Pe. Antonio Machoni el Grado de Coadjutor Temporal para el $\mathrm{H}^{\mathrm{o}}$ Antonio María Lugas: en 24 de Octubre de el mismo año al Pe Geronymo de Hariza Provl. de Andalucia la Profession de 4 Votos para el Pe. Juan Escandon: y en 12 de Dize. del dicho año, embié al Pe. Franc ${ }^{\circ}$ Castañeda, Procur ${ }^{\circ} r$ de Indias en el Hospicio de el Puerto de Sta Maria la Profession de 4 Votos $\mathrm{p}^{\mathrm{a}}$ el Pe. Adolfo Skal. Este ultimo no pudo tener la noticia: los otros dos dudo se han echo el Grado, por no averme avisado nada el Pe. Machoni: y debiendo averse hecho estos tres Grados el 2 de Febrero de 1734, ordeno á VR, que luego, que reciva esta, en el primer dia de fiesta, que señalará, reciva por si mismo, ô señale quien reciva en mi nombre la Profession de el Pe. Skal, y los otros dos Grados de el Pe. Escardon y $\mathrm{H}^{\circ}$ Lugas, si no se han hecho estos dos aun. En 12 de Dize. de el mismo año embié á VR por mano de el Pe. Castañeda la Profession de 4 Votos, que avran de hazer á su tiempo, como ya diré $\mathrm{p}^{\mathrm{a}}$ los PPes Ignacio Ciereheim, y Juan Bapt ${ }^{\mathrm{a}}$. Marcheseti: por si no ha llegado esta Carta, repito este aviso. Promuevo tambien ala misma Profession de 4 Votos $\mathrm{p}^{\mathrm{a}}$ hazerla á su tiempo á los PPs. Carlos Tur, Juan Procuelo, y Juan Mensner. El tiempo en que á estos cinco sugetos les corresponde hazer la Profession, se ajustará por las sigtes. noticias el Pe.

297 Carlos A. Page. Las cartas de los generales... a la provincia del Paraguay... 259-322. 
Ciereheim nacio á 29 de Julio de 1703; y entró en la Compañía á 14 de Octubre de 1722, aviendo estudiado tres años de Philosophia en el siglo. El Pe. Marchesetti nacio á 10 de Dizbe. De 1704, y entró en la Compa á 28 de Octubre de 1720. El Pe. Tur nació á 13 de Agto. de 1700, y entró en la Compa á 24 de Octubre de 1718. El Pe. Proveled nació á 16 de Abril de 1701, y entró en la Compa á 21 de Noviembre de 1718. El Pe. Mensner nació á 23 de Mayo de 1703, y entró en la Compa á 9 de Octubre de 1722, aviendo estudiado un año de Philosophia en el siglo. Los PPes. Marchesetti, y Mensner harán su $3^{\text {a }}$ Probacion, si no la han echo ya allá: los PPes. Tur, Ciereheim, y Proocueld la han hecho. Estos Grados recivirá en el tiempo, que á cada uno corresponde el Provl. que entonces fuere, ô señalará quien lo reciva en mi nombre: y para todos cinco Grados debe preceder consulta, en que á maior numero de Votos de el Provl, y CCs. Ordinarios, y ad Graviora se determine si debe diferirseles el Grado por faltas, que aian cometido, y de que no estén bastantemte. emendados. Consultadas con los PPs. Assistentes las Informes. ad Gradum, que me remite su Antecessor de VR, comparece de los mismos determino, hagan la Profession de 4 Votos los PPes Ignacio Oyarzabal, Manuel Olmedo, Felix Vrbino, Antonio Estellez Thomas Arnaú, Salvador Quintana, y Esteban Fina. Se formará Coadjutor Espiritual el Pe. Diego Palacios; y Coadjutor Temporal el $\mathrm{H}^{\circ}$ Ignacio Andrade. Estos Grados recivirá VR, ô señalará quien los reciva en mi nombre; y entendiendose esto quanto los interessados aian cumplido la edad y tiempo de religion: y que no aian incurrido en faltas, por las quales á $\mathrm{m}^{\circ}$ r. numero de Votos de el Provl. y CCs $\operatorname{Ordin}^{\circ} \mathrm{s}$, y ad graviora deba diferirseles el Grado: para lo qual ha de preceder conculta. $=$

Varias vezes se ha juzgado conveniente en essa Prova no duren por mucho tiempo, ô muchos años los Curas en las Missiones, sino q passado algun tiempo, se sacassen de ellas para los Colegios. Los motivos, que se han propuesto, han sido tan efficaçes, que el $\mathrm{Rd}^{\mathrm{o}} \mathrm{Pe}$. Tyrso quiso poner Curatos, como son los Rectorados por trienio, y no mas. Mi Antecessor de B.M. el $\mathrm{Rd}^{\circ}$. Pe. Tamburini refiriendo esto mismo, y repitiendole de essa Prov ${ }^{\mathrm{a}}$ la misma instancia, ordenó en 1 de Mayo de 1716, que se consultasse, y examinasse en Consulta de Prov $^{a}$, si era conveniente una tal mutacion de tres en tres años. Mas se ha tenido sobre este punto la misma respuesta, que sobre otros muchos de mi Antecessor en sus Despachos; passandose los 16 y mas años sin saber la execucion de lo que acá se ordena: ô sea porque los Provinciales no leen los Despachos embiados a sus Antecessores; ô porque les falta valor para poner en execucion lo que se manda, facilitando su omision (por no darle otro nombre) lo tarde que esta se sabe en Roma, y lo mas tarde qe pueda remediarse. Yo no solamte. tengo presentes estos deseos, y disposiciones de mis Antecessores, sino las causas, que tuvieron, y la qualidad de los sugetos,que sobre esta mutacion han informado. Los Visitadores y Provinciales mas zelosos, que ha tenido essa Provincia son los que han clamado sobre la importancia de este punto, insistiendo todos en que no conviene continúen por muchos años los Curas en un mismo Pueblo: pues assi se evitará aquel despotico Dominio de su Administra ${ }^{\circ} \mathrm{n}$, y derecho, que pretenden despues de algunos años para conservarse en los Curatos; especialmente, si son pingues; se evitarán las intercessiones, y aun regalos que á este fin se han hecho, obligando assi á los Provinciales, ô á condescender violentados y de mala gana; ô á malquistarse con los que interceden: se evitarán finalmente otros inconvenientes, que tal vez se han experimentado de menor subordina ${ }^{\circ} n$ á las disposiciones de los Superiores, y se hará menos dificil la vida regular de los Colegios despues de algunos años, que despues de Muchos en las Missiones. Estos y otros muchos

298 Carlos A. Page. Las cartas de los generales... a la provincia del Paraguay... 259-322. 
motivos junto a las instancias, que de nuevo se me hazen, me obligan a la siguiente providencia, q VR pondrá en execucion immediata mente. Ordeno pues, que ningun Missionero nuestro esté de oi en adelante por mas tiempo, que el de cinco años, en algun Pueblo, ô Reduccion, aunque lo haga bien y con la satisfaccion, que se debe; sino que passados los cinco años sea removido, y señalado á algun $\mathrm{Col}^{\mathrm{o}}$; ô si lo juzgare assi conveniente el Provl. señalado á otro Pueblo de la misma, ô de otra Mission, y en que, $\mathrm{qd}^{\circ}$ mas, avrá de estar otros cinco años. Por lo muy vtiles, que algunos sugetos pueden ser en las Missiones, y lo que á éstas importe el que se conserven muchos años, y aun toda su vida en ellas (lo que no será muy vniversal) permitto puedan mudarse á otro Pueblo, sin obligar á que passados los cinco años, sean señalados á algun $\mathrm{Col}^{\circ}$ : mas no aviendo tal importancia, y necesidad de que se conserven en un mismo Pueblo pasados los cinco años, se mudarán infalliblemente, passados estos. Si tal vez (que será muy rara) sucediere, que por solos los motivos de la Gloria de Dios, y bien de aquellas almas, y á que no pueda ocurrirse por otro sugeto, se juzgáre conveniente, que continúe el que está, aun passados los cinco años, en este caso conferidos dichos motivos en Consulta de los Ordinarios CCs, y ad graviora determinará el Provl. por si lo que delante de Nrô Señor juzgare mas conforme á los dichos motivos, ô removiendo el sugeto, ô prorrogandole por el tiempo, que juzgare conveniente, en el mismo Pueblo. Pero ordeno, que deba el Provl. avisarme de esta prorrogacion, y de los motivos, que tuvo para ella, pues sobre otras muchas causas que tengo $\mathrm{p}^{\mathrm{a}}$ ello, me sera de grande consolacion en el señor saber quien es el sugeto tan interesado en su Gloria, y bien de los Proximos, y con quien tan justamente se usa esta singularidad, y excepcion de mi Orden, que desde luego concedo muy gustoso, por motivos tales. Y aunque esta mi disposicion, no puedo dudar, será recivida de los Missoneros con la religiosidad, y conformidad de animos, que á hijos dela Compañía conviene, para que á VR se le haga mas facil la execucion, y conozcan todos que en ella no haze mas que obedecer; inmediatamente, que reciva este Despacho intimará en todas las Missiones este mi orden, y el que nuevamante doi de que comienze VR á ponerlo en execucion con todos aquellos, que quando esta llegue avrán cumplido los cinco años de habitacion en un mismo Pueblo. Estoi muy cierto de que $\mathrm{VR}^{\mathrm{a}}$ executará quanto aquí ordeno: y creo tambien harán lo mismo sus Succesores en el oficio, sin darme ocasión á que yo desde acá señale los Curatos, quando embio nuevo Gobierno, y que ponga en ellos el termino solo de tres años, que concedo ahora por cinco: ni menos me darán ocasión á lo que tanto rehuso de confirmar con Preceptos de obediencia las Disposiciones, que de acá se embian. No tengo otra cosa, que dezir en el presente Despacho, remitiendome á quanto en los antecedentes de mi Antecessor y mios se ha escrito: los que por contener muchos, y gravissimos puntos me tienen con gran cuidado, asta saber q han llegado, y que VR ha puesto en execucion las importantes providencias, que para bien de essa Provincia se dán en ellos. En los Stos Sacrificios de VR me encomiendo. Roma y Abril $\underline{1}^{\mathrm{o}}$ de $\underline{1734}$.

De VR

Siervo en Xpto.

Francisco Retz 
$1^{a}$ et $-2^{a} v i a-26-V I-1734$.

de Francisco Retz al Pe. Provincial

P.C.

Hallandose en essa Prov a el Pe. Geronymo de Gama, embiado desu Prov a de el Brasil, debo participar á VR mi determina ${ }^{\circ} \mathrm{n}$, de que dho Pe quede assignado á essa Prov ${ }^{\mathrm{a}}$; y donde se tratará como si fuesse sugeto deella: y al mismo tiempo encomendar á su zelo y vigilancia, y al delos Superiores immediatos el cuidado, que debe tenerse con el Pe. en orden á su proceder. En los Stos Sacrificios de VR meencomiendo. Roma y Junio 26 de 1734.

De VR

Siervo en Xpto.

Francisco Retz

$1^{a}$ via $-14-V-1735$.

de Francisco Retz al Pe. Provincial

P.C.

Aviendome concluido la Fabrica y Nuevo Hospicio de Indias, que mi Antecessor de B.M. ordenó se hiziesse en el Puerto de Sta $\mathrm{M}^{\mathrm{a}}$ para $\mathrm{m}^{\circ} \mathrm{r}$ comodidad de las Missiones, que allí se juntan, y de los Procures., que de Indias vienen; y debiendose regular entre todas los gastos de esta fabrica, tocan á essa Prov a en la distribucion, y repartimientos que yo he hecho, la suma y cantidad de 9150 pessos- 2reas, y 1/2, que deben satisfazerse al officio de dho Nuevo Hospicio, y su $\operatorname{Proc}^{\circ} \mathrm{r}$ el Pe. Franc ${ }^{\circ}$ Castañeda. La mas prompta satisfaccion de dha Cantidad no solo urge, para darla á este officio, gravado en los costos de esta fabrica; sino q es tambien util á essa Prova ${ }^{\mathrm{a}}$, para exonerarse quanto antes de esta Deuda. Por tanto $\mathrm{VR}^{\mathrm{a}}$, y sus sucessores con la $\mathrm{m}^{\mathrm{o}} \mathrm{r}$ brevedad possible irán remitiendo por lso PPes Procuradores, ô por la via mas segura, que tuvieren $1 \mathrm{la} \mathrm{m}^{\circ} \mathrm{r}$ cantidad, que puedan, quando toda de una vez no puedan satisfacerla. Espero, que esta sola insinua ${ }^{\circ} \mathrm{n}$ bastará á evitar qualquier omission en este punto; y que sobre serme muy sensible, me obligaria á mas estrecha providencia. En los Stos Sacrif ${ }^{\mathrm{o}}$ de $\mathrm{VR}^{\mathrm{a}}$ me encomd ${ }^{\mathrm{o}}$ Roma 14 de Mayo de 1735.

De VR ${ }^{\mathrm{a}}$

Siervo en Xpto.

Francisco Retz

$7^{a}$ carta $-2^{a}$ via $-15-1-1736$.

300 Carlos A. Page. Las cartas de los generales... a la provincia del Paraguay... 259-322. 
de Francisco Retz al Pe. Provincial Jayme de Aguilar

P.C.

No creiera tal desorden en esse oficio con las cartas de este, á no expresarmelo VR sin mucha ponder ${ }^{0} n$. se deja conocer el gravisimo daño, y mus. inconvente. que consigo trahe divulgarse las cartas delos Genles. por la Prov ${ }^{\mathrm{a}}$; y que conservada una via de ellas en el Archivo, las otras anden por las manos de tantos. Renovando lo qe ordene sobre este punto en el año de 1732; ordeno nuevamte., que al Provl., que acaba, no le ha de quedar via alguna delas que se remiten; pues para responder alas cartas de este oficio, basta, que haga una apuntacion delo que contienen, para responder a ellas: y quando llega alguna via, si la otra se ha recevido antes; abierta esta por el Provl., y CCs. se ha de quemar todo lo que fuere copia de aquella recivida; smqe en el Archivo quede alguna mas de via, y sin que aya carta alguna fuera del Archivo. Siendo assi, que de el caudal, que dieron las Missiones, para comprar la Finca, y que solo fue de 48000 Pesos; solo debe reintegrar la Prova 18000, como en estas ultimas cartas me dice $\mathrm{VR}^{\mathrm{a}}$ : por que los 30000 restantes deben compensarse por otros tantos, que debieran aver contribuido a los Proces.; en las ocasiones de venir a Europa, las $\mathrm{dh}^{\mathrm{a}}$ Missiones: esta suma debera satisfacer en el modo, que ordené en mi Despacho de 1732. Mas atendiendo ala necesidad, y pobreza, en que oi se halla essa Prova ${ }^{\mathrm{a}}$, la dispenso por aora enla oblign., que con precepto le impuse de reponer todos los años 3000 Pesos; entendiendose, que para quando pueda, queda obligada en sus Superiores a el citado precepto, hasta la efectiva paga, y reintegrar ${ }^{0} \mathrm{n}$ de los 18000 Pesos gastados. Espero me imbie VRa, con el Despacho de 20 de Hen. de 1735 copia dela Fundaz ${ }^{\circ}$., que en Buenos Ayres hacen los Señores Dn Ignacio Bustillo Zeballos, y Dña Ana Rabanal; y supongo tenga arreglado aloque establecen nrâs Leyes, para que Yo la apruebe, interim me sirve de singular gusto lo vtil, que me dice $\mathrm{VR}^{\mathrm{a}}$ sera esta Fundaci ${ }^{\circ} \mathrm{n}$. Las tres Missas, y tres coronas, que $\mathrm{VR}^{\mathrm{a}}$ ordeno en la $\operatorname{Prov}^{\mathrm{a}}$; por $\mathrm{dh}^{\circ} \mathrm{s}$ Señores, las ordenare Yo efectivamte. por toda la Comp ${ }^{\mathrm{a}}$; quando acceptada la Fundac ${ }^{\circ}$., se me avise han dado todo lo que se requiere para esta, ademas delos 20000 pesos ya dados. Supongo sean para venta de esta Fundac $^{0} \mathrm{n}$ las casas, de que me abla VR ${ }^{\mathrm{a}}$ en estas Cartas; y de que nada ve, hasta ver los antecedentes. Bien dichas estan las dos Missas enla $\operatorname{Prov}^{\mathrm{a}}$, por la $\mathrm{Sr}^{\mathrm{a}} \mathrm{Dn}^{\mathrm{a}}$ Isabel de Tapia, y Herrera, que dono dhas. casas, y cuiosreditos son de mas de 500 pesos. Espero con las dha cartas saber lo que ay enla Fundac ${ }^{\circ} n$ de $\mathrm{Col}^{\circ}$ en Jujui; y me alegrara poder contribuir a esta, condesdendiendo con la peticion de VR ${ }^{\mathrm{a}}$; y deseos de Dn. Joseph Barreda, para ser segunda vez recivida enla Comp $p^{\mathrm{a}}$; â quien quiere dexar sus bienes para $\mathrm{dh}^{\mathrm{a}}$ Fundacion; mas no me lo permiten las causas de su dimission enla Prov ${ }^{a}$ de Chile, que tengo presentes; y solo puedo conceder, que portandose bien, como espero, sea recivido mi articulo mortis, para lo que doi mi lizencia. Doi la tambien (pues su Santidad le ha dispensado en el impedimt ${ }^{\circ}$ ) para que Cosme Gutierrez (quien tambien me escribe) entre enla Comp ${ }^{a}$, al estado de Herm ${ }^{o}$ Coadj ${ }^{\circ}$, sobre los ordenes, y provids, que $\mathrm{VR}^{\mathrm{a}}$ dexa en el $\mathrm{Col}^{\circ}$ de Buenos Ayres, no tengo que decir, sino alabar mucho zelo; pues todos ellos eran debidos: y siento en el Pe. Herran con el descuido, y omision en tales puntos, el empeño, en que se enmendasen. En los 35000 pesos, que resultaron de vtilidad ala Prova, enla vuelta a ella del Pe. Herran, por los generos comprados en Europa, y vendidos allá; y cuio exemplar, me dice $\mathrm{VR}^{\mathrm{a}}$, ha seguido el Pe. Machoni; tengo muchos motivos de sentimt ${ }^{\circ}$, assi por la sustancia dela cosa, como por el modo; pues tan crecida summa no parece puede resultar sino es comprando generos en mas abundancia delo que se necesita $\mathrm{p}^{\mathrm{a}}$ la provision de $\mathrm{Col}^{\circ} \mathrm{s}$, y Missiones; y vendiendolos

301 Carlos A. Page. Las cartas de los generales... a la provincia del Paraguay... 259-322. 
despues, sino al precio, que se vendieran de seglares, mucho mas caros delo que se compraron en Europa. Y si a esto se llega el venderlos a seglares, como parece da â entender $\mathrm{VR}^{\mathrm{a}}$, no estraño la nota, y mala fama en nrô nombre; ni es por cierto, para adquirirlo bueno, ver partir a Europa dos jesuitas, para conducir Missiones, que conviertan la Gentilidad; y verlos de vuelta echo mercaderes delos generos, comprados en Europa. Para occurrir â tantos males, y cerrar la puerta a tantos desordenes, y aun escandalos, como pueden temerse; ning ${ }^{\mathrm{a}}$ provid ${ }^{\mathrm{a}}$, sobre las ya dadas, puede de nuevo darse, que asegure $\mathrm{p}^{\mathrm{a}}$ en adelante; si sobre ella, y sobre las muchas dadas, no vela el zelo delos Superes. Mas por q la gravedad dela mat ${ }^{a}$ precisa a ocurrir a estos daños, por los medios todos posibles, he juzgado poner los siguientes. En primer lugar ordeno en virtud de Sta. obeda. Pena de peccado mortal a todos los Procurades., que en adelante vendran de essa Prov a Europa, que ni por si, ni por otros, mediaté, rel'mmediaté puedan vender alos externos cosa alguna delas que llevan de Europa, aunqe. sea delas que sobran, despues de provistos los $\mathrm{Col}^{\circ} \mathrm{s}$. y Missiones. Ordeno en segundo lugar, (lo que al primer lamento en contrario prohibire con precepto) que delos generos, y cosas, que llevan $\mathrm{p}^{\mathrm{a}}$ la $\operatorname{Prov}^{\mathrm{a}}, \mathrm{Col}^{\mathrm{o}} \mathrm{s}, \mathrm{y}$ Missiones, no puedan venderse, sino al precio, que ellos costaron en Europa, y gastos, que tienen enla conduccion. Ordeno lo tercero, que si, satisfechos los encargos, y comisiones sobrare algo; esso no lo venda el Procurador por si mismo; sino que lo entregue al Provl., para qe por el Proc $^{0}$ r de Prov ${ }^{a}$ se le de el éxito convente., sin nota, y escandalo delos seglares. Ordeno lo quarto, que pues estas resultas, y sobras producen delos generos comprados $\mathrm{p}^{\mathrm{a}} \operatorname{los} \mathrm{Col}^{\circ} \mathrm{s}, \mathrm{y}$ Missiones con dinero, que estas, y aquellos dieron; la vtilidad deba ceder en beneficio de ambos, y no de sola la Prov ${ }^{\text {a }}$, computandose los gastos para los nuevos Procurades.; con igualdad, y proporcion entre las Missiones, y $\mathrm{Col}^{\circ} \mathrm{s}$, con respeto ala vtilidad, que ha resultado delos ântecedentes. De aquí es, que resultando esta vtilidad; lo qe faltare a completar la suma neces ${ }^{\mathrm{a}}$, $\mathrm{p}^{\mathrm{a}}$ imbiar nuevos Procurades., no se ha de sacar de solas las Missiones, sino de estas, y de los $\mathrm{Col}^{\circ} \mathrm{s}$, que deben con proporcion, y igualdad ser gravados, como aquellas. Esse precepto, y ordenes se intimaran alos Procurades., quando vienen â Europa; y sobre la observ ${ }^{a}$ de todos, encargo la conciencia de los Superos: Y quienes, pues saben la instruc ${ }^{\circ}$. delos Procurades., y deben saber todas sus comissiones, y encargos; debieran tambien, según estos, regular la conducta delos Procurades. y ver si es la solamte. debida â cumplir con los encargos; ô si es mas bien de Mercaderes en mucha parte delo que llevan,con conocimt $^{\mathrm{o}}$, cierto de qe ha de sobrar en abund ${ }^{\mathrm{a}}$ para venderlo, y hacerlo dinero.En los Stos. Sacrifs. de VR ${ }^{\mathrm{a}}$ me encomd ${ }^{\mathrm{o}}$. Roma, y Henero 15. de 1736.

De VR ${ }^{\mathrm{a}}$

Siervo en Xpto.

Francisco Retz

$8^{a}$ carta - $2^{a}$ via - 15-I-1736.

de Francisco Retz al Pe. Provincial Jayme de Aguilar

Consultadas conlos P.P.A.A. las informs. ad gradum,que $\mathrm{VR}^{\mathrm{a}}$ y su Antecc ${ }^{\circ} \mathrm{r}$ me imbiaron; determino hagan la Proffess ${ }^{\circ} n$ de 2. Votos los P.P. Joseph Salguero, Raymundo 
de Toledo, Jul. Esponella, Geronimo Nuñes, Antonio Gutierrez, Buena Ventura Castel, Joseph Candiel, Pedro Morales, Ygnacio Xavier de Leyva, Juan de Barrera; y Jul de Molina, si tuviere tres sufragios minimé dubios en el examen de lengua, y cuias censuras me remitiria $\mathrm{VR}^{\mathrm{a}}$ se formara coadj ${ }^{\circ} \mathrm{r}$ espiritl. el Pe. Nicolas de Araoz; y coadj ${ }^{\circ}$ s temporales los Herm $^{\circ}$ s, Sebastian Viader, Jorge Cobel, Volfango Cleisner, Jorge Herel, Gerardo Lerher, Jacobo Rosh, Thomas Heyrel, Antonio del Castillo, Jul. Blanco, Jul. Blanco, Jul. Amilga, Pedro Phelipe Ybarluzea, Franc ${ }^{\circ}$ Teran, Guillermo Catalani, y Guillermo Schelton. Haga VR ${ }^{\mathrm{a}}$, nuestras informac ${ }^{\mathrm{s}}$, del Pe. Diego Pharias de Araoz; y si leidas en consulta de siete, se juzgare â pluralidad de votos, que puede hacer el Grado; hara el de Coadj ${ }^{\circ}$; sino, se le diferira. Los P.P. Salguero, Cardiel, Morales, y Barrera, y el $\mathrm{H}^{\mathrm{o}}$ Catalani seran avisados delos defectos, que constan en sus informs.; para que los enmienden. VR ${ }^{\mathrm{a}}$ recurrira, ô señalara quien en mi nombre reciva estos Grados; ylos que deben hacerse, quando aian los interesados cumplido la edad, y tiempo de religion; y que no ayan incurrido en faltas, por que apluralidad de votos en consulta de siete (la que debe preceder) se le deba a alguno diferir el Grado.

Supongo aya VR ${ }^{\mathrm{a}}$ recivido mi Despacho de $1^{\mathrm{o}}$ de Abril de 1734 y otra carta suelta de 12. De Dicbe. de 1733: en qe le avisaba algunos Grados. Por sino han llegado, digo, qe ordenaba en ellas hiciese la Profess ${ }^{\circ} n$ de 4 Votos el Pe. Skal en el primer dia de Fiesta; y a su tiempo tambien la misma Profess ${ }^{\circ} n$, los P.P. Chierelieim, Marchisetti, Tur, Procveld, y Mesner. Y por que ya tiene $\mathrm{VR}^{\mathrm{a}}$ los Catalogos de estos sugetos, no repito tal circunstancias del tiempo, en que â cada uno corresponde hacer el Grado. Despache entonzes los de essa Prov $^{\mathrm{a}}$, embiando Profess ${ }^{\circ} \mathrm{n}$ de 4 Votos alos Padres Ignacio Oyarzabal, Manl. Olmedo, Felix Vrbina, Antonio Estellez, Thomas Arnan, Salvador Quintana, y Estevan Fina; y que se formase Coadj ${ }^{\circ}$ r Espiritl. el Pe. Diego Palacios; y temporal, el Herm ${ }^{\circ}$ Ignacio Andrade. En los Stos. Sacrifs. de VR ${ }^{\mathrm{a}}$ me encomd ${ }^{\mathrm{o}}$. Roma y $\mathrm{Hen}^{\mathrm{o}} .15$ de 1736.

De VR ${ }^{\mathrm{a}}$

Siervo en Xpto.

Francisco Retz

$1^{a}$ carta $-1^{a}$ via - 15-VII-1737.

de Francisco Retz al Pe. Provincial Jayme de Aguilar

P.C.

Recibo 28 cartas de VR ; $^{\mathrm{a}}$ las 19 de 20 de en $^{\circ}$ de 1735; y las otras 9 de 14 de Marzo de 1736, con los Papeles adjuntos, y Informes. ad Gradum. Consultados estas, determino, hagan la Profess ${ }^{\circ}$ de 2 Votos los PP. Andres Fernandez, y Miguel Morales; y tambien los P.P. Lorenzo de Andrade, y Raphael Castañares, si a juicio de los CCs. todos en particular consulta pudiese seguramte. á pluralidad de Votos conferirseles el Grado. Al Ho Juan Ant ${ }^{\circ}$ de las Heras se le diferira el Grado de Coadj ${ }^{\circ}$., templ; avisandole de sus defectos, para que

303 Carlos A. Page. Las cartas de los generales... a la provincia del Paraguay... 259-322. 
se enmiende. A Los PP. Marchiseti, y Mesner se embio la Profess ${ }^{\circ}$. de 4 Votos; áquel en Dice, de 1733; y á este en Abril de 1732. Depida VR ${ }^{\mathrm{a}}$ de la Compa , y deles Dimission al Pe. Rodrigo Perez, $\mathrm{y} \mathrm{H}^{\circ}$ Fran $^{\circ}$. Xavier de Cuevas, coadjes. formdos.

Entrando aora á responder alas de $\mathrm{VR}^{\mathrm{a}}$ y á comunicarle el contenido de otras; no sé, que orden pueda tener, para hablar con alguno en tanta multitud, y variedad de especies. Comenzare por aquellas, que mas separadas estan del contenido de otras cartas. En orden al Pe. Geronimo de Gama qualquiera determin ${ }^{\circ}$, que yo dé, sera posterior ala que creo executada, de averlo remitido a su Prova. del Brasil. Sacarlo de Buenos Ayres, y aun de toda essa jurisdiccion, y Prov ${ }^{\mathrm{a}}$; era preciso; pues assi lo queria el Gobernd ${ }^{\circ}$ r. mas si en otro $\mathrm{Coleg}^{\mathrm{o}}$, fuera de la jurisdicion de Buenos Ayres, pudiera con seguridad tenerse; fue mal echo el remitirlo; debiendo superarse, que ai mui graves motivos para que no este en su Prova: y que el Provl. de essa me avria dado cuenta, como lo hize; y avise yo a VR ${ }^{\mathrm{a}}$ en 26 de Junio de 1732, para esperar lo que yo determinase.

No estraño la respa , de la Aud ${ }^{\mathrm{a}}$, y ViRey sobre hiz ${ }^{\mathrm{a}}$, para fundar en Jujui; antes si puede temerse, no solo se niegue semejante hiz ${ }^{\mathrm{a}}$. En el consejo para la Fund ${ }^{\circ} \mathrm{n}$. de nuevo Colg ${ }^{\mathrm{o}}$ en Buenos Ayres; sino que se derribe lo echo, y sereprehenda el adelantarse á fabricar casa, y Igl ${ }^{\mathrm{a}}$, en dhâ ciudd., sin hiz ${ }^{\mathrm{a}}$ del Rey. En vna, y otra Fund ${ }^{\circ}$, me es de agradecer el zelo de $\mathrm{VR}^{\mathrm{a}}$ : pero no puedo aprobar la conducta que en esto se ha tenido, que me parece algo apresurada. Y de la Resida . de Jujui ô Fund ${ }^{\circ} n$, que se intenta, ya la experiencia ha comenzado á dar algun desengaño, y aun con este otros, que debieran antes averse tenido presentes; pues el estan expuesta esta Ciudd. á continuar invasiones de Gentiles (motivo entre otros porque ya parece asiento VR á esta Fund ${ }^{\mathrm{o}} \mathrm{n}$ ) debio tenerse presente enlos primeros informes. Las esperanzas, que en estos se datan de vna buena Dotacion, ygual con otros Dn Jul del Portal avia prometido; con el nuevo estado, y casamt ${ }^{\circ}$. de este, parece, que las mira $\mathrm{VR}^{\mathrm{a}}$ perdidas. Y si de los 30000 pesos, en que se estima la Dotacion, casi las dos partes avia Dn Juan ofrecido; faltando esta Dotacion; falta tambien la Dotacion neces ; ala que ni basta lo que afrece Dn. Agustin de Leyza, y déla Joseph Barreda: y sobre quien escribi $\mathrm{VVR}^{\mathrm{a}}$, en 15 , de en ${ }^{\mathrm{o}}$ de 1736 ; sintiendo no poder volverle á recurrir enla Comp $p^{\mathrm{a}}$; y haciendole quanta gracia puedo. Por todo lo dho hizo VR ${ }^{\mathrm{a}}$ bien en no imbiar sugeto á Jujui, cuia Fundacion admitire: quando aia Dotacion, y se satisfaga álos [...]onvenientes, que aora, y antes se han representado sobre la situacion de essa ciud ${ }^{\mathrm{a}}, \mathrm{y}$ enfermo de su temple.

Lo mismo digo de la Fund ${ }^{\circ}$ n de nuevo Colg $^{0}$ en la ciud $d^{\mathrm{a}}$, de Buenos Ayres; que aunque no dudo sera mui util, y de mucha gloria de Dios; pero hasta aora ni se á quanto llega lo que Dn Ignacio Bustillo Zeballos y su Muger dieron; ni enlas summas, q se expresan, se dice á punto fixo, sino con mucha variedad, á qto, llegue esta Donacion. En 26. De Abril de 1735; y en 20. de en ${ }^{\circ}$. de 1736, me dice VR ${ }^{\mathrm{a}}$, han dado estos Señores 20000 pesos: y en 14 de marzo de 1736, dice han dado 12000, y 18000 pesos. Con tal diversidad ni puedo intimar sufrag ${ }^{\circ}$; ni hacer juicio de lo que ai para esta Fund ${ }^{\circ} n$. Las casas, que dexo la Sra. Dña. Isabel de Tapia tampoco sé, en qto, se aprecian; aunque me dice VR ${ }^{\mathrm{a}}$ el valor de su arrendamt ${ }^{\circ}$, annuo en 500 pesos. A esto se llega, que aviendo nuestro Dn Ignacio, y dexado tantos Hijos, sera dificil, que la $\mathrm{Sr}^{\mathrm{a}}$. su muger pueda efectuar sus deseos de hacer casa, y Igl ${ }^{\mathrm{a}}$. No obstante, si assi fuere, ó que se den los 20000 Pesos, que Dn. Ignacio avia ofrecido; no quedara por mi aceptar esta Fund ${ }^{\circ}$; para que debe solicitarse hiz ${ }^{\mathrm{a}}$. del Rey, Y

304 Carlos A. Page. Las cartas de los generales... a la provincia del Paraguay... 259-322. 
para esse caso debe remitirse relacion clara, y distinta delas Donaciones con los nombres de los Donadores, y copias authenticas de las Escrituras, que se celebraren, y en que no puede ponerse pacto alguno de justicia, contrario á nrâs constituciones, y Leyes. En los Stos. Sacrifs. de VR ${ }^{\mathrm{a}}$ me encomd ${ }^{\mathrm{o}}$. Roma y Julio 15 de 1737.

De VR ${ }^{\mathrm{a}}$

Siervo en Xpto.

Francisco Retz

$2^{a}$ carta - $1^{a}$ via - 15-VII-1737.

de Francisco Retz al Pe. Provincial

P.C.

De mucho consuelo me ha sido, quanto sobre Missiones circulares, y $\operatorname{exerc}^{\circ} \mathrm{s}$ de seglares en nrôs Colg ${ }^{\circ}$, me dice $\mathrm{VR}^{\mathrm{a}}$, y el Pe. Martin Lopez Administror de la Renta, dexada para tan Santos fines: pues veo que en todo el año de 1734 llegaron á 526 Persn $^{\mathrm{a}} \mathrm{s}$. las que hicieron los exerc ${ }^{\circ}$ s. Y por que $\mathrm{dh}^{\mathrm{o}} \mathrm{Pe}$. imbiando distinta relacion, y razon de aquella Administr ${ }^{\circ}$, que tan adelantada tiene, me pide algunas cosas para su contestacion, y aumento; dare aquí provid ${ }^{\text {a }}$, sobre ellas, sobre lo que $\mathrm{VR}^{\mathrm{a}}$ me dice en puntode exercicios, y sobre la casa de estos en el Estero. La buena Administro $n$, zelo, y pericia del Pe. Martin Lopez se hace visible enlo que ha dado a $\operatorname{los} \mathrm{Colg}^{\mathrm{o}} \mathrm{s}$, por el gasto de Missioneros, y exercitantes; teniendo tan adelantada la Hacienda de Calamuchita, de ganados; que valiendo esta el año de 1728, cinquenta y dos mil pesos; el año de 1732 . Valia ya mas de 100000. pesos. Esto junto ala religiosidad, y buenos informes, que ay aquí de $\mathrm{dh}^{\mathrm{o}} \mathrm{Pe}$. me hace reqerir lo que en años pasados ordené, de que se conserte $\mathrm{dh}^{\circ}$ Pe. en la Adminisr ${ }^{\circ} \mathrm{n}$; si graves, y justificadas causas no lo impidieren. Y por que al cultivo, y aumento de $\mathrm{dh}^{\mathrm{a}}$ Hacienda el aiuda mucho con su pericia, y zelo el $\mathrm{H}^{\circ}$ Domingo Huarte, no aviendo grave inconveniente en que alli continue, se le de casa por compañero suio. A este mismo fin conduce mucho, que $\mathrm{dh}^{\mathrm{o}}$ Administr ${ }^{\mathrm{o}} \mathrm{r}$, habote enla Hacienda, y que no se le ocupe en ministerios en el Colgo . de Cordova; pues estando bien distante el $\mathrm{Colg}^{\mathrm{o}}$; el habitar en esse es incompatible con el cuidado debido á tal Administrador. Finalmte. por que ella es de tanta gloria de Dios, de tanto provecho â las Almas, y de tanta vtilidad ala Prova ${ }^{\mathrm{a}}$ y alos Colg ${ }^{0}$ s todos, que se interesan en sus ventas, ordeno, que esta Administr ${ }^{\circ} \mathrm{n}$. y Hacienda de calamuchita siempre este encomendada á algun sacerdote, y no fiada solamte. á $\mathrm{Herm}^{\circ}$ s. No sé, á titulo de que pretenda el $\mathrm{Colg}^{\mathrm{o}} \mathrm{Max}^{\mathrm{o}}$, que $\mathrm{dh}^{\mathrm{a}}$ Hacienda le aiude á pagar sus Diezmos con 75 pesos annuos. La Hacienda en nada pertenece á $\mathrm{dh}^{\circ} \mathrm{Colg}^{\circ}$, ni este tiene derecho alguno sobre ellas y mas en punto de Diezmos. Basta, que se vtilice de ella en 200, ô mas Pesos al año, por las Missiones, y exerc ${ }^{\circ} \mathrm{s}$; como los demas $\operatorname{Colg}^{\mathrm{o}} \mathrm{s}$; y que no quiera sobre estos, ser privilegiado en un tributo, que no se le debe. Ordeno, que nunca se dé tal cosa; y aviselo $\mathrm{VR}^{\mathrm{a}}$ en nombre mio al $\mathrm{R}^{\mathrm{o}} \mathrm{r}$ y $\operatorname{Procur}^{\mathrm{o}} \mathrm{r}$, del $\mathrm{Colg}^{\mathrm{o}} \mathrm{Max}^{\mathrm{o}}$ y al Administro ${ }^{\mathrm{r}}$ para que se note en sus Libros. 
Mui diferentemte. se me informa dela Casa de $\operatorname{Exerc}^{\circ}$ s en Sn.tiago del Estero; y sobre que parece no reprueba $\mathrm{VR}^{\mathrm{a}}$ el contrato, que se hiço en tiempo del P. Herran con Dn. Gaspar Xuarez Bibiano, para que este acabase á su costa dhâ casa; y que á el, yá sus Sucessores sirviese con la sola condicion de averla de desocupar dos vezes al año para el tiempo de Exerc ${ }^{\circ}$. Por otra parte se me dice, que aviendo dado, amo es cierto, Dn Alonso de Alfaro 6000 pesos, para fabricar esta casa, la dexó tan adelantada el Pe. Martin Lopez, que solo le faltaba cubrirla: pero que despues, que el Pe. dexó este cuidado, se tuvo grande en deshacer lo echo, destruiendo casi las tres partes dela casa, y llevandose al Colg ${ }^{\mathrm{o}}$ las texas y maderage de $\mathrm{dh}^{\mathrm{a}}$ fabrica; y la que despues se reduxo al contrato, que $\mathrm{VR}^{\mathrm{a}}$ me expresa. Si esto es assi, no necesita de encarecimt ${ }^{\circ}$ lo mal que en esto se ha procedido, y lo injustamte. se ha vtilizado el Colgo: ni me parece bien, que vna casa destinada para Exerc ${ }^{\circ} \mathrm{s}$. y fabricada á esse fin, se aya dado, y enagenado de tal suerte, aunqe. aquel pueda bien cumplirse, como dice VR ${ }^{\mathrm{a}}$. el Pe. Martin Lopez, noticioso de esto, me pide acabar $\mathrm{dh}^{\mathrm{a}}$. Casa á expensas de aquella Administro ${ }^{0}$. pues le sobra, para hacerlo: y solo me detuve á ordenarlo assi el no saber, si la cosa sera factible, y sin costoso pleyto con Xuarez, despues de escriturada: el contrato con este. $\mathrm{VR}^{\mathrm{a}}$ lo examine con sus CCs., y si se juzgare hacerse, y anular el contrato, lo avisara al Pe. Lopez, para que prosiga, y acabe la fabrica; y ala que el $\mathrm{Colg}^{\mathrm{o}}$, debe restituir lo que de ella se ha vtilizado. El orden de mi Antecess ${ }^{\circ}$, de 22 de Junio de 1726, no fue prohibir, se tuviese en comun la meditacion, y Leccion; sino que á esto no se les precisase á los Exercitantes, pudiendo hacerlo en su retiro. No obstante, diciendome $\mathrm{VR}^{\mathrm{a}}$, que muchos, y especialmte., las mugeres no saben leer; estos, y los que de los exercitantes quieren podran juntarse enla sala comun alos exerc ${ }^{\circ} \mathrm{s} . \mathrm{dh}^{\mathrm{o}} \mathrm{s}$. Y assi en esse punto, como en el de que envien á hacer $\operatorname{Exerc}^{\circ} \mathrm{s}$, quantos cupieren, y no 20 solamte., como ordeno mi Antecess ${ }^{\circ}$., en el citado Despacho, convengo enlo que $\mathrm{VR}^{\mathrm{a}}$ me pide; y dispenso en estos dos ordenes. En los Stos. Sacrifs. de VR ${ }^{\mathrm{a}}$, me encomd ${ }^{\mathrm{o}}$. Roma y Julio 15. de 1737.

De VR ${ }^{\mathrm{a}}$

Siervo en Xpto.

Francisco Retz

$3^{a}$ carta - $1^{a}$ via - 15-VII-1737.

\section{de Francisco Retz al Pe. Provincial}

P.C.

Aviendo $\mathrm{VR}^{\mathrm{a}}$ ordenado algunas cosas, consultandome en ôtras, y pidiendome determine sobre varias, dire aquí lo que juzgo de todas. Pareceme bien, ordenase VR ${ }^{\mathrm{a}}$. en el Colgo, de la Rioja no saliesen los nrôs a confesar por [roto] diciendo, y á los que habitan enla campaña sin comp ${ }^{\circ}$ jesuita: mas no juzgo, que el orden de remitir a su Parochio los Penitentes en el caso, que en el $\mathrm{Colg}^{\circ}$ no se pudiera dar $\mathrm{Comp}^{\circ}$, al Conf ${ }^{\circ}$; se entienda aun alas circuns $\mathbf{s}^{\mathrm{a}} \mathrm{s}$. de llamar a algunos para confesarse in articulo mortis; pues en estas debe ir el conf ${ }^{\circ} \mathrm{r}$ aunqe. no tenga comp ${ }^{\circ}$. en lo demas el orden es mui importante, aunque le sea sensible al Pe. Florentin. El que los nrôs no se introduzcan, y familiarizen con seglares, y 
que se impidan visitas inutiles á estos, es mui bien echo mas que en tarija aya de ser solo el $\mathrm{R}^{\mathrm{o}} \mathrm{r}$ qn por todos cumpla en ocasión de Pasquas, ó alguna otra de atencion, y vrbanidad; no puedo absolutamte. aprobarlo; pues ai circunst ${ }^{\mathrm{a}} \mathrm{s}$, en que algun otro debe hacerlo; bastando la vigilancia del immedt ${ }^{\circ}$. Sup ${ }^{\circ}$, para impedirlo á qn juzgare convente., y que sin necesidad visita. No aviendo proxima esperanza de fundarle en Jujui; ni aun necesitandose en el caso de fundarse, de los 21 esclavos, que desfruta el Colg de Salta; aplico á este dhôs esclavos por las razones, que $\mathrm{VR}^{\mathrm{a}}$ me dice. Mui de mi aprob ${ }^{\circ} \mathrm{n}$ ha sido, y como tal lo confirmo el orden de $\mathrm{VR}^{\mathrm{a}}$ en el Es[roto], para no encargarse el Colg, de arrendar, y buscar los carros, y cavalgaduras, para transportar al Peru las mercaderias, y generos de los Mercaderes, que por alli pasan: y no dixo seria esto motivo de gravissimas murmuraciones, y descredito nrô, y de fundamt ${ }^{\circ}$, á sospecharse nos interesabamos en esta especie de monopolio en detrimt ${ }^{\circ}$., de la vtilidad, que pudiera tener cada vno, si por si mismo arrendase alos Mercaderes sus cavalgaduras, y carros.

Sobre la igualdad, y proporcion entre Missiones, y $\mathrm{Colg}^{\mathrm{o}} \mathrm{s}$ de $\operatorname{los}$ generos, que lleban los P.P. Procres., y de los que sobrando se venden, para repartirse con igualdad la vtilidad, y gastos entre todos; tengo abundantemte. Proveido en 15. de $\mathrm{En}^{\circ}$ de 1736: ni juzgo añadir cosa álo alli ordenado. Por la grave regencia, que $\mathrm{VR}^{\mathrm{a}}$ me expresa, apruebo, que con parecer de sus CCs. permitiese, se ordenasen de sacerdotes, antes de los exames. de moral, y Lengua, essos cinco estudtes. A Dn. Roque Gaica, ô Ganca /no he podido entenderlo/ Benef ${ }^{\circ} r$ de tarija; á el Pe. Sebastian de Fragnas, Benef ${ }^{0}$ r. del mismo Colgo., y a Dña. Juana de Herrera, Benef ${ }^{\mathrm{a}}$ del Colg $^{\mathrm{o}}$ de Cordova; corresponden por cada vno de estos, vna Missa, y vna corona en la Prov ${ }^{\mathrm{a}}$; y tres en el Colg ${ }^{\mathrm{o}}$. A Dn. Martin de Juangorena, por la viña, que legó al Colgo de Tarija, estimandose en 20000 Pesos, vna Missa por toda la Compa $p^{\mathrm{a}}$, dos en la Prov ${ }^{\mathrm{a}}$, y tres en el Coleg ${ }^{\mathrm{o}}$. Intime $\mathrm{VR}^{\mathrm{a}}$ de orden mio estos Sufrag ${ }^{\mathrm{o}} \mathrm{s}$, sin nombrar es estos al Pe. Fraguas pr. su nombre, sino con el titulo de vn Benef ${ }^{\circ}$. A $D^{a}$ Blanca Godoy, tres Missas y tres coronas en el $\mathrm{Colg}^{\mathrm{o}}$ de Sta Fe; y dos enla Prov ${ }^{\mathrm{a}}$. Apruebo, y tengo a bien, se entierre en nrâ Igl ${ }^{\mathrm{a}}$, y sea recevido en articulo mortis esse Anciano Jul ${ }^{\circ}$ de Salazar: y le avisara á este oficio, quanto sea el valor de lo que en su testamt ${ }^{\circ}$ dexare al $\mathrm{Colg}^{\mathrm{o}}$ de tarija. Vna, y otra gracia concedo á Joseph de Barrera dimisso; si viviendo bien, se hiciere digno de ellas. Mui bien echo ha sido no condescender alos deseos del Sr Dr Dn Juan Melganejo, Dean del Paraguay, para imbiarlo â Missiones; pues de tanta gloria de Dios, de tanta vtilidad a los proximos, y ála Comp ${ }^{\text {a }}$, es su presencia, authoridad y exemplo en aquella Igl ${ }^{\mathrm{a}}$ y ciudd. de la Assump ${ }^{\circ}$ concedo á Dn Miguel Machado, continuando á vivir bien, el que haga los votos in articulo mortis. Esse VR $\mathrm{VR}^{\mathrm{a}}$ seguro, que no admitire segunda vez enla Compa ${ }^{\text {a }}$ á Dn Pedro, y Dn Jul. Monge, Dimissos, que hasta aora nada me han escrito de esto. El otro Dimisso dela Prov ${ }^{\mathrm{a}}$. de Quito, no diciendome VR ${ }^{\mathrm{a}}$ su nombre, no sé quien es. Deseo, que esse $\mathrm{Herm}^{\circ}$ estudte. Continue procediendo tan bien, como se porto en el Noviciado, y á cuia causa juzgaron $\mathrm{VR}^{\mathrm{a}}$, se le debia dar credito en orden a su edad para los votos de viennio: y me alegro procedan tan bien los Novicios, y demas sugetos de la Mission, que llevo el Pe. Machoni. [roto] natural, le concediese Yo á boca la facultad, para recevir algunos antes de los 15 años cumplidos; y para admitirlos alos votos antes de los 17: mas quando assi no sea, todo queda subsanado en el modo, que $\mathrm{VR}^{\mathrm{a}}$ me dice.En los Stos. Sacrifs. de VR ${ }^{\mathrm{a}}$ me encomd ${ }^{\mathrm{o}}$. Roma y Julio 15 de 1737

De VR ${ }^{\mathrm{a}}$ 
$4^{a}$ carta $-1^{a}$ via - 15-VII-1737.

de Francisco Retz al Pe. Provincial

P.C.

La situacion de los nrôs ala Ciudd., y Colgo de la Assump ${ }^{\circ}$, en el Paraguay es el

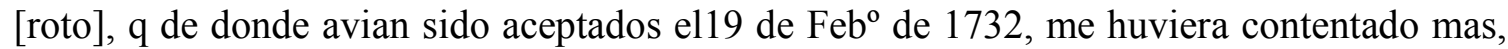
si aunque menos solemne, ypublica, huviera sido mas decorosa al comp ${ }^{\mathrm{a}}$; ala justificacion de su innocencia, y buen nombre, y ala verdad de nra causa, que no queda ay solamte., sino que se ha derramado, yestando por toda la Europa. Ni álas demostraciones en[roto] de la ciudd., y publico, corresponden [roto] procedian, despues de tan singulares finezas como les hizo VR ${ }^{\mathrm{a}}$; pues aun se retenian algunos las Haciendas nrâs. Los ordenes de VR ${ }^{\mathrm{a}}$, poca que se perdinan alos Pobres lo que nos huviesen defraudado, o causadode daño; para que á los ricos, comprehendidos en estos delitos mismos, no se les pidiese, y obligase por justicia ala paga; para que el Colg ${ }^{\mathrm{o}}$ vendiese las tierras al nras, que arrendaba, yde que no necessita, y para que el Colgo , no venga mas que vn Baron, y en que no [roto] otros generos, que los de sus [roto]; todo esto requiere summa prudencia, caridad, deseo de una consciente paz, y zelo del buen nombre de la comp ${ }^{\mathrm{a}}$ que no dudo padeceria mucho en su [roto], tenido como especie de nogociación el tragin de [roto] no puedo aprobar, antes [roto] determinase $\mathrm{VR}^{\mathrm{a}}$, (y según me dicen sin mas que vn consultor á su favor) se [roto] á dha. Compa sin que precediese lo que en [roto] restitucion se hizo de quemar, los [roto] y documt ${ }^{\circ}$ s injuriosos ála Compa . Esa satisfaccion no es graciosa, sino debida ala innocencia, ala justicia, á reparar la violencia, deshonraa, daño temporal, y tropel de calumnias, con que la Comp ${ }^{\mathrm{a}}$ fue arrojada de la Ciud ${ }^{\mathrm{a}}$. y odiado sus nombres en toda la Prov ${ }^{\mathrm{a}}$, y no esta consentido se entrare á la Ciudd. que ordena archivado tan infame padecer de los Jesuitas [roto] el Sr Dn Bruno Zabala no pudo de no se [roto] á conseguir esto; y si con el $\mathrm{S}^{\circ} \mathrm{r}$ obispo insinúa á que volvieran los nrô nada de esto obligara á atropellar, y pasar por todo, por solo entrar asu Colgo que tanto ha dado, que hacer siempre [roto] es el caso de obligarnos, no debiera hacerse sin vna general protesta de la violencia, con que la Comp ${ }^{\mathrm{a}}$ entre[roto] para que assi en ningun tiempo pasase nrô silencio por vnatacita contestacion de nrâ deshonra.

Dicenme, que $\mathrm{VR}^{\mathrm{a}}$ no ha querido pasar por un contrato, que con $\mathrm{Lic}^{\mathrm{a}} \mathrm{y} \operatorname{aprob}^{\mathrm{o}} \mathrm{n}$ del Pe. Herran se hizo entre el Colg ${ }^{\circ}$ de Cordova, y el Pueblo del Pe. Astorga enlas Missiones. $\mathrm{Y}$ el que, si es, como me dicen parece [roto] el Colgo se obligo á co[roto], y poner en la Ciudd. de Buenos Ayres 150 fanegas [roto]; y desde alli al Pueblo á costa de esse avian de conducirse, siendo el infimo precio de la fanega de sebo en Buenos Ayres a 10 Pesos; ymportando assi las 1500 fanegas 900 Pesos. El Pueblo, ó el Pe. Astorga ofrece 150 arrobas de jerba, que á costa del Colgo, avian de conducirse por esas á Buenos Ayres; y de alli á S. Fe; siendo el precio regular de la arroba de jerba enlas Missiones á [roto]pesos y importando assi las 2 arrobas [roto], que por todos lados se representa junto, dicen ordenó $\mathrm{VR}^{\mathrm{a}}$, no se diese la Yerba al Colg ${ }^{\mathrm{o}}$, sino al precio, que en StaFe se vende; yque siendo assi; 
que en $\mathrm{StaFe}$ se vende á 4 pesos, el $\operatorname{Proc}^{\circ}$ r. de Missiones no quieredarla menos de á 5 pesos. El contraro, vuelvo á decir, parece justo; el $\mathrm{Colg}^{\mathrm{o}}$, no compró en $\mathrm{St} \mathrm{F}^{\mathrm{a}} \mathrm{Fe}$, sino enlas Missiones; el conducir la Yerba á su riesgo, y costa ha sido: y en fuerza de esto, no descubro, por que razon se le aya de dar á 5. Pesos lo que licitamte. compro á 2: y condenar al Colg ${ }^{\mathrm{o}}$ porque 1350 Pesos de mas. VR ${ }^{\mathrm{a}}$ examine esto con sus CCs. y hallando aver sido justo el contrato echo; estese á el; ni pague el [roto] de los 900. Pesos, que debe. En los Stos. Sacrifs. de VR ${ }^{\mathrm{a}}$. me encomd ${ }^{\circ}$. Roma y Julio 15 de 1737.

De VR ${ }^{\mathrm{a}}$

Siervo en Xpto.

Francisco Retz

$5^{a}$ carta $-1^{a}$ via $-15-$ VII-1737.

de Francisco Retz al Pe. Provincial

P.C.

Aunqe. el P. Saffe, $\mathrm{R}^{\mathrm{o}} \mathrm{r}$ de Corrientes por su malvida, y genio, (noticias totalmte. opuesta alo q antes se me avia escrito fuere poco apto para el gobierno; en orden ala mala adminst ${ }^{\circ} \mathrm{n}$ del Pe. Gaete, con que ha empeñado el $\mathrm{Colg}^{\mathrm{o}}$ en mas de 1000 pesos y ninguna culpa, me dicen ha tenido: que sobre [roto] del Colgo; y sobre si á sido inteligente [roto] temples.; [roto] al Pe. Gaete le sobre astucia como, [roto]n dicen, lo experimentado [roto] para persuadir al $\mathrm{R}^{\circ} \mathrm{r}, \mathrm{qt}^{\circ}$ quisiere el aver puesto vna [roto] ha sido bien echo; y ordeno, que al Pe. Gaete en ning ${ }^{\text {a }}$ [roto] Procuracion se ponga en adelante.

Si el Pe. Astorga ni con satisfac ${ }^{0} n$. cumplia en el $\operatorname{Retd}^{0}$ de Rioja, ni le iba bien de salud, aviendose el mismo escusado de [roto] no esa neces ${ }^{\circ}$ mas para administrarle la Propuesta con [roto] y sin necesidad [roto] cargos, y esperar su respt ${ }^{\mathrm{a}}$; pues se con[roto] el fin [roto] que tenia visos de caridad; y obra los [roto] y justicia. No solo poco inteligente de Administr ${ }^{\circ}$. dicen, que es el Pe. Franc ${ }^{0}$ de Aguilar, sino de tan mal modo, y genio, y de trato tan incivil, que es molestissimo alos de casa, ofensivo alos de afuera, y poco grato á los Fundadores dela nueva $\mathrm{Ciu}^{\mathrm{a}}$, de Buenos Ayres. Con estas partidas siento, lo aya puesto $\mathrm{VR}^{\mathrm{a}} \operatorname{Sup}^{\mathrm{o}} \mathrm{r}$, de aquella; y mas, si como me dicen, ha sido contra el Dictamen de tanto, como en Buenos Ayres hablaron en esto aVR ${ }^{\mathrm{a}}$.

Es assi lo que desos Estud ${ }^{\circ}$, dice el P. Flaviano dela Pazyen orden al genio tengo bastante noticias del tiempo que vivio Jesuita en la Prov ${ }^{\mathrm{a}}$ de Thexien. Si al Pe. Jul ${ }^{\mathrm{o}}$, Nicolas de Araoz, favorecieren tres sufrago ${ }^{\circ}$ minime dubios en el examen de Lengua, promovere ala Profess ${ }^{\circ} \mathrm{n}$, de 2 votos á su tiempo [roto] pues hasta el Te[roto] no cumple la edad; y para [roto] las censuras, y los Informes. al Grado [roto] VR ${ }^{\mathrm{a}}$ conlas noticias dela aplicación de este [roto] estudio dela Lengua, el zelo, y [roto] $15 \mathrm{de} \mathrm{en}^{\circ}$, de 1736 respondi ala duda sobre el Precepto impuesto, para no hacer cosa alguna a las Missiones q los Colg ${ }^{\mathbf{0}}$ : ni tengo que añadir en este punto. $Y$ en el que aquellas limosnas, que se hicieron mientras no avia llegaron la prohibicion, yde que me habla $\mathrm{VR}^{\mathrm{a}}$ enlas cartas de $7 \mathrm{de} \mathrm{en}^{\mathrm{o}}$, de 1735 . Apruebo

309 Carlos A. Page. Las cartas de los generales... a la provincia del Paraguay... 259-322. 
tambien el orden, que en las Missnes. dio $\mathrm{VR}^{\mathrm{a}} \mathrm{p}^{\mathrm{a}}$ que los ornamt ${ }^{\circ} \mathrm{s}$. viejos se vendiesen ó dieren de limosna á las Igla s. pobres, y Capillas de Campo en las [roto]lare, si el Decreto 27 de la Congron. [roto] sobre no leer las cartas delos electos, [roto]n, ylas a ellas escritas, deba entenderse tambien [roto] institutos delos Procures. que en segundo lugar vienen [roto] que si, pues estos vienen con sus ad conexegationem Genlem. Para la que pueden comunicarseles noticias, que ningun Particular, ó immedt ${ }^{\circ}$ s. Superes. deben saber.

Entremos a hablar de las Missiones, y en primer lugar de los chiquitos, y las [roto] estos [roto]e sirve de especial consuelo el grande, [roto] el $\mathrm{P}$ [roto] de $\mathrm{St}^{\mathrm{a}} \mathrm{Cruz}$ en la visita de los Chiquitos, y[roto]Ilma. quedo del zelo de los nrôs. sobre las excursiones de estas a la Gentilidad, y Cureldad, que executaban por la parte del Norte, respondi en el vltimo Despacho, suponiendo, huviese $\mathrm{VR}^{\mathrm{a}}$ ordenado (y si no es assi, lo ordenara)no se hagan $\mathrm{dh}^{\mathrm{a}} \mathrm{s}$. excursiones, sin que vaya algun Pe. acompañando alos indios, como q el Sur hace el Pe. Castañares; $\mathrm{p}^{\mathrm{a}}$ impedir assistida violencia, y crueldad, si el nuevo Govern ${ }^{\circ}$ r.toma con empeño, y calor proteger la Miss ${ }^{\circ} \mathrm{n}$ de Lules, que fundo el Pe. Machoni, puede esperarse su restauracion, y aumento, en que tanto detrimt ${ }^{\circ}$ ha recivido por las invasiones delos infieles del Chaco, que a 120 Personas la reduxeron. La puerta, y entrada á esta hasta Gentilidad del Chaco, no tenia dificil, si se reduxe sin los chiriguanos: mas la repetida inconst ${ }^{\mathrm{a}}$, veleidad, y apo[roto] de esta Nacion, su crueldad y exercicio enlas armas, [roto] la esperanza. No obstante ni la pierdo, ni deja de aumantar[roto] sangre derramada, y la muerte del Pe. Julian [roto] de 1735 aser [roto] los Chiriguanos [roto] quemando la Igla , y Pueblo. Y ya que todo dispuesto, no omito decir, me es summamte. sensible venga esta noticia tan concisa, y sin expresarse, si esta muerte fue, o no, in odium dixo. Y como con la exper ${ }^{\mathrm{a}}$, de semejantes omissiones se ha descuidado tanto en hacer Processos, se llora aora el no tener en los Altares algunos de tantos como q la Sta.Fe han perdido la vida. El siervo de Ds. Pe. Cavallero, Apostol de essas Missiones, es vno de aquellos, de qn. parece pudiera esperarse, se avian de hacer Processos; ylo que aun aora no seria dificil. Vea $V^{\mathrm{a}}$, y examine, si seria asequible el poder justificarse, que el $\mathrm{dh}^{\circ}$. Pe; ó el Pe. Lizardi aian sido muertos in odium fidei; pues si esto fuese, debieran hacerse Processos ante el Ordinario, antes que muriesen los testigos. Y para el caso que ninguna Luz ai se tuviese del modo de hacerlos, se imbiaria de aca Instrucción, con qno saliesen errados. No estraño, que la nueva Reduccion de los Zamucos sea solo de 300 Familias; que [roto] alos principios, la vecindad á tan bravos Indios, y exercitados en las armas, impedira mucho su aumento. En los Stos. Sacrifs. de VR $^{\text {a }}$ me encomd ${ }^{\circ}$. Roma y Julio 15 de 1737.

De VR ${ }^{\mathrm{a}}$

Siervo en Xptô.

Francisco Retz

$6^{a}$ carta - $1^{a}$ via - 15-VII-1737.

de Francisco Retz al Pe. Provincial

P.C.

310 Carlos A. Page. Las cartas de los generales... a la provincia del Paraguay... 259-322. 
$\mathrm{Su}\left[\right.$ roto] $\mathrm{VR}^{\mathrm{a}}$. estuvo en Buenos Ayres se inf[roto] en congreg ${ }^{\mathrm{o}}$. [roto] se hablo, alas Naciones, que de Buenos Ayres acia el Sur, y estrecho de Magallanes habian entre los Cesmes, y Patagones que vio es cosa de exponerse á aventuras, ó á empresas sin fruto, y sin fundte, esperanza de conseguir el fin. Lo que mui en mi corazon agradezco aVR ${ }^{\mathrm{a}}$, a [roto] yo, y confirmo, ordenando se continue, es la obligacion, que dexo en Buenos Ayres. y el orden de que aya vn Pe. destinado, que á exemplo del Vc. Pe. Claver es Cartagena, y como se practica yo en $\mathrm{dh}^{\mathrm{a}}$ ciud $\mathrm{d}^{\mathrm{a}}$; atienda ala conversion de los miserables esclavos, que en aquel Puerto venden los ingleses, quando llegan sus Naves. Y debo esperar, aya [roto] $\mathrm{VR}^{\mathrm{a}}$ en esta ocupacion vn Hombre de grande caridad; y zelo de las Almas. Siento lo disminuido que esta por las turbaciones del Paraguay la Miss ${ }^{0} n$. delos tobatines. Dios quiera, que, sosegadas aquellas, se aumente esta; como yla de los Guañanas en sus nuevas Reducciones.

Quando escribo esta me llegan otras dos de VR $\mathrm{VR}^{\mathrm{a}}$, de 26 de Abril de 1735; y 23 de Febe. de 1736, con el aviso de aver recivido mis cartas de $1^{\circ}$ de Abril de 1734: y con la noticia de estar aun detenidos los PPs. Procures. sin poder salir por causa de essa guerra. Las demas noticias son con siguientes alo qe enlas cartas, á qe voi respondiendo, se contiene. Si sera necessario quede en Madrid alguno de los P.P. Procures. y especialmte. el Pe. Rico, lo tengo ya acordado aVR ${ }^{\mathrm{a}}$. en el Despacho antecedte.; mas espero, que no; pues el Pe. Rodexo ha hablado con tal eficacia sobre el punto de no aumentar contribucion alos Indios, que parece, nada se innovara en esto.

No quisiera llegar á hablar sobre estas Missiones, y la [roto] ni sé, que remedio pueda darse á tantos y tan grandes daños, como padecen, y como los [roto] el [roto] exterminio denra Christiandad, que siendo en el año de 1732 compuesta de 141252 Almas, le vera en el año de 1736 reducida al solo numero de 107593, faltando assi en el solo espacio de 4. años 33709 Almas. No he podido leer sin vna sentidissima afliccion la serie de males con qe nrô Sr. ha aflixido essa Christiandad; y los excesos, crueldades, y violencias, á qe ella en mucha parte se ha relaxado, sé por las cartas de VR ${ }^{\mathrm{a}}$, y de muchos nros las frequentes pestes, extremas hambres, y continuas guerras, que essas Missnes. han padecido, y padecen; lo que en sus costumbres se han viciado, essos xpnôs, yla [roto] que en la guerra han aprendido; sus excesos, y adulterios, hasta robar las mugeres ajenas; sus embriagueses, odios, y homicidios, hasta beberse efectivamte. la sangre; sus impiedades aun con los cadaveres, y sirviendose de los huesos $\mathrm{p}^{\mathrm{a}}$ sus echizos; y finalmte. su apostasia de la Fe en muchos de ellos, retirandose alos montes, y Gentilidad. Y si bien todo esto me consusta yaflixe summamte; no puedo negar se me aumenta la afliccion y cuidado del fin de essas Missiones con las noticias, que me dan del summo decaimiento de animo, que todo esso ha causado enlos Missioneros; queriendo mucho dexar las Missiones; y mirandolas otros con summa tibieza; y casi todos, como cosa ya perdida. Si como quando mas aflixidos, y mas necesitados aquellos pobres xprô de quien les aliente y convenga, se descuida con ellos; que puede temerse sino que a va tal abandono siga la perdicion de tantas Almas, yla destruccion de vna christiandad tan gloriosa a Ds, á su Igla a la Compa ${ }^{\mathrm{a}}$, y á essa Prov $^{a}$. Y aunqe. sobre esto escribo al Pe. Superior, para que con su zelo anime a sus eros, compañeros, no puedo menos que repetirlo $\mathrm{aVR}^{\mathrm{a}}$, y sus successores, para que en nombre mio signifique alos Missioneros todos la gravissima solicitud, en qe me dexan estas noticias; y la que solo puede templar el conseimt ${ }^{\circ}$. y experiencia del Apos. Zelo, que en cada vno considero, y la ardiente caridad con qe espero, no desamparen á aquellos, por cuia

311 Carlos A. Page. Las cartas de los generales... a la provincia del Paraguay... 259-322. 
salvacion han dexado sus Patrias, expuestose á peligros, y ofrecido á Dios su misma vida. En los Stos. Sacrifs. de VR ${ }^{\mathrm{a}}$. me encomdo. Roma y Julio 15 de 1735.

De $V^{\mathrm{a}}$

Siervo en Xptô.

Francisco Retz

$7^{a}$ carta - $1^{a}$ via - 15-VII-1737.

de Francisco Retz al Pe. Provincial

P.C.

Algo dicen, puede contribuir á este desmayo en los Missioneros, la imposibilidad de observar el orden, que [roto]ó; y que a mi me lo expresan mui diferente. de aquello, que $\mathrm{VR}^{\mathrm{a}}$ me dice. Esto es, que no pueden castigarse al Indio, que no quisiere trabajar en aquello, a que no esta obligado, y que solo cede en servicio, y vtilidad del Pe, este orden assi es mui conforme al Precepto de mi Antec ${ }^{\circ}$. de $1^{\circ}$ de en ${ }^{\circ}$. de 1707. pues si por el insinuado Precepto se excluie el imponerles vn tal servicio, o trabajo; mucho mas queda excluido, obligarlos a el con castigo. Mas a mi me dicen, que el orden de $\mathrm{VR}^{\mathrm{a}}$ es, que á ninguno se castigase, por no querer arar, sembrar, et ${ }^{\mathrm{a}} \mathrm{y}$ juntamte. que a ninguno se castigase, sino por pecados mortales. si esto es assi; no solo no apruebo, sino que revoco dichos ordenes. Que males no deben temerse de castigarse los pecados mortales solamente, y que se disimule con la natural pereza, y desidia de los Indios? Si aun obligandolos con el castigo alo que es neces ${ }^{\mathrm{o}}$, para su sustento, y conertacion del Pueblo, son tan descuidados, y con tanta violencia lo hacen; quando sin esse freno entiendan, que solo por pecados mortales pueden ser castigados; que de ociosos, y de gente perdida no avra enlos Pueblos? Quien de estos obedecera al Pe. en los trabajos, a qe son obligados? Quien cultivara las tierras para sustento de su Familia, para las viudas, huerfanos, culto divino, y servicio del Rey? Persuadirles oblig ${ }^{0}$. grave en todo esto; y que su ociosidad es culpa grave; ni esto es assi, ni aquello asequible: con que sera preciso disimular, y consentir con su ociosidad, origen de los infinitos males, y peccados, que pueden temerse. VR ${ }^{\mathrm{a}}$ mismo confiesa, y lo dicen todos, que cada Puesblo esta, según es el Missionero; si este aplicado y zeloso, cuidadoso de sus Indios; el Pueblo esta bien; si el Missionero descuida el Pueblo esta perdido; por qe los Indios no cuidan delo qe aun cede en su bien, y vtilidad propria: que el Missionero ha de ser como el Pe. de Familias, pues el Indio, en qualqa, edad neccessita, como el niño, de instrucción, y castigo, $\mathrm{p}^{\mathrm{a}}$ su bien. Por todo esto, y conforme ala explicacion, qe de su Precepto hizo mi Antec ${ }^{0} \mathrm{r}$ en 2 de Abril de 1713, de poderse obligar los indios á trabajar enlo que para servicio de ellos, su comida, y vestido, para los huerfanos, y viudad, para el culto de la Igl ${ }^{\mathrm{a}}$ y para pagar al Rey su Tributo, es neces ${ }^{\mathbf{o}}$; digo, que aun conel castigo, si de otra suerte no se puede han de obligarse á esto. Digo tambien, que si el Indio hiciere cosa alguna, que aunque no de culpa grave, merezca castigo (como pueden ser muchoas) sea castigado. Determinar que cosas ayan de ser estas, seria lo mismo que pedir a Vs. Pe. dixese los casos todos, en que avra de castigar a su Hijo, para darle vna buena educacion.

312 Carlos A. Page. Las cartas de los generales... a la provincia del Paraguay... 259-322. 
La prud ${ }^{a}$, la caridad de los Missioneros, y el zelo de los Supes. es solamte. la regla, que puede darse, la que siempre se ha dado, y la que ha conservado essas Missiones. Si el Missionero excede enlos castigos, no ai cosa mas encomendadas, (y lo ordeno yo de nuevo) que sacarlo de las Missiones, sino bastan los avisos.

Los otros ordenes qe para restauracion de las Missiones, y $\mathrm{p}^{\mathrm{a}}$ bien de los indios dexó $V^{a}$, me parecen bien: assi en el permitir entrasen algunos españoles a cuidar de las Pastorias, y aumentar los ganados; como en que por estos, y por cavallos se permutase y vendiese la Yerba. El aver instituido carnes de las Missnes. a $\mathrm{S}^{\mathrm{a}} \mathrm{Fe}$, y conque cada tres messes se tengan cartas, y respt $t^{\mathrm{a}} \mathrm{s}$, ha sido bien $\mathrm{p}^{\mathrm{a}}$ el mejor gobierno de las Missnes., en la mas frequente comunicación. teniendo tantos ministerios en algunos dias los Missioneros; y hallandose algunas vezes en ellas vno solo, hizo bien $V^{a}$ de que en tales circunst ${ }^{a}$, dixesen la Letania de $\mathrm{N}^{\mathrm{a}}$. $\mathrm{S}^{\mathrm{a}}$. enlugar de la maior. Apruebo la prohibicion echa alos Missioneros sobre comprar, y vender alos españoles tabaco, yerba, yotros generos del Pais, ó de Europa; pues sobre poderse surtir de esto, en $\mathrm{qt}^{\circ}$ lo necesitasen, por el Proc ${ }^{\circ} \mathrm{r}$. delas Missiones, se evita assi toda especie de negociacion, y de murmur ${ }^{\circ} \mathrm{n}$. en este punto. No tiene dificultad, que algun Indio cantor cante la Epistola en las Missas solemnes, como se acostumbra en muchas partes de España, y de Indias, en que el Sacristan canta la Epistola enla missa solemne de vno solo. Prohibo a todos los Parochos, y Missioneros, poder hacer, y celebar contratos, y ventas en nombre suio de los Bienes de los Indios. Mas permito, que por el peligro de poder ser engañados los Indios en el precio y valor de muchas cosas, especialmte. generos de Europa, les aconsejen, y aun asistan á sus ventas; mas en que los nrôs de ninguna manera sean los contraientes, y á voz, y nombre suio partes enlos contratos. No sé, que otra cosa pueda determinar; ni me es facil hacerlo con acierto en tanta multitud de dudas, como aquí se imbian; y en qe aun allá, donde estan presentes alas cosas, no saben, como determinarlas. En los Stos. Sacrifs. de VR ${ }^{\mathrm{a}}$ me encomdo. Roma y Julio 15 de 1737.

De VR ${ }^{\mathrm{a}}$

Siervo en Xptô.

Francisco Retz

$9^{a}$ carta - $1^{a}$ via - 15-VII-1737.

de Francisco Retz al Pe. Provincial

P.C.

No se, que vtilidad pueda averse seguido al Colgo, de Buenos Ayres delas fabricas, que hizo el Pe. Thomas Verle; pues enla carta, que $\mathrm{dh}^{\circ}$. Pe. me escribio con la planta desu fabrica, todo cedia en vtilidad de las Missiones. Y aun disculpandose el en su gastos, y sintiendo lo mal, que en el $\mathrm{Colg}^{\mathrm{o}}$ se llebaban estos, ni aduce este motivo de vtilidad al Colg; ; ni pone alguna otra que al de averse donado a costa de las Missiones el Retablo del Altar Maior, en qe se avian gastado 4.000 escudos. No obstante digo, que VR ${ }^{\mathrm{a}}$ examine con

313 Carlos A. Page. Las cartas de los generales... a la provincia del Paraguay... 259-322. 
sus CCs. la vtilidad, que me dice; y si se jusgase que por ella debe pagar el Colg ${ }^{\mathrm{o}}$, los gastos correspondtes. a dhâ vtilidad, los pague.

Aunqe. me es de singularissimo consuelo, y mui especial edificacion el zelo de VR $\mathrm{V}^{\mathrm{a}}$; y al que en mucha parte atribuio la vigorosa observ ${ }^{\mathrm{a}}$, de essa Prov ${ }^{\mathrm{a}}$; sus Colg $\mathrm{C}^{\mathrm{o}}$, y Missiones; assegurandole, quedo con mucha satisfaccion de su religiosa conducta, y qual me prometia de su religiosa conocida exemplaridad; ni puedo aprobar sus disposiciones sobre el vso dela yerba, y tabaco; ni restringir estas [roto] alos terminos, que $\mathrm{VR}^{\mathrm{a}}$ desea. No me detengo á expresar los motivos, que á ello me inducen, y solo insinuo, que menos inconvente. es disimular con esto, de que estoi mui informado; que exponerse a estos [roto] y mui especialmte. al de continuas faltas de castigo, murmuraciones, quexas y repetidos sentimientos á ese oficio. A esa Prov ${ }^{\mathrm{a}}$, pasan muchos Europeos, acostumbrados al tabaco, cuio vso mui varo[roto] el que la pueda dexar sin detrimt ${ }^{\circ}$, enla salud. Pasan muchos acostumbrados a algun desaiuno ligero de chocolate, Té, ó Café; que no teniendo esto, trabaj[roto] y ministerios, y hallando tan [roto] como vsado aun de los infimos esclavos la Yerba; beban esta, como en sus Provas, con mucho maior costo, y sin relaxacion dela vida religiosa, bebieran chocolate $\mathrm{D}^{\mathrm{a}}$, no es cosa de impedirse por tan severos medios; como $\mathrm{VR}^{\mathrm{a}}$ desea. Sobre vno, y otro punto tengo repetidas vezes escrito mi dictamen; y sobre el de la Yerba añado el orden siguiente. A ninguno se permitira el vso de la Yerba, sino teniendo necesidad para ella á juicio del Medico, y con lizencia in scriptis del Provincial y ni por tal lizencia, o vso, debera eximirse del veo, y turno de missas, ni debera combidar a otros. Estas dos cosas ordeno, las expresen los Provles. enlas liza s. que dieren, zelando los immedt ${ }^{\circ}$ s superes, sobre la observ ${ }^{\mathrm{a}}$, de quanto aquí ordeno.

Lo que me dexa con grave sentimt ${ }^{\mathrm{o}}$, por si mismo, y por las conseq ${ }^{\mathrm{a}} \mathrm{s}$, que deben temerse; es la no mui perfecta vnion, y caridad fraterna de vnos con otros. De esto aun sin las repetidas quejas de sugetos zelosos, tengo sobradissima luz en muchas cartas de algunos, que describiendose á otros, se hacen vn vivo retrato de su interior, y me manifiestan bien sus pasiones, y afecto, especialmte. el de la nacionalidad: ni dexa de conocerse en su pluma lo que tan frequentemte. sé, que tienen en boca: mi Reyno; mi Nacion; mi Prov ${ }^{\mathrm{a}}$, vn Jesuita ninguna ha de mirar con la parcialidad de suia, y en todas ha de vivir, como en la propria; ni debe inclinarle el amor de sus naturales, y pa[roto], quando con vna summa igualdad de caridad deba proceder con todos si assi no es, en lugar de ser, vna Prova ${ }^{\mathrm{a}}$ y $\mathrm{Colg}^{\mathrm{o}}$ de sugetos observantes, gustosos con su destino, y vocacion (para qe [roto] Reyno, Prova , y Patria) cuidadosos de su bien, y conduciendo todos ala salvacion de las Almas; reinara el [roto] dolencias, el arrepentimto. de aver pasado a Indias, el deseo de volverse; se oiran continuas murmuraciones y quexas, se vera premiada no la virtud, y zelo del que se mira como estrangero, sino la qe [roto] y exalte el amor, y afecto racional. Este sera quien regule los sentimt ${ }^{\circ}$ s., dignos pa los informes, y distribuia los empleos, y tenga en su mano la conducta toda de vna profes ${ }^{\circ} n$, yvida, que solamte. debiera regular vn prudente, santo, y desinteresado zelo del bien dela Religion. Sé, que el de VR ${ }^{\mathrm{a}}$, y su conocida virtud estan mui essemptos de tan pernicioso defecto: mas siendo este de tan sensible conseq ${ }^{\mathrm{a}} \mathrm{s}$, y quexandoseme tantos $\mathrm{y}$ experimentando yo esta falta de vnion, y caridad, exhorto $\mathrm{aVR}^{\mathrm{a}}$, ya sus successores Per Viscera Jesu Xptô á empeñar todo su zelo, espiritu, y prud $\mathrm{d}^{\mathrm{a}}$, en extingir el fundamt $\mathrm{t}^{\mathrm{o}}$, de estas quexas, en fomentar la caridad fraterna, y conspirar á que todos vivan con aquella paz, y gozo, que infunde el verdadero espiritu de Dios; cuia gloria, y bien de las Almas sea en todos aquel objeto, que miren con parcialidad

314 Carlos A. Page. Las cartas de los generales... a la provincia del Paraguay... 259-322. 
de afecto, y porque vnicamte. vivan interesados. En los Stos. Sacrifs. de VR ${ }^{\mathrm{a}}$ me encomd ${ }^{ }$. Roma y Julio 15 de 1737.

De VR ${ }^{\mathrm{a}}$

Siervo en Xptô.

Francisco Retz

$10^{a}$ carta - $1^{a}$ via - gobierno - 15-VII-1737.

de Francisco Retz al Pe. Provincial

P.C.

En esta, despues de dar a $\mathrm{VR}^{\mathrm{a}}$ mis agradecimt ${ }^{\circ}$ s., por su $\mathrm{St}^{\mathrm{o}} \mathrm{Zelo}$, y prud ${ }^{\mathrm{a}}$ en el gobierno de essa Prova ${ }^{\text {a }}$ asegurandole, ha sido mui de mi satisfaccion su conducta, y de confirmarme en el concepto que de su virtud, y espiritu tenia, paso á remitir nuevo Gobierno. Y ante todas cosas renuevo, y confirmo los ordenes, y Preceptos de mis Predecesores, para no alterar, ni immutar estas disposiciones, sino en el caso de muerte de alguno de los nombrados,ó de legitimas causas, que a juicio del Provl. y CCs. todos, a pluralidad de votos, sean tenidas por tales,para no darle la Patente. En los quales casos ordeno, deba proseguir el Antecess ${ }^{\circ}$, si por mi no es promovido á otro Gobierno; ó que no aya en el antecedentemte. satisfecho á pluralidad de Votos del Provl. y CCs. todos. Confirmo tambien, y renuevo los ordenes, y Preceptos impuestos á cerca de la solemnidad, con que deben guardarse los casus mortis; y quemarsse cerrado, y sellados los antiguos. Consultadas pues con los P.P. A.As. las informes., ad gobernandum, determino, como se sigue: será

Provl. de essa Prova , el Pe. Antonio Machoni.

$\mathrm{R}^{\mathrm{o}} \mathrm{r}$ del Colg${ }^{\mathrm{o}}$. $\mathrm{Max}^{\mathrm{o}}$, Pe. Jayme de Aguilar.

$\mathrm{R}^{\mathrm{o}} \mathrm{r}$ del Colgo . de Buenos Ayres, Pe. Pedro de Arroyo.

$\mathrm{R}^{\mathrm{o}} \mathrm{r}$ del Colg . dela Assumcion, Pe. Lucas Zavala.

$\mathrm{R}^{\mathrm{o}} \mathrm{r}$ del Colg${ }^{\mathrm{o}}$. de Sn.Tiago del Estero, Pe. Simon Bailina.

$\mathrm{R}^{\mathrm{o}} \mathrm{r}$ del Colg . de $\mathrm{St}^{\mathrm{a}}$. Fe, Pe. Bernd ${ }^{\mathrm{o}}$ Nusdorfer.

$\mathrm{R}^{0} \mathrm{r}$ del Colg${ }^{\circ}$. de Salta, Pe. Gabriel Novat.

$\mathrm{R}^{\mathrm{o}} \mathrm{r}$ del Colg${ }^{\mathrm{o}}$. de Tucuman, Pe. Franc ${ }^{\mathrm{o}}$ Lardin.

$\mathrm{R}^{\mathrm{o}} \mathrm{r}$ del Colg${ }^{\mathrm{o}}$. de Rioxa, Pe. Miguel Benavides.

$\mathrm{R}^{\mathrm{o}} \mathrm{r}$ del Colg${ }^{\mathrm{o}}$. de Tarija, Pe. Gernm ${ }^{\circ}$ Zevallos.

$\mathrm{R}^{\mathrm{o}} \mathrm{r}$ del Colg${ }^{\mathrm{o}}$. de Corrientes, Pe. Thomas Gonzalez.

Para todos estos imbio Patentes, que les dara VR

315 Carlos A. Page. Las cartas de los generales... a la provincia del Paraguay... 259-322. 
Maestro de Novicios, Pe. Geronimo Herran.

Comp $^{0}$ del Provl. Pe. Bartholome de Mora; Pe. Carlos Gervasoni.

Sup ${ }^{\circ}$ r. de Chiquitos, Pe. Bartholome de Mora; sino fuere elegido para comp ${ }^{a}$ del Provl. y si fuere elegido, sera Sup ${ }^{\circ}$. de Chiquitos el Pe. Agustin de Castañares.

Sup ${ }^{0}$ r. de Paraná, y Vruguay, Pe. Raphael Cavallero; Pe. Felix Villagarcia.

Consultores $\operatorname{Ordin}^{\circ}$ s. ${ }^{\mathrm{o}} \mathrm{r}$ del Colg${ }^{\mathrm{o}}$. Max ${ }^{\mathrm{o}}$; Mrô de Novicios; Comp ${ }^{\mathrm{o}}$ del Provl.; y Pe. Pedro Piedra Buena.

Consultes. ad graviora, P. Diego Garcia; Pe. Jul. de Alzola.

Deseo toda felicidad a essa Prova; el acierto en este gobierno. En los Stos. Sacrifs. de VR ${ }^{\mathrm{a}}$ me encomd ${ }^{\circ}$ Roma y Julio 15 de 1737.

De VR ${ }^{\mathrm{a}}$

Siervo en Xptô.

Francisco Retz

$12^{a}$ carta $-1^{a}$ via $-15-$ VII-1737.

de Francisco Retz al Pe. Provincial

P.C.

Respondiendo aora alas de $\mathrm{VR}^{\mathrm{a}}$ digo, que al $\mathrm{H}^{\mathrm{o}}$ Falconer solo se le puede permitir el curar con las limitaciones, y condiciones, que se expresan enlos Privileg ${ }^{\mathrm{s}} \mathrm{S}$ Verbo Medici; Mucho agradezco $\mathrm{aVR}^{\mathrm{a}}$, su zelo, y especial recomendac ${ }^{\mathrm{o}} \mathrm{n}$. alos Rectes, y Procures, sobre los Depositos, según lo que se les ordena en sus Reglas. En orden ala Fund ${ }^{\circ} n$ de Jujui, donde $\mathrm{VR}^{\mathrm{a}}$, avia nombrado dos P.P. y Vn $\mathrm{Herm}^{\mathrm{o}}$, nada tengo que añadir alo escrito; pues es cierto no la admitire sin las condiciones, que dexo expresadas: y ni puedo aprobar, ó reprobar, se imbiasen estos sugetos, por no poder formar juicio dela cosa; según la variacion, y contrariedad en lo que se escribe. Es mui justo, y como tal lo ordeno assi que el dia de Sn. Luis Gonzaga, Protector delos Estud ${ }^{\circ}$. se celebre en esse Colg ${ }^{\circ}$ y Vniversd., con missa cantada, como hasta aquí agradezco a $\mathrm{VR}^{\mathrm{a}}$ las noticias, que del $\mathrm{Colg}^{\mathrm{o}}$. $\mathrm{Max}^{\mathrm{o}}$. [roto] y Assumpn. Me da: y pido á N.P. que en este $\mathrm{Colg}^{\mathrm{o}}$ continuen las cosas con la quietud, y paz, que hasta aora. La duda, sobre dispensar, ó no, con el $\mathrm{H}^{\mathrm{o}}$ Luis del Valle, se funda sobre el echo; y informaciondose aquí con tanta contrariedad del echo mismo; mal se puede aca decidir lo que aun alla se ignora, como es $\mathrm{VR}^{\mathrm{a}}, \mathrm{y}$ otro $\mathrm{Cons}^{\mathrm{o}} \mathrm{r}$. me dicen, que le da a vezes el mal de corazon, sin presentirlo ell tres dicen, que siempre lo presiente, y conoce media hora antes. Si esto es; no debe ordenarse. $\mathrm{VR}^{\mathrm{a}}$, ó su sucessor llame á $\mathrm{dh}^{\circ} \mathrm{Herm}^{\mathrm{o}}$ encarguele la conciencia; y estrechelo á que confiese lo que en esto ay. Si el mismo confiesa, que siempre presiente el mal, con anticipacion bastante á concluir la Missa, ó, á no decirla; dispensese con el. Si confiesa, que ó no lo presiente, á no con esta anticipacion; no se dispense con el; pues no ha de exponerse á decir missas con tal peligro. Esto es lo que juzgo puedo Yo

316 Carlos A. Page. Las cartas de los generales... a la provincia del Paraguay... 259-322. 
desde aquí determinar. Consultadas conlos P.P.A.As. las informes. ad gradum, determino, se formen Coadjes. espiritles. Los P.P. Martin Briones, y Thomas Gonzalez, el Pe. Joseph Rodriguez se propondra á su tiempo; pues le falta mucho para el Grado. No juzgo darla Profess $^{0} \mathrm{n}$. aunqe. lo favorecen los sufragios en examen de Lengua al Pe. Jul. Bapt ${ }^{\mathrm{a}}$. Spetfner aunque presentemte. Proceda tan bien; á esto mismo conducira el temor de poder ser despedido. Formese Coadj. Espiritual á su tiempo se formaran Coadjes. temporales los Herm $^{\circ}$ s. Pedro Echezarraga, Pedro Ellacuniaga; Juan Carreño, Franc ${ }^{\circ}$ Arbizu, Miguel Reguera, Jacinto Quintana; y Diego Navarro, avisados estos tres de sus faltas. este Grado se diferira alos $\mathrm{H}^{\circ} \mathrm{s}$. Domingo Funes, y Christiano Elvens. Hara la Profess ${ }^{\circ} \mathrm{n}$. de 2 Votos el Pe. Feliz Gutierrez. VR ${ }^{a}$ recevira estos Grados; ó señalara, quien en mi nombre los reciva. Entendiendose esto, que para el tiempo de hacerlo, tenga cada vno cumplida la edad, y años de Religion; y que no ayan incurrido de nuevo en faltas, por las quales; a pluralidad de votos del Provl. y CCs. todos, deba diferirsele el Grado: y para lo que debe preceder consulta, donde se trate de cada vno en particular. En los Stos. Sacrifs. de VR ${ }^{a}$. me encomd $^{\circ}$. Roma y Julio 15 de 1737.

De VR ${ }^{\mathrm{a}}$

Siervo en Xptô.

Francisco Retz

$19-I V-1738$.

de Francisco Retz al Pe. Provincial

P.C.

Aviendo nrô $\mathrm{S}^{0}$ r. llamado á si el dia 2. de Dice., del año pasado al Pe. Franc ${ }^{\circ}$. Sierra, Assiste. de Esp ${ }^{\text {a }}$; cuia muerte me ha sido mui sensible, por la perdida de vn tal sugeto, y de tan experimentada religiosidad, zelo, y prud ${ }^{\mathrm{a}}$, en servicio dela Relig $\mathrm{n}$, doi aviso áVR ${ }^{\mathrm{a}}$, hallarse de suces ${ }^{0}$, del Dift ${ }^{\circ}$, el Pe. Franc ${ }^{\circ}$. De Miranda, dela Prov ${ }^{\mathrm{a}}$, de Castilla, y donde segunda vez era $\mathrm{R}^{\mathrm{o}} \mathrm{r}$, del $\mathrm{Colg}^{\mathrm{o}}$. de Salamc ${ }^{\mathrm{a}}$, despues que goberna de Provl. la Prov ${ }^{\mathrm{a}}$, toda con tal zelo, prud ${ }^{\mathrm{a}}$, y acierto, qual corresponde á su grande religiosidad, varias prendas, y escogida literatura. Este conjunto, que mui justamte. le merecio singular credito, y aplauso vniversal enlos principales theatros de Valladolid, y Salamc ${ }^{\text {a }}$; leiendo por 18, y mas años en esta la Cathedra de Prima en su Vniversd; le han ganado tambien mucho credito enla Relig ${ }^{0}$; y á mi me ha merecido igual $\operatorname{satisfac}^{\circ} \mathrm{n}$, por la grande, que en todos sus empleos me ha dado; y que me confia, que el acierto en su nuevo empleo confirme el que he tenido en vna tal eleccion. Aviso de esta á $\mathrm{VR}^{\mathrm{a}}$, para qe, en lo que ocurriere, escriva á dho. Pe. Assiste. En los Stos. Sacrifs. de VR ${ }^{a}$ me encomd ${ }^{\circ}$. Roma y Abril 19 de 1738.

De VR ${ }^{\mathrm{a}}$

Siervo en Xptô. 
$2^{a}$ via $-21-X I I-1738$.

de Francisco Retz al Pe. Provincial

PX

\section{Revde. In Chrõ Pater}

Et si non dubitem, quin amnes nostri pro es, quo ni communem amantissimam Matrem feruntur amore, societatis incolumitatem, ac felicitatem summiperé cordi habeant, Vt à Deo exorare numquam non satagant; nihilominus meatum partium esse dussi hoc procique tempore, quo complures Provincia gravibus premuntur calamitatibus, omnes maiore quo possum stadio hortari, Vt solito andentrus durinam societati opem implorare conentur. Singulariter Vero preces nostras, et suffragia efflagitat goana Provincia, vbi, vt litteris nuperaimè acceptis nunciatur, et christiana religio, et nostra societas ni maximum discrimen adducta est. infideles enim, et christiani nominis hortes magnam illarum regionum partem armis nevasserunt, et occuparunt ingentinon solum religionis, sed peculiari quoque societatis damno, et maiore etiam deinceps periculo; navi cum in ilhis, quas hostes invasserunt, regionibus proventas ferè omnes constituti vint, è quibus trum ipsa Goana, tum abra orientalis India Provincia, ac Missiones sustentantantun, illis deficientibus, ha quoque magna ex parte corruant necesse est cum summo rei christiano, ac dinino gloria detrimento. Quanto autem aliundè etiam Tunkinenses Missiones in periculo verrentur, abondè notum omnibusarbitros, postquam nuver intellenerunt gloriosam mortem quatuor nostrorum Patrum, quor Rex ille Christiano fidei persecutor, ea solum de causa, quod ad prædicandum christi fidem illud Regnum ingressi fuerint, capise plecti inssit. His omnibus cum accedant alid quoque calamitates, quibus societas pluribus in locis impectitur, et assligitur; cum que insuper varia gravis momenti negocia tractanda nune occurrent, è quorum faliú sucessu maior Dei gloria, Proximorum salus, et societatis bonum plurimum pendet; ideò non solum ego magnum sacrificiorum, et precum numerum, ex thesauro societatis mihi concredito, Deo offeram, sed omnes etiam, et singulos iterum que hortor, et obtestor, vt quod in tantis malis, et iterum que hortor, et obtestor, vt quod in tantis malis, et necesitatibus tantum hebemus residui, oculos suos contertant ad Deum, et corde contrido et humiliato accedant ad thonum Missericordia eius; ac penitentia operibus, corporis afflictutionibus, srdentibus, et continuis orationibus, virtutum que omnium ferventioribus exercitationibus, Dei à nobis iram avertere, euis que elementiam; et auxilium societati miplorare studeant, vt quod vnicè intendimus diunam gloriam, et animarum salutem sine obstaculis magis ac magis promovere possimus. Cupio autem, Vt quo quisque ad hoc obtinendum Deo offerre voluerit, superiori loci'm quo degit, significet, referenda deindè in indiculum à Provincia Proposito, at que ad nos huc mittenda. Vt verò communibus etiam, et coniunctis precibus Deum per intercessionem SSm${ }^{\mathrm{a}}$ Matria sua facilius, et eficacius in vota nostra flectamus, per vnius anni spacium consuetis liganijs omnim Sanctorum Litania Lauretano cum oratione, Deus refugium $\mathrm{V}^{\mathrm{a}}$ adnengantur. Demum $\mathrm{Rev}^{\mathrm{a}}$ Vrã hanc nostram epistolam 
omnibus communicet, me que sanctissimis corum sacrificijs, et orationibus enixè etiam commendet. Roma 21. Decemb. ann. 1738

Rev $^{\mathrm{a}}$ Vrã

Servus In Chrô

Franciscus Retz

$1^{a}$ via - 21-XII-1739

de Francisco Retz al Pe. Provincial

Revde. In Chxo Later. Diversa elogia

Mitto ad Rm. Vtrám accluja hic elolgia Patrum Bartholoæi Alvarez, Emanuelis de Abreu, Vincentij de Cunha. Joannis Gasparis Cratz, pro Christi fide occigorum, ac Ps. Hervai Guzmond, quæ Societatis Menologio inserenda, ac deincéps publicé pro more in [roto] legenda erunt.

Ruoniam veró a pluribus ex [roto] Provincijs desideratun, imo iam olim a Congregc. Generalis XII nomine complurium Provinciarum postulatum fuit, vt Menologium Societatis repurgaretum, et in meliorem formam redigeretun, ac denig. vniforme toti Societati exhiberetun, id quod etiam ipsa Congrego ${ }^{\circ}$ act. 20. Probavit, ciusque executionem commendavit; hinc[roto] quod hactenús ob varia obstacula prostitum non fuit, tandem perfici pogit, $\mathrm{R}^{\mathrm{a}} \mathrm{Vtra}$ sequentia commendanda cenfui: $\mathrm{Vt}$ menologiu repurgebun aliqua commendanbun

In primis curet $\mathrm{R}^{\mathrm{a}} \mathrm{V}^{\mathrm{a}}$, elenchum confici, in quo iuxta ordinem mensium[roto] dierum contineantun nomina corum omnium, quorum elogiarun ista Provinciam legi consueverunt.

Secundo [roto] Menologio describi, et in latinim idioma transferri elogia corum Latrum, ac Fratrum, qui in istâ Prova . obierunt, eaq. aliquibus viris sapientibus, et eruditis examinanda committat, qui diligenter expendant, an aliquid sit in ijs corrigendum, addendum, aut demendum, ac suum de hoc indicium proferant; imó si hâc occasione in elogijs etiam aliorum, qui in elijs Provincijs defuncti sunt, parachonismos, navos, aut errata aliqua adverterent, ea quoque notare debebunt.

Tertió denique Censorum horum indicia, vná cum prædictis elogijs, et plencho simúl collecta, et accuraté descripti $\mathrm{R}^{\mathrm{a}} \mathrm{V}^{\mathrm{a}}$ per Procuratorem, in prima Congrege. Provinli. eligendum ad [roto] transmittat. Spero $\mathrm{R}^{\mathrm{a}} \mathrm{V}^{\mathrm{a}}$. condisone, pensé commendo. Roma 1 Decem. Anni 1739.

Rev $^{\mathrm{a}}$ Vtrâ

Servus in Chro

Franciscus Retz

319 Carlos A. Page. Las cartas de los generales... a la provincia del Paraguay... 259-322. 
$2^{a}$ via - 21-XII-1739

de Francisco Retz al Pe. Provincial

Revde. In Chro Pater.

Tametsi in consultatione cum PP.AA. meis institutâ indicatum fuerit, a celebrando altero anno seculari societs. nostra publicâ aliquâ pompa, seu istu, ob graves plané rationes, exemplo aliorum religiosorum Ordinum supersederi debere, nullatenús tamen ideirco censeo, abstinendum se a reddendis privato quil[roto]mmuni autem Nostrum studio Divinæ Bonitati gratijs, [roto] singularia sané, ac plurima beneficia, [roto]bus per alterius sæculi decursam tane minimam familiam suam cumulare, atque exornare dignata, fuit. Quinimo tanquam quid maximé conveniens desidero, vt omnes, ac singuli id præstent es animi fervore, ac diligentiâ, quæ nos gratijs, [roto]isque beneficis dignos efficiant. Porró cui ad hoc obtinendum, profunturum existimarom, sî eiusmodi Indulga Pleria in firma jubilæi impetraretun, qualem 20 Septembris 1639 pro anno primo sæcunari concessit Vrbano VIII. S.M.; pro eâ supplicitér stiti apud SS. D.N. Clementem XII, qui pro singulari illâ æstimatre, quam habet de vtilitate Ministeriorum Societatis ntra, et desiderio, sapé [roto] mihi explicat[roto] quo eam ad proferendo in Ecclesia vberiores semper fructus, in donis Dei, ac virtutibus Apostolicis [roto] cupit, non solum benignissimé, sed etiam libentissimé postulato meo annuit, atque omnibus, et singulis nostra Societatis Religiosis, et Novitijs, qui intra annum Christi millesimum septingentesimum quadragessimum (in Indijs veró per ser menses postquam huius concessionis notitia eó perqvenenit) certâ die, per Propositum Generalem, vel per vnumquemq Provincialem in suâ Prova; vel per quembibet alium Superiorem Localem in vnaquâque Domo, vel Collegie dicta Societatis, cui prærit, designandâ, vel statuendâ, veré pænitentes, et Confessi, ac SS ${ }^{\circ}$. Eucharistiæ Sacramº . Refecti, pro Christianorum Principem concordiâ, hæresum extirpatione, Gentilium conversione, ac Sanctæ Matris Ecclesia exaltatione, necron Societatis [roto] progressu, et fælici statu pias ad Deum preces essudenont, Plenariam omnium peccatorum suorum Indulgentiam, et remissionem pro unâ die dumta[roto] forma jubilæi, citra tamen facultatem eligendi Confessarium, qui abslvat a Casibus Apostolicæ Sedi quomodolibet reservatis, Authoritate Apostolicá misericorditen in Dño concessit; quæ Indulgentiæ ab his etiam obtineri poterunt, quibus Superior ob legitimam causam, y el ob commodiorem, ved vberiorem præparationem, quæ per Exercitia Spiritualia more ntra Societatis fiere solet, diem eandem in aliam diem commutandam censurit.

Vt igitur ad consequendum spiritualem hunc thesaurum nos pro viribus præparemus, et quod publicæ solemnitati deest, privatâ devotione compensaturde PP. Assistentium consilio sequentia ordinanda, ac commendanda censura.

1. Reva . Vtra, auditis priús [roto]oribus suis, pro singulis Provæ. sua Doncilijs vel Ipsamet designet vel Superioribus Locorum designandum ommittat diem opportunum, et commodum, quo Nostri Indulgentias Jubilæi, a SS . Dño Ntro tam benigné concessas, cuismodi esse posser Festum aliquod Bæ. Virginis, aut Dominica, seu alia dies infra octavam S.P.N. Ignatijs, aut SS. Cosmæ, et Damiani, oc. 
2. Consultum enit, vt præcedent triduo, in maioribus saltem collegijs SSm. Eucharistiæ Sacramentum in Sacello Domestico per horas aliquot dorandum exponatun, ea feré ratione, quâ in triduo ante Renovationem Votorum fieri consuevit; vbi Nostri per ferventes orationes, piasve mediationes ad Indulgentias maiori animi puritate, ac devotione obtinendas se præparent.

3. Pridie $\mathrm{p}$ [roto]us Festi, seu [roto]ei assignati institutun exhortatio Dometica, argumento accommodata, quâ omnes ad agendas Deo gratias, novas per novum fervoris, ac perfectionis sutium promerendas animentur.

4. Ipso veró die, obtinendis Indulgentijs præstituto (qui eâ feré solemnitate inter Domesticos parientes etiam in triclinio celebrandus erit, quâd Renovationis celebrari solent) Ntri omnes maiori, quâ possunt, devotione, fervore ea omnia præstare conentur, quæ ad consequendas Plenarias Iubileo Indulgentias a Sanctitate suâ frerunt præscripta. Singulariter veró Divinæ Bonitati pro præstitis Societati ntra hoc præciqué secundo sæculotor, tantisa beneficijs gratias agant, ac pro eiusdem Societatis progressu, et fatiei statu pias ad bonorum omnium fontem preces essundent, atque ad hune finem Sacerdotes Missa Sacrificium, Fratres veró sacram communionem, et Coronam Deo offerant.

Postquam elapsum fuerit tempus, quo preces, pro Societatis necessitatibus indictæ, peragi debent, per reliquum anni 1740 decursum in Litanijs solitis adiungatur oratio pro gratianrum actione: Deus, cuius Misericordiæ, quâ to affectu Divinam precemur Misericordiam; vt sicut ex infinito. Bonitatis suæ thesauro tot in Societatem bona contulit, ita deiceps eam non deserens ad pramia futura disponat.

Demum cum in concessione præsentis Jubilai nulla facultas fiat eligendi Confessarium; vt hoc etiam solatio Ntri non careant, facultatem omnibus concedo eligendi sibi pro libito vna vice Confessarium vnum e sacerdotibus Ntris, qui eso etiam a pecatis reservatis, ante notiam huius concessionis commissis, absolvere popit si quod Deus avertat, id opus fores. Curet Reva. Vtrâ, vt hæc in omnium votitiam deveniant, mei veró in SS. suis sacrificijs memor sit. Romæ 21 Decemb. anni 1739.

$\operatorname{Rev}^{\mathrm{a}} \mathrm{Vtr}^{\mathrm{a}}$

Servus in Chro

Franciscus Retz

\section{Bibliografía}

Mellinato G. (†) “Retz, Francisco [František]”. In O’Neill SI, Charles E. y Domínguez SJ, Joaquín M. (Ed.) (2001), Diccionario histórico de la Compañia de Jesús. Biográfico Temático, Tomo II, Roma-Madrid: Universidad de Comillas. 
Page, Carlos A. (2013), "Las cartas de los generales Tirso González y Miguel Ángel Tamburini para la provincia del Paraguay", IHS. Antiguos jesuitas en Iberoamérica, Vol. $1 \mathrm{n}^{\mathrm{o}} 1$.

Westerhout, Arnold van (1756), Ritratti de'prepositi generali della Compagnia di Gesú / delineati ed incisi da Arnoldo Van Westherhout; aggi aggiuntivi i brevi ragguagli delle loro vite dal Padre Niccolo'Galeotti... della medesima compagnia. In Roma : a spese di Venanzio Monaldini, mercante-libraro al Corso: nella stamperia di Giovanni Zempel, presso Monte Giordano. 